\title{
Female return migration and reintegration strategies in Ethiopia
}

Citation for published version (APA):

Kuschminder, K. (2014). Female return migration and reintegration strategies in Ethiopia. [Doctoral Thesis, Maastricht University]. Maastricht University. https://doi.org/10.26481/dis.20140910kk

Document status and date:

Published: 01/01/2014

DOI:

10.26481/dis.20140910kk

Document Version:

Publisher's PDF, also known as Version of record

\section{Please check the document version of this publication:}

- A submitted manuscript is the version of the article upon submission and before peer-review. There can be important differences between the submitted version and the official published version of record.

People interested in the research are advised to contact the author for the final version of the publication, or visit the DOI to the publisher's website.

- The final author version and the galley proof are versions of the publication after peer review.

- The final published version features the final layout of the paper including the volume, issue and page numbers.

Link to publication

\footnotetext{
General rights rights.

- You may freely distribute the URL identifying the publication in the public portal. please follow below link for the End User Agreement:

www.umlib.nl/taverne-license

Take down policy

If you believe that this document breaches copyright please contact us at:

repository@maastrichtuniversity.nl

providing details and we will investigate your claim.
}

Copyright and moral rights for the publications made accessible in the public portal are retained by the authors and/or other copyright owners and it is a condition of accessing publications that users recognise and abide by the legal requirements associated with these

- Users may download and print one copy of any publication from the public portal for the purpose of private study or research.

- You may not further distribute the material or use it for any profit-making activity or commercial gain

If the publication is distributed under the terms of Article $25 \mathrm{fa}$ of the Dutch Copyright Act, indicated by the "Taverne" license above, 


\section{Female Return Migration and Reintegration Strategies in Ethiopia}


(C) Copyright Katie Kuschminder, Maastricht 2013 


\section{Female Return Migration and Reintegration Strategies in Ethiopia}

\section{DISSERTATION}

To obtain the degree of Doctor at Maastricht University, on the authority of Rector Magnificus, Prof. dr. L. L. G. Soete in accordance with the decision of the Board of Deans, to be defended in public on Wednesday 10th September, at 12:00 hours

by

Katie Kuschminder 


\section{Promoter:}

Prof. dr. Khalid Koser

\section{Co-promoter:}

Prof. dr. Jean-Pierre Cassarino, European University Institute, Italy

\section{Assessment Committee:}

Prof. dr. Ronald Skeldon, Chairman

Dr. Marta Bivand- Erdal, Peace Research Institute of Oslo, Norway

Prof. dr. Russell King, University of Sussex, United Kingdom

Dr. Melissa Siegel

This dissertation is part of the IS Academy: Migration and Development: A World in Motion project funded by the Dutch Ministry of Foreign Affairs. 


\section{Acknowledgements}

This PhD has been a journey across several continents and I am eternally grateful to all of the people who have supported and assisted me along the way. First and foremost, I have often considered myself very fortunate to have had such excellent supervision. Khalid, your writings were an inspiration from my early days as a Bachelors student reading on forced migration and I have learned a tremendous amount from you over the past years, for which I will always be grateful. JeanPierre- you took me in under your wing without having ever met me and have assisted me through several dissertation challenges. This dissertation would not be the same without your guidance and support and I am forever grateful for your kindness and wisdom. I will greatly miss our wonderful lunches in Fiesole, which were one of my key highlights on this journey, but do plan to continue to visit you for your insights and good company.

I am grateful to the members of the reading committee for your valuable comments on the previous draft of this thesis. Your remarks not only improved the thesis, but encouraged me to think in new ways regarding my dissertation.

This PhD is a part of the IS Academy: Migration and Development: A World in Motion project funded by the Dutch Ministry of Foreign Affairs. I would like to express my sincere gratitude to the Dutch Ministry of Foreign Affairs for funding this project and my work. I have greatly enjoyed meetings in The Hague and Maastricht to exchange ideas on migration and sharing my work at your lunch seminars.

Thank you to Melissa Siegel for giving me the opportunity to come to Maastricht and do this Phd. You have led the IS Academy project (and many others!) with unending enthusiasm and I am grateful for your support in exploring all the different caveats of return. Your energy and optimism is a constant source of inspiration and motivation.

My fieldwork was conducted in Ethiopia and I am forever appreciative to the Ethiopian Development Research Institute (EDRI) for hosting me in Addis. The fieldwork would not have been possible without the support and dedication of Asmelash Haile Tesgay, who was my ambassador to Ethiopia. Your dedication to our project was phenomenal, but our lasting friendship is deeply appreciated. Thank you, to you and your family, for all the late nights, weekends, assistance with finding interviewees, and smiles throughout. Ahmesugenalew. 
I also want to express my gratitude to all the fieldworkers who collected surveys throughout Ethiopia on the IS Academy project, to Tsegay for excellent translation assistance in Ethiopia, and to all of the other people who assisted me with data collection, translation, and transcription. Ethiopia would also not have been complete, without my partner in the field, Lisa Andersson, who made Ethiopia much more fun and sunny with her positive attitude and smiles.

This PhD would also not exist without all of the women who allowed me into their lives for the interviews. Your strength is an inspiration. I am grateful for the opportunity to have met you and thank you for taking the time to allow me to speak with you.

At Maastricht University there are several people who have assisted me along the way throughout this PhD: Chris, Franziska and Mindel, thank you for your comments and support in the early days. Susan, Mieke, Janneke, Floortje, Eveline, Howard, Sueli, and Herman your assistance with so many things has been greatly appreciated.

The IS Academy migration team: Ozge, Sonja, Silja, Natasja, and Katherina it has been great to work, learn, and grow with all of you. I have enjoyed our 'migration debates' as we have worked through survey developments, fieldwork, and analysis together, and also of course our 'migration' dinners and events. For the wider migration team: Elaine, Katrin, Marieke, Biljana, and all of the others who have been with us, it has been great to work with you and get to you know you and I look forward to continuing with all of you at Maastricht. To my cohort and our first year of adventures: Illire, Luciana, Irina, Kristine, Carlos, and Guney, this journey would not have been the same without you. Michaella and Craig, thank you for your support, assistance and friendship, and for always answering my many menial questions in the office with a smile.

Thank you to my family- my parents for always teaching me that I can do anything and to my grandma, aunt, and brother, thank you for your love and encouragement.

Finally, to the most important people in my life, Jordon and Mackenzie, thank you for your endless support and love throughout this entire process. Jordon- this $\mathrm{PhD}$ would not exist without your insistence that I follow my dreams to Maastricht. You are my best friend, my greatest supporter, my advisor and confidant. Thank you for your endless encouragement, sacrifices, and strength. Mackenzie, you light up every day and are the greatest joy. I am so proud of you and thank you for all that you teach me every day. I am incredibly fortunate to have you both in my life and assisting me at every turn. This book is dedicated to the both of you. 


\section{Table of Contents}

Table of Contents vii

List of Figures $\quad$ xi

List of Tables xii

List of Acronyms xiii

Chapter 1: Introduction $\quad 1$

Objective: Addressing the "Re" in Re-Integration 2

Relevance of this Study 3

A Gendered Approach: Female Return Migration $\quad 4$

Ethiopia: A Dynamic Case of Return and Reintegration 5

Structure of the Study: An Exploration of the Reintegration

$\begin{array}{ll}\text { Strategies } & 7\end{array}$

Chapter 2: Return Migration and Reintegration 9

Introduction 9

Overview of Return Migration 10

Categorizing Return Migration 11

Reintegration $\quad 15$

Learning from Integration $\quad 20$

$\begin{array}{ll}\text { Transnationalism } & 23\end{array}$

Social Networks $\quad 24$

Migration Networks $\quad 27$

Social Networks and Return Migration $\quad 29$

Social Change $\quad 30$

Return Migration and Social Change 31

Return Migrants' Potential to Affect Social Change 32

The Reintegration Strategies: A Framework for Analysis 33

Structural Conditions 33

The Reintegration Strategies 34

Reintegration Strategies and the Potential to Vernacularize 39

Structural Environment, Reintegration Strategies and Potential

to Verncaularize $\quad 40$

Assumptions of the Model $\quad 41$

Summary $\quad 42$

Chapter 3: Research Methodology 43

Introduction $\quad 43$ 
Field Site $\quad 43$

Approach and Sampling Strategy $\quad 45$

$\begin{array}{ll}\text { Interviewee Characteristics } & 46\end{array}$

Research Techniques $\quad 47$

Semi-structured Return Migrant Interviews $\quad 47$

Key Stakeholder Interviews $\quad 47$

$\begin{array}{ll}\text { Field Notes } & 48\end{array}$

Local Media Sources $\quad 48$

Supplementary Quantitative Data Sources $\quad 48$

$\begin{array}{ll}\text { Analysis } & 49\end{array}$

Ethical Considerations $\quad 51$

Informed Consent and Confidentiality $\quad 52$

Do No Harm 52

Reciprocity and Compensation $\quad 53$

Translation and the use of Local Researchers 54

The Dual Imperative $\quad 55$

Summary $\quad 56$

Chapter 4: The Structural Environment of Return in Ethiopia 57

Introduction $\quad 57$

A Brief History of Return Migration to Ethiopia 57

Note on Return Terminology in Ethiopia $\quad 58$

Flows and Forms of Current Return Migration to Ethiopia 58

IS Academy Return Migration Survey $\quad 59$

Number of Diaspora Investors (Ethiopian Investment Agency) 62

Addis Ababa Airport Administration $\quad 63$

Institutions Involved in Return Migration $\quad 64$

Government Institutions $\quad 64$

International Organisations $\quad 65$

Non-Governmental Organisations $\quad 65$

Government Policies on Return Migration $\quad 67$

Citizenship and the Ethiopian Yellow Card 69

Former Incentives for Diaspora Return - Land Policies and

$\begin{array}{ll}\text { Duty Free Importation } & 70\end{array}$

Businesses and Investments $\quad 71$

Promotion of Temporary Return of Highly Skilled 71

Government's Position on Return Migration $\quad 71$ 
Local Attitudes and Perceptions towards Returnees

Characterizing the Structural Environment of Return Migration in

Ethiopia

Professionals $\quad 79$

$\begin{array}{ll}\text { Students } & 81\end{array}$

Domestics $\quad 81$

Summary $\quad 82$

Chapter 5: Overview of Female Return Migration to Ethiopia:

Professionals, Students, and Domestics $\quad 84$

Introduction $\quad 84$

The Migration Cycle and Return to Ethiopia 85

The Professionals: Refuge and Decided Return 86

Students: The Optimal Migration Episode 93

The Domestics: Shattered Dreams, Interrupted Cycles, and

Stories of Success 95

The Importance of the Migration Cycle in Return and

$\begin{array}{ll}\text { Reintegration } & 102\end{array}$

Resource Mobilization 103

Readiness to Return $\quad 103$

Summary 104

Chapter 6: Reintegration Dimensions of the Analytical Groups 105

$\begin{array}{ll}\text { Introduction } & 105\end{array}$

Cultural Orientation and Maintenance 106

Professionals: Negotiation and Adaptation 107

$\begin{array}{ll}\text { Students } & 109\end{array}$

Domestics: Freedom at Last 111

Overview 112

$\begin{array}{ll}\text { Social Networks } & 112\end{array}$

$\begin{array}{ll}\text { Professionals } & 112\end{array}$

$\begin{array}{ll}\text { Students } & 116\end{array}$

Domestics 118

$\begin{array}{ll}\text { Overview } & 120\end{array}$

Self- Identification $\quad 120$

$\begin{array}{ll}\text { Professionals } & 121\end{array}$

$\begin{array}{ll}\text { Students } & 123\end{array}$

$\begin{array}{ll}\text { Domestics } & 124\end{array}$ 
$\begin{array}{ll}\text { Overview } & 124\end{array}$

Access to Rights, Institutions, and the Labour Market $\quad 125$

Professionals 125

$\begin{array}{ll}\text { Students } & 125\end{array}$

Domestics 126

$\begin{array}{ll}\text { Overview } & 127\end{array}$

$\begin{array}{ll}\text { Summary } & 127\end{array}$

Chapter 7: Reintegration Strategies of Female Return Migrants to

$\begin{array}{ll}\text { Ethiopia } & 129\end{array}$

Introduction $\quad 129$

Reintegration Strategies $\quad 129$

$\begin{array}{ll}\text { Reintegrated } & 131\end{array}$

$\begin{array}{ll}\text { Enclavists } & 134\end{array}$

Traditionalists 136

$\begin{array}{ll}\text { Vulnerable } & 138\end{array}$

$\begin{array}{ll}\text { The Potential to Vernacularize } & 140\end{array}$

Moving between Reintegration Strategies $\quad 145$

$\begin{array}{ll}\text { The Reintegration Strategies } & 148\end{array}$

Summary $\quad 150$

$\begin{array}{ll}\text { Chapter 8: Conclusion } & 151\end{array}$

Main Findings: Reintegration Strategies $\quad 151$

Implications of the Reintegration Strategies $\quad 155$

Female Return and Reintegration in Ethiopia 156

Beyond Ethiopia: The applicability of the Reintegration Strategies

to Other Cases 159

Final Remarks $\quad 160$

$\begin{array}{ll}\text { References } & 161\end{array}$

Appendix 1: Return Migrants Interview Guide 174

Nederlandse Samenvatting $\quad 178$

$\begin{array}{ll}\text { Valorization } & 181\end{array}$

Biography 184

MGSOG Dissertation Series $\quad 184$ 


\section{List of Figures}

Figure 1: Berry's Model of Assimilation $\quad 21$

Figure 2: Pictorial of Assimilation Strategies (Berry, 1997) 22

Figure 3: Map of Ethiopia $\quad 44$

Figure 4: Year of Return and Reason for Return $\quad 61$

Figure 5: Number of Diaspora Investment Projects per Year 62

Figure 6: The Migration Life Cycle 84

Figure 7: Cultural Orientation Upon Return 106

Figure 8: Analytical Groups Reintegration Strategies 131 


\section{List of Tables}

Table 1: Structural Environment for Return 35

Table 2: Typology of Reintegration Strategies 36

Table 3: Reintegration Strategies and Potential to Vernacularize 40

Table 4: Potential to Vernacularize based on the Reintegration Strategy and Conditions of the Structural Environment $\quad 40$

Table 5: Return Migrants per Region in Ethiopia 59

Table 6: Returnees Training Areas from Association for Forced Migrants 67

Table 7: Perception Questions by Household Type $\quad 73$

Table 8: Addis Ababa Respondents Perception Questions compared to Total $\begin{array}{ll}\text { Respondents } & 75\end{array}$

Table 9: Overview of the Structural Environment of Return $\quad 79$

Table 10: The Structural Environment of Return in Ethiopia per Analytical Group 83

Table 11: Participants Overview: Professionals, Students, and Domestics 88

Table 12: Typology of Reintegration Strategies 107

Table 13: Typology of Reintegration Strategies 131

Table 14: Reintegration Strategies and Potential to Vernacularize 141

Table 15: Vernacularization Potential of the Reintegration Strategies and Conditions of the Structural Environment of Return 


\section{List of Acronyms}

$\begin{array}{ll}\text { AVR } & \text { Assisted Voluntary Return } \\ \text { EDRI } & \text { Ethiopian Development Research Institute } \\ \text { EIA } & \text { Ethiopian Investment Agency } \\ \text { EOC } & \text { Ethiopian Orthodox Church } \\ \text { HRW } & \text { Human Rights Watch } \\ \text { ILO } & \text { International Labour Organisation } \\ \text { IOM } & \text { International Organisation for Migration } \\ \text { IT } & \text { Information Technology } \\ \text { MidEth } & \text { Migration for Development in Ethiopia } \\ \text { MFA } & \text { Ministry of Foreign Affairs (Ethiopia) } \\ \text { NGO } & \text { Non-governmental Organisation } \\ \text { OECD } & \text { Organisation for Economic Co-operation and Development } \\ \text { OWWA } & \text { Overseas Workers Welfare Administration (the Philippines) } \\ \text { SNNPR } & \text { Southern Nations Nationalities and Peoples Region } \\ \text { TRQN } & \text { Temporary Return of Qualified Nationals } \\ \text { UAE } & \text { United Arab Emirates } \\ \text { UN } & \text { United Nations } \\ \text { UNDESA } & \text { United Nations Department of Economic and Social Affairs } \\ \text { UNDP } & \text { United Nations Development Programme } \\ \text { UNHCR } & \text { United Nations High Commission on Refugees } \\ \text { UNODC } & \text { United Nations Office on Drugs and Crime } \\ \text { UN Women } & \text { United Nations Office on Women }\end{array}$




\title{
Chapter 1: Introduction
}

\begin{abstract}
"When you go from your native land to another culture there is culture shock. The culture shock is okay because when you cross the boundaries you are expecting something different...You know, somehow mentally, to a degree you are prepared and you shift. Now the re-entry culture shock is different. Because yes, you know this culture, what you have in your mind is what you grew up in and you can visualize things. But then when you actually come back to it things are not the same. Things are not the way you left them. Although they look like it on the surface, they are not exactly that way. And because it's dynamic, it's changing for the better or for the worse. So when you come back, do you fit in is a different question?"
\end{abstract}

\section{- Participant 36}

Decades of research have been invested into understanding integration; the process of migrants adaptation to the country of migration. Various theories of integration have been put forth from pre-eminent migration scholars such as Stephen Castles and John Berry. The field has been rich with discourse and analysis to understand the different dimensions of integration and how different immigrant groups integrate. In general, return migration, on the other hand, has been less researched. In 2000, Russell King wrote: "Return migration is the great unwritten chapter in the history of migration" (7). The fall of the Berlin wall, increasing conflicts in the south, and the high number of asylum seekers in Europe in the 1990s, have all led developed countries to increase their attention on return over the past decade.

Return is the process of returning, and reintegration is generally the story of what happens next, yet, a decade after King's statement, few studies have actually focused on reintegration. We lack understandings of how people reintegrate and theoretical models to explore the different dimensions of reintegration. This is most likely due to the explicit assumption that there is no story in reintegration. People are returning to their country of origin, their culture, their home, and therefore the process is straightforward. As the above quote demonstrates and research has vividly illustrated in the 1990s in the works of scholars such as Laura Hammond (1999), John Rogge (1994), and Koser and Black (1999), this is not the case. Return is not merely going home and reintegration is not simply fitting back into your old life. Both of these phenomena represent processes. Reintegration is a process that takes time, years for some and for others reintegration can never be achieved, which may result in a re-migration. 


\section{Objective: Addressing the "Re" in Re-Integration}

The objective of this study is to increase understandings of reintegration, including an examination of the processes of reintegration, and how different return migrants reintegrate. The primary research question guiding the study is: How, and to what extent, do different return migrants reintegrate upon return?

This starts with defining reintegration. The current definitions and use of reintegration are inherently problematic for two key reasons: first, they focus solely on the individual and do not include the wider community in the reintegration process and secondly, they assume re-assimilation to the culture of the country of origin versus a reintegration that acknowledges the cultural changes adopted by the migrant during the migration experience. Reintegration is currently at the 'assimilation' stage of the integration debate wherein returnees are incorporated into society through a one-sided adaptation process. Following from the integration literature, the key elements of viewing reintegration as a two way process between the return migrant and the receiving society and acknowledging that migrants may undergo cultural changes are essential in conceptualizing reintegration. Incorporating these elements, reintegration in this study is defined as the process in which return migrants are supported in maintaining their cultural and social identities by the host society and the whole population acquires equal civil, social, political, human and cultural rights.

This study proposes a new approach to reintegration, termed reintegration strategies. The reintegration strategies define the process of how people reintegrate across the four dimensions of cultural orientation, social networks, self-identification, and access to rights, institutions and the labour market. Reintegration in this view is multidimensional, encompassing many different elements. The reintegration strategies are fundamentally impacted by the life cycle of the return migrant and the choices they make in their reintegration. Secondly, the structural environment of the country of return plays a vital role in reintegration. Like integration, we must envision reintegration as a two way process occurring between the individual and the country of return. Return migrants cannot reintegrate if they are not accepted by the local population, the government, and labour market institutions in the country of return. Reintegration is a fluid concept and after identifying the process of reintegration through the reintegration strategies, the study examines how return migrants can move between reintegration strategies.

The final stage of the study explores the potential of return migrants to vernacularize - the ability of returnees to bring new ideas from the country of migration and present them in ways that are accepted by the local population (this concept that is based on the work of Levitt and Merry (2009) will be explained further in the next chapter). Through the reintegration strategies, it is evident that 
people reintegrate differently. The final section identifies the conditions that empower certain returnees to act as vernacularizers and share new ideas within their social environment upon return. The analysis elicits five key conditions that impact the ability of return migrants to have the potential to vernacularize and the final stage of this study examines this relationship within the context of the case study.

\section{Relevance of this Study}

This study is relevant to both academia and policy. The PhD takes a multidisciplinary approach drawing on the geographical, sociological, anthropological, and political science disciplines. The objective of this $\mathrm{PhD}$ is to make a contribution to the academic literature on return migration and reintegration, but it is firmly rooted in empirical science with the aim to understand the real world phenomena of return and reintegration. This does mean that there is a direct policy relevance of this research in understanding how people reintegrate and how return and reintegration impact development that is worthy of attention.

In the Netherlands (and other countries), one of the return policy objectives is to achieve a "sustainable return". In this context, sustainable return essentially means that the return migrant does not re-migrate. In order for someone not to feel the impetus to move again they must reintegrate. In order to understand if someone has reintegrated, we must understand the process of reintegration, how return migrants do or do not reintegrate, and the factors leading to or detracting from their reintegration.

Further to this, there are increasing discussions in the policy arena regarding the relationship between return migration and development. In academia, development is a broad term that takes on different definitions in economics and sociology and moves from the macro to the micro level in examinations of gross domestic product to human development. In this study, I cannot examine social change or development because my unit of analysis is limited to the returnees themselves. Therefore, I can only examine the potential of returnees to vernacularize upon return, that is, to share new ideas within their social environment upon return. In essence, knowledge transfer and new ideas are key components of development and social change, thus there is a similarity here to what policy makers refer to as development when conceptualized on the micro level. One of my findings, as will be illustrated in this thesis, is that there is a multifaceted relationship between reintegration, vernacularizers, and social change. Returnees must meet certain conditions in order to have a high potential to share new ideas in their communities of return. In my study less than 15 per cent of the returnees met these conditions. It cannot be assumed that all returnees contribute to development or social change, but under specific conditions return migrants can have a high potential to be powerful agents of change in their countries of return. 
The academic relevance of this thesis is to contribute to our understandings of reintegration. This study puts forth a new definition of reintegration and a new approach for understanding the process of reintegration, as discussed at the beginning of this chapter and which is further elaborated upon in Chapter 2. The typology of the reintegration strategies needs further assessment, refinement, and testing to determine its applicability in different contexts. This study uses a case analysis of female return migration to Ethiopia to explore the approach which provides many insights into understanding the process of reintegration for different return migrants. The objective of this study is not to provide an in-depth study of Ethiopia, but to contribute to the discourse of return migration.

\section{A Gendered Approach: Female Return Migration}

In this study, I specifically examine the case of female return migrants. Since the 1960s there has been an increasing prevalence of female migration worldwide. According to the United Nations Department of Economic and Social Affairs (UN DESA) and Organisation for Economic Co-operation and Development (OECD), 48 per cent of global migrants are women, which is an increase from 46.6 percent in 1965 (Zlotnik, 1998). Furthermore, there are significant differences in the stock of female migrants by region with Europe showing the highest percentage of female migrants at 51.9 per cent, compared to 45.9 per cent in Africa and 41.6 per cent in Asia (UN DESA/OECD, 2013). It is noteworthy that at the country level, the countries with the highest rates of female emigration are in Asia with 72.6 per cent of emigrants from Thailand being female and 61.9 per cent from the Philippines being female (UN DESA/OECD, 2013). The majority of research on female migration has been conducted in Asia and Latin America, with significantly less known about the African context.

The term 'feminization of migration' has gained popularity in recent decades. The term refers not only to this increase in the stock of female migrants, but also the changing patterns of female migration reflecting increasing female empowerment. Formerly, females were viewed as 'passive reactors to males migration decisions' and as migrating solely for family reasons or family reunification (Cerrutti and Massey, 2001). It is now recognized that females migrate increasingly as labour migrants and can be active decision makers in the process, thus using migration to demonstrate their own agency (Donato, 1993; Oishi, 2002; Wilson, 2009).

Previous research has also demonstrated that migration motivations and the reasons for migration are different for males and females (Cerrutti and Massey, 2001; Gaetano and Yeoh, 2010; Piper, 2004; Silvey, 2004; Sim and Wee, 2009). Female migrations are shaped by the household power dynamics and structural opportunities for male and female labour migrations (Cerrutti and Massey). As an 
example, Asis, Huang and Yeoh (2004) found that in the case of the Philippines, women will initiate the idea of migration and have autonomy in the migration decision, but the decision is made in the interest of the family or 'for the family', which reflects the dynamics of the household. Female migration predominates from the Philippines because the largest demand is for female domestic workers, thus illustrating how the structural opportunities in receiving societies greatly affect the flows of migration. In a comparative analysis of the Philippines and Bangladesh, Oishi (2002) further highlights that the structural environment of the sending state significantly affects female migration. In theory, Bangladeshi women would be more desirable as domestic workers as they are Muslim, but female emigration is not socially acceptable in Bangladesh, whereas it is openly promoted in the Philippines by the government and widely accepted within society. Female migration is thus shaped by the structural conditions of the host and sending state, in addition to the household dynamics.

This study focuses on the experiences of female migrants and returnees as this is a less researched area in migration studies, particularly in the case of Africa. It is known that women have different experiences of migration, which logically translates that they will have different experiences upon return and face gendered specific challenges in return. This study thus seeks to make a contribution to understanding the specific dynamics of female migration and return.

\section{Ethiopia: A Dynamic Case of Return and Reintegration}

In order to explore the reintegration strategies approach, this study uses the case of female return migration to Ethiopia. Ethiopia experienced a conflict period from 1974-1991 and since 2000 has been experiencing high levels of economic growth. During the conflict period, millions of people fled from Ethiopia and a large number of the countries highly educated and/or elite migrated to North America or Europe. With the stabilizing of the country in the late 1990s and the high growth rate resulting in business opportunities, some of these people have now returned.

Migration and return migration have both increased to and from the country in the past decade. Ethiopia is currently working to build its education system and an increasing number of Ethiopian students are going abroad for education. Despite the growth in Ethiopia, there are high levels of unemployment, which are frequently higher for women than men. Exact figures are unknown, but it is estimated that up to 500,000 Ethiopian women are migrating to the Middle East for domestic work annually. A study conducted by Anbesse et al. (2009) examines the mental health of returning domestic workers from the Middle East and highlights the challenges specific women face upon return. Different types of female migrants thus return to very different conditions and situations in Ethiopia. 
This study examines return migration of three analytical groups:

- Professionals- Women who migrated in the 1980s and 1990s primarily and returned to Ethiopia after an extended duration abroad having worked in the country of migration, acquired skills, and returning to Ethiopia with professional expertise.

- Students- Recent migrants that migrate primarily to European countries for the purposes of Bachelors or more commonly a Master's degree.

- Domestics- Women from primarily lower class families that migrate to the Middle East for domestic work.

These three groups have different migration lifecycles, experiences and opportunities abroad and reasons for return. As such, they have different reintegration strategies upon return. In regards to the different analytical groups reintegration strategies it is hypothesized that:

1. Professionals will fit within the reintegrated or enclavist category.

2. Students will fit within the traditionalist category.

3. Domestics will fit within the traditionalist or vulnerable category.

These hypothesis will be discussed in Chapter 7 of this thesis.

In this study, I have focused on the case of female return migrants in Ethiopia for two key reasons. First, historically Ethiopia is a patriarchal society. Today, Ethiopia is ranked 173rd of 186 countries in the United Nations Development Programme (UNDP) gender inequality index, illustrating that large gaps still exist between men and women in Ethiopia. This index reflects inequality between women and men reproductive health, empowerment and the labour market (UNDP, 2013). Female empowerment has become a politicized issue in Ethiopia receiving a lot of attention from International Organisations. Ken Oishi from the World Bank in Ethiopia stated in 2011 that "The voice of change [in Ethiopia] is more likely to come from women". This study is rooted in the perspective that women are more likely to be change agents than men in Ethiopia, especially when considering return migration. Women that migrate to Western countries have the opportunity to experience cultures with higher levels of female empowerment. One of the assumptions in this study is that this enables female returnees to bring with them new perspectives on female empowerment in their return to Ethiopia.

Secondly, Ethiopia has experienced a strong feminization of migration. The IS Academy survey from Ethiopia finds that 60 per cent of the current migrant households sampled in the survey are female. When considering the country of destination, 68 per cent of current migrants from Ethiopia in the Middle East are female (Kuschminder, Andersson, and Siegel, 2011). These numbers are comparable to that of Sri Lanka, Indonesia, and the Philippines where females account for 62-75 per cent of all emigrant flows (Asis, 2005). The migration story in Ethiopia is thus 
highly gendered and focusing on female migration and return is well suited to this country case.

It is well recognized that in order to have a gendered analysis, there must be the inclusion of men in the sample. My objective was not to construct a gendered analysis, but to address the specific challenges of female returnees. My objective was to understand how people reintegrate and I sought to find balance in variation within my sample. Recognizing that women face gendered specific challenges in their reintegration, and that there is a strong gendered dimension to migration from Ethiopia, focusing only on female respondents allowed me to have variation within the sample in other characteristics such as: skills, country of destination and reason for migration. It would be beneficial to have included men within the sample and to compare the experiences of men and women; however it was not feasible for me to have six analytical groups within the scope of this study. Therefore, I made the decision to focus on three analytical groups of female returnees.

Ethiopia provides for a unique case study wherein different types of migrants are regularly retuning to the capital of Addis Ababa. This allowed for the ability to capture diversity between the analytical groups in their return to one location. The case of Ethiopia has had little exploration in the recent decade (previous work has studied the impact of return in the post-conflict period) and brings new elements into the debate. The country specific conditions of Ethiopia will be further explored in Chapter 4 of this thesis.

\section{Structure of the Study: An Exploration of the Reintegration Strategies}

This study consists of seven chapters in addition to the Introduction. Chapter 2 provides the basis for this study. Following an in-depth literature review of return migration, reintegration, social networks, and social change, Chapter 2 introduces the approach of the reintegration strategies. With the exception of Chapter 3, which presents the methodology used in this study, each of the following chapters flows from a key element of Chapter 2. Chapter 3 examines the approach taken in the qualitative interviews, the analytical approach, and ethical issues taken into account in the study.

Chapter 4 presents the structural environment of return migration in Ethiopia. Following from Chapter 2, the structural environment is assessed according to the four elements of: treatment of returnees from the local government, the treatment of returnees from locals, the treatment of returnees in the labour market, and the flows of return migrants. These four elements are analysed to assess if the return environment is favourable, adverse or neutral to return migrants in Ethiopia. 
Chapter 5 examines the lifecycle of the returnees of the three analytical groups: professionals, students, and domestics. The reintegration strategies approach highlights in Chapter 2 that the lifecycle of the migrant is critical to understanding their reintegration strategy. Chapter 5 therefore details the lifecycle of each analytical group in order to understand their reintegration.

Chapter 6 analyses the three analytical groups within the four dimensions of the reintegration strategies. The four dimensions of cultural maintenance, social networks, self-identification, and access to rights, institutions and the labour markets are introduced in Chapter 2 and examined in depth in Chapter 6. The differences between and amongst the analytical groups are highlighted across the dimensions.

Following from the previous chapters, Chapter 7 assesses the reintegration strategies of the returnees as: reintegrated, enclavists, traditionalists or vulnerable. Whereas Chapter 6 examines the dimensions of the reintegration strategies, Chapter 7 assesses the reintegration strategies of the return migrants. Following from the model established in Chapter 2, Chapter 7 elicits the differences in reintegration strategies between the return migrants. This chapter develops the process of how returnees can move between the reintegration strategies and puts forth key elements and conclusions of the reintegration strategies.

Chapter 8 is the conclusion of the study. Chapter 8 provides reflection on the key points in the study, implications of the reintegration strategies, a final assessment of reintegration in Ethiopia and the application of the reintegration strategies to other cases. 


\section{Chapter 2: Return Migration and Reintegration}

\section{Introduction}

Since 2000, there has been an increase in the number of studies that examine return migration from multiple perspectives, including notions of 'diasporic homelands' (Markowtiz and Stefansson; 2004), second generation return (Tsuda, 2009), imagined and provisional return (Long and Oxfeld, 2004), contributions to theory (Ammassari, 2009; Cassarino, 2004), and many empirical studies. Today, the topic of Assisted Voluntary Return (AVR) is particularly prevalent in policy circles and increasing research is being conducted on the impacts of AVR on returnees and their countries of return (Collyer, 2009; Majidi, 2012). Despite the increase in research on different forms of return migration, a consensus on defining, categorizing and the effects of return migration is still lacking. Similarly, definitions, categories, and effects of reintegration are currently imprecise across the literature. There is also discrepancy in the literature as to the impacts of return on development and the role that reintegration of return migrants plays in impacting communities of return.

This chapter will provide clarity on return and reintegration by drawing on literature across multiple fields or research including refugee studies, integration, transnationalism, social network theory, social change, and the wider migration literature. A new conceptualization of reintegration will be put forth as a cornerstone of the reintegration strategies approach. The reintegration strategies offer a new method of inquiry for assessing different levels of reintegration. The social network and social change literature are essential to the discussion as they provide cornerstones for understanding how people reintegrate and how to assess the impact of reintegration on communities. Although this study cannot examine the impact of returnees upon their communities of return, this is a central piece of the reintegration literature that is therefore included in this section. Key questions will also be addressed such as: How can reintegration learn from the experiences of integration? What is the role of social networks in return and reintegration? How can the relationship between return migration, reintegration and social change be characterized?

The first section of this chapter will provide an overview of return migration and its categorisations. The second section will discuss the concept of reintegration through a background on the term and exploring learnings from the concept of integration that can be applied to reintegration. This will lead to a discussion of transnationalism theory and the relationship between reintegration and transnationalism. The third section will then move to discuss the theory of social networks and the application of network theory in migration studies and return migration. Next, the chapter will examine the topic of social change and how social 
change concepts have also been applied in migration studies and return migration. Finally, the chapter will conclude with the framework of the reintegration strategies. Integral to this model are the concepts of cultural maintenance, social networks, and individual's self-identification, which will be discussed in sections throughout the chapter.

\section{Overview of Return Migration}

At first glance, defining return migration appears straightforward. Gmelch (1980) provides an overarching definition of "Return migration is defined as the movement of emigrants back to their homelands to resettle. Migrants returning for a vacation or an extended visit without the intention of remaining at home are generally not defined as return migrants, though in some settings it is difficult to distinguish analytically the migrants returning home for a short visit or seasonally from those who have returned permanently" (136). This definition implies a permanency in the return movement, as migrants are to 'resettle' in the homeland. Return migration has historically been thought of as the 'end part of the migration cycle', but recent work has illustrated that the return movement may be only another step in the cycle as people lead increasingly fluid lives of mobility (Riiskjaer and Nielsson, 2008; Stefannson, 2006).

King (2000) provides an alternative definition that does not imply a resettling: "Return migration may be defined as the process whereby people return to their country or place of origin after a significant period in another country or region" (8). However, as suggested by Ammassari (2009), King does not specify what a 'significant period' entails. There is debate as to how long one has to be abroad to be considered a migrant, and thus a return migrant. The United Nations defines a return migrant as an individual who has been abroad for at least 12 months. Alternatively, there is also the argument that a period of three months can also be viewed as significant enough to be considered as a migration episode, especially in terms of circular or seasonal migration.

The United Nations (UN) identifies two categories for people entering a country: citizens and foreigners (1998). International migrant citizens are defined as returnees and are classified by the following types:

- Returning from study or training abroad

- Returning from employment abroad

- Returning after working abroad as international civil servants

- Humanitarian migration:

- Repatriating refugees

- Repatriating asylum-seekers

- Citizens deported from abroad

- Other returning citizens 
Other returning citizens are defined as: "All international migrant citizens returning to their own country for a lengthy stay (of at least 12 months) who cannot be classified into previous categories. In particular, citizens who settled abroad and return to establish their place of usual residence in their own country should be included in this category" (UN DESA, 1998). This definition is problematic in the case of states that do not offer dual citizenship, as is the case in Ethiopia. If an individual migrates from Ethiopia and lives abroad for ten years they may choose to acquire the citizenship of the host country. When they return to Ethiopia, they would thus be classified as a foreigner by the UN definition. However, if they are returning to 'resettle' in their homeland and have been abroad for a 'significant period' they would classify as a return migrant by the definitions provided by both Gmelch (1980) and King (2000).

It is evident that definitions of return migration are not necessarily straightforward. This becomes problematic when working across disciplines as researchers, policy makers, and practitioners may conceptualize return migration in different ways. There is a need to create uniformity in terms across the spectrum to ensure clarity in debates. In general, a definition of return migration must remain broad so as to include the multiple categories of return migrants (as discussed in the next section). Thus, I would argue that a basic definition as provided by King is best suited to return migration, and that scholars should define a 'significant period' for their work. In this study return is therefore considered as: "the process whereby people return to their country or place of origin after a significant period in another country or region" (King, 2000: 8) wherein a significant period is considered as a minimum of three months abroad. Three months has been selected instead of the UN recommended one year based on the argument that three months can provide enough time for exposure to another culture and context to have an impact on individuals' values and behaviours, which is important for their ability to potentially impact social change. A distinction is also made to ensure that the three months abroad was a migration episode, meaning it was intended for the purposes of moving, and not for a vacation or visit. Furthermore, this definition is appropriate as it avoids the problems of the UN definitions that only citizens can be returnees. This is a fundamental flaw of the UN definition in that it fails to capture all returnees that may have acquired foreign citizenship. Although exact numbers do not exist on this in Ethiopia, it is assumed that the majority of highly skilled returnees have given up their Ethiopian citizenship as the majority migrated during the conflict period in Ethiopia and have been abroad for over ten years.

\section{Categorizing Return Migration}

In addition to varying definitions, return migrants can be categorized in multiple ways. Perhaps the most significant distinction is between voluntary and forced migration movements as they have different terminologies for both the initial 
migration movement and return. This distinction can be made on two levels: first if the initial migration movement was voluntary (migrant) or forced (refugee), and secondly if the return migration movement is voluntary (return migrant) or forced (deportee or refoulement for refugees). Multiple other categorizations have been established for return migrants. As noted in the previous section on definitions, the UN classifies return migrants according to the purpose of their initial migration that is, if the migration was for study, employment, working as a civil servant or humanitarian migration.

A key element in many return typologies is the differentiation of the intention of the migration episode to be either permanent or temporary. In reality, intentions are difficult to measure as intentions may frequently change. Combining the intention and the eventual migration outcome, this typology has been refined by Bovenkerk (1974) and further developed by Gmelch (1980) and King et al. (1983). The typology encompasses the following four categories of: 1) intended temporary migration with return; 2) intended temporary migration without return; 3 ) intended permanent migration with return; and 4) intended permanent migration without return. This typology has been useful in respect to remittance behaviour, as evidence exists that remittances are higher when migrants plan to return home (Ammassari, 2009). However, while abroad migrants intentions may change.

A third typology is based on the amount of time spent in the home country. This typology has the following four categories: occasional returns for a short-term visit to see family and friends; seasonal returns based on seasonal work activities; temporary returns- which occur when the migrant returns to the homeland for a significant period but may intend to remigrate, and permanent return which are those that settle in the home country for good (King, 2000). The notion of a temporary return has gained increasing prominence in the literature with new programmes designed for brain gain and temporary return such as the IOM Migration for Development in Africa Program (Terazzas, 2010; OECD, 2010). The challenge with this approach is that returnees may change their mind regarding return and at one point plan to be a permanent returnee but remigrate and become a temporary returnee.

This leads to a fourth typology that is based on the relationship between the countries of migration and return. It includes the following three categories of: return from less-developed countries to highly developed countries; return migration of labour migrants from the developed industrial countries to their lessdeveloped home countries; and return movements between countries of broadly equal economic status (King, 2000). This typology has not been widely utilized in the literature and also fails to offer a consensual approach to categorizing return migration. 
It is evident, that categorizing return is not a straightforward exercise. Perhaps the most commonly utilized typology is that developed by Cerase (1974), and it is striking that the most common typology is almost 40 years old. This typology is based on the achievements of the return migrant and includes the following four categorizations:

1. Return of failure - occurs when migrants fail to adapt to the host society and return quickly to the homeland.

2. Return of conservatism- occurs after a few years in the country of migration, where the migrant's orientation has been towards the country of migration and the migrant is active in sending remittances and savings to the home community.

3. Return of innovation- Migrants have stayed in the destination country beyond the "target return", but realize they will never fully acculturate and apt for return, bringing with them new ideas, values, and ambitions to their home country.

4. Return of Retirement- At the end of their working lives migrant's return.

This typology is the most robust of those discussed thus far; however, many elements remain that are not included in this typology. Of most interest in this typology is the third option for the return of innovation, but it is questionable as to how much duration abroad is the only factor affecting return innovation. Overall, Cerase was sceptical that returnees could affect innovation in their home country. This thesis will argue that returnees with specific attributes combined with certain conditions in the host and home country can lead to innovation in their home country. The fundamental difference in my work from Cerase's argument of return of innovation is that in my sample returnees do not return because they "realize they will never fully acculturate". In my sample, some of the returnees have fully acculturated to the country of migration but opt for return for other reasons, thus bringing with them new ideas, values, and ambitions for their home country that they are able to use to influence social change.

Cerase's typology was based on his own work of return migrants from the US to Italy. Other authors have also developed typologies to suit their case studies. For instance in a case study of emigration, return and development in Cape Verde Carling (2004) proposes the following four categorizations for returnees: 
1) Classic returnees- spent much of their adult life abroad, they have managed to secure a relatively high standard of living in Cape Verde, and they have usually not re-entered the Cape Verdean wage labour market

2) Empty-handed returnees- unsuccessful migrants who come back no better off than when they left, which includes deportees and voluntary returnees

3) Intermediate returnees- who are between these two extremes, have not been abroad as long as the classic returnees, have accumulated less savings and not secured pension rights

4) Graduates from Foreign Universities- students who return from study abroad.

This classification is based on multiple elements including the purpose of migration, a voluntary or forced return and the level of success of the return. Following from this approach, I have also developed my own categories for returnees that are relevant to the Ethiopian case study and will be examined in Chapter 5.

More recently return typologies have also been expanded to include nonphysical returns. Oxfeld and Long (2004) propose three categories of refugee return:

1) Imagined returns- these occur before a person leaves the country of migration and includes their perceptions, images, and expectations of the home country and return;

2) Provisional returns- include return visits to initially see the changes in the home country;

3) Repatriated returns- includes both voluntary and non-voluntary returns and is the actual act of moving back to the home country.

These categories are slightly overlapping with the previous typology that determines the return based on the time spent in the home country; however, it adds the element of 'imagined returns'. This highlights the importance of the visioning of the return before it occurs, however, it is also debatable as to if non-physical returns can actually be included as a form of return migration. Imagined returns are arguably a part of the return process, similar to the notion of the 'myth of return', however if one does not physically return, than it remains a myth and not an actual return.

It is apparent that several typologies exist to categorize return migrants, however, no one typology is consistently utilized within the literature. This creates problems in making generalizations or comparisons across the literature regarding certain groups of returnees. As illustrated, forms of return migration present several differences making it difficult to compare topics such as the impacts of return migration for refugees, deportees, and highly skilled returnees.

The most frequently utilized distinction appears to be voluntary versus forced returns, which in itself has recently become a clouded distinction. The use of the term Assisted Voluntary Return (AVR) in policy programmes has changed the 
definition of what is voluntary? AVR refers to primarily rejected asylum seekers (and in some countries other migration groups) who voluntarily agree to return to return to their country of origin in exchange for a reintegration package (such as cash and/or business set-up support) from the host country. This voluntary decision is generally made after an asylum claim has been rejected and the individual lacks any opportunity to legally stay in the country of migration. From a policy perspective, AVR is critically differentiated from enforced removals wherein migrants choose for voluntary return.

Yet many scholars and advocates have raised the question: to what degree is this actually a voluntary return? Cassarino (2008) poses the question in another way: as to if this form of return is decided or compelled? Decided return refers to those who "chose on their own initiative to return, without any pressure or coercion", whereas compelled return refers to those "who returns to his/her country of origin as a result of unfavourable circumstances and factors which abruptly interrupt the migration cycle" (Cassarino, 2008: 113). Although termed voluntary return, AVR is clearly a form of compelled return. The increasing prevalence of the use of the term voluntary to include these forms of compelled return, has led academics to start clarifying in their work that they mean 'truly voluntary' (Majiidi, 2012) or 'genuinely voluntary' (Oeppen, 2012) return. Due to the complexity of these terms, for the purposes of this study the term decided return will be used to refer to individuals who "chose on their own initiative to return, without any pressure or coercion" (Cassarino, 2008).

This debate highlights that categorizations of returnees is problematic. Discussions between academics and policy makers regarding voluntary return can have truly different meanings. Clarity and consistency in discussions of categories of return are thus essential for understanding the different impacts of return migration.

\section{Reintegration}

In general, after the act of return, individuals begin the process of readjustment and reintegration. Similar to the return typologies, there is a significant difference in the literature on reintegration of forced and non-forced migrants.

In terms of the refugee literature, reintegration is often coupled with the $4 R^{\prime} s$ of "repatriation, reintegration, rehabilitation, and reconstruction" (Lippman and Malik, 2004). The focus of reintegration is thus on refugees who are repatriated. In the 1980s, King viewed repatriation as a form of forced return when "return is not the initiative of the migrants themselves but is forced on them by political events or authorities, or perhaps by some personal or natural disaster" (King, 1986: 5). The UNHCR, however, focuses on 'voluntary repatriations' which define voluntariness as "not only the absence of measures which push the refugee to repatriate, but also means that he or she should not be prevented from returning, for example by dissemination of wrong information or false promises of continued assistance" 
(UNHCR, 1996). Despite this definition, it is fundamental to recognize that repatriation is often a situation wherein refugees have limited options, as they are generally no longer welcome in the country of asylum. Although repatriation may not be considered forced return, it is often a compelled return as refugee's circumstances leave them no other alternatives.

Return through repatriation can therefore bring many challenges and may not be a homecoming or a pleasant experience (Allen \& Morsink, 1994; Koser and Black, 1999; Rogge, 1994;). Furthermore, repatriation often occurs in large flows (such as the recent repatriation of 500,000 refugees from Tanzania to Burundi from 20072009), placing significant pressure on the country of origin and organisations seeking to provide assistance to returnees, which can make the experience more challenging for the individual and the communities to which they return.

Reintegration of repatriates has largely focused on meeting basic needs such as access to land, shelter, food, water, and essential services. In addition, reintegration focuses on larger structural factors of protection, law and order, property restitution, reconciliation and peace building, and restoration of livelihoods (Davies, 2004). Reintegration thus becomes a process that is largely focused on rights and equalizing the rights of returnees with the rights of locals. It also becomes intertwined with the idea of 'sustainable return', which essentially can be defined as: "Return migration is sustainable for individuals if returnees' socio-economic status and fear of violence or persecution is no worse, relative to the population in the place of origin, one year after their return" (Black et al., 2004: 39). The notion of a sustainable return has gained in popularity over the last decade as there has been increasing recognition that reintegration needs to be sustainable over the long term. From a political standpoint it essentially means that people do not re-migrate, making it an attractive concept in relation to AVR. Sustainable return can also be viewed from a more long term perspective that focuses on social and economic rights and the successful reintegration of the entire community (Black and Gent, 2006). However, agreed upon definitions of what is 'successful reintegration' and 'sustainable return' at a community level have yet to be established.

The United Nations High Commissioner on Refugees (UNHCR) defines reintegration as "equated with the achievement of a sustainable return - in other words the ability of returning refugees to secure the political, economic, [legal] and social conditions needed to maintain life, livelihood and dignity" (UNCHR, 2004: 6). This is furthered by: "Reintegration is a process that should result in the disappearance of differences in legal rights and duties between returnees and their compatriots and the equal access of returnees to services, productive assets and opportunities" (UNHCR, 2004: 7). It is evident, that in terms of repatriation and return of refugees, the literature focuses primarily on ensuring equal access to rights, 
safety, and the elimination of persecution. These aspects are highly relevant in a post-conflict setting wherein refugees initially fled due to persecution.

The literature on reintegration of non-refugee populations bears some similarities to the above, but does not have a focus on access to basic needs and equalizing rights. Presumably, this is because it is assumed that non-refugee returnees are not in situations of vulnerability upon return and that non-refugees return with enough resources so that they can independently meet their needs. This assumption is not always correct as deportees, rejected asylum seekers, and lowskilled migrants can all return in situations of vulnerability wherein they need support in order to be able to meet their basic needs and struggle for equal access to rights. This will be evidenced later in this thesis with the case of returning domestic workers from the Middle East that have had interrupted migration cycles and return without any resources.

In general, non-refugee returns can be further categorized as follows: voluntary highly-skilled return, voluntary low-skilled return, seasonal migration return, student return (forced or voluntary), return of rejected asylum seekers, assisted voluntary return, forced deportations, and second generation returns. The process of reintegration is thus quite different within these categories. Christou (2006) uses the term 'adjustment' for second-generation returns as she rightly highlights that they really have not 'returned' at all. For all returnees, however, the process is one of 'adjustment'.

In the case of decided return, reintegration can be defined as the "process through which a return migrant participates in the social, cultural, economic, and political life in the country of origin" (Cassarino, 2008). Social aspects would include participation in organisations, relationships and acceptance with family and friends (such as respect within the household), access to information sources, and societal acceptance. Cultural aspects would include participating in religious or cultural events, and participation in the norms and values of the society. Economic reintegration refers to the occupational and employment status of the returnee and their ability to afford a certain standard of living. It also includes entrepreneurial activities and local investments. Political reintegration refers to participation in the political process of the country.

The final category of returnees to consider in reintegration is rejected asylum-seekers, forced returnees, and/or deportees. This category includes individuals who have been forcibly removed from the country of migration. It also includes AVRs, which includes rejected asylum seekers who voluntarily agree to return to their country of origin. Individuals who engage in AVR generally receive a reintegration package from the country of migration that includes either financial compensation or in-kind benefits such as training or starting a business. The reintegration of this group can also be assessed as per the four categories discussed 
above. In a study of 178 rejected asylum seekers and migrants that did not obtain residence permits to six countries (Afghanistan, Armenia, Bosnia and Herzegovina, Sierra Leone, Togo and Vietnam), it was found that reintegration was a difficult process upon return (Ruben, Van Houte, and Davids, 2009). The authors found that the majority of returnees were able to survive, but few were able to build sustainable livelihoods, access to social networks were crucial to providing support, and for some traumatic experiences prior to migration and/or abroad tended to limit feelings of belonging to the return society (Ruben, Van Houte, and Davids, 2009). Overall, it is recognized that involuntary returnees are often vulnerable upon their return to their country of origin and face several challenges reintegrating.

Reintegration is thus a process that incorporates multiple patterns to varying degrees. The individual's experiences and social status prior to migration, their experiences in the country of migration, and the conditions of their return, all influence reintegration. Gmelch (1980) termed this reintegration the 'readaptation of return migrants'. Gmelch proposed that there are two ways to assess the readaptation: first, by examining the actual economic and social conditions of returnees, and secondly, by focusing on migrants own perceptions (1980).

The first approach of examining the actual conditions of return migrants has been examined in several empirical works (Alquezar Sabadie et al., 2010; Ammassari, 2009; Cassarino, 2008). Quantitative indicators that have been used to assess postreturn conditions include employment, access to services (such as healthcare), finances, entrepreneurship, and plans for re-migration (Alquezar Sabadie et al., 2010; Cassarino et al., 2008). Additional qualitative works have focused more on social aspects and migrants own perceptions by examining topics such as: changes in gender roles upon return, adaption to the work and cultural environment, and subjective opinions regarding return (Ammassari, 2009; Thomas Hope, 1999).

The challenges of reintegration also differ for return populations. In Ammassari's (2009) study of highly skilled return migrants, Ammassari determined four categories of reintegration challenges experienced by returnees. The first is in regards to the employment and business sector that include both trials associated with being employed in the environment of return and obstacles of establishing ones' own business. The second category is the local work conditions, which are assessed in terms of work attitudes and professionalism of colleagues. Ammassari found that reintegration was more difficult for people working in the public sector than those working in the private sector. The third challenge is the local living conditions, which includes contact with friends and family and gender roles. The final reintegration challenge is satisfaction with return and the decision to reemigrate or remain in the country of return.

For all types of return migrants, reintegration is a process that is influenced by the structural conditions of the return environment. The structural conditions of 
the return environment affect the ability of any individual to reintegrate. Structural conditions include government policies, such as the rights extended to returnees in terms of citizenship, property restitution, or other privileges (Kibreab, 2005). Secondly, the context of safety and security is critically important for structural reintegration in post-conflict societies. Thirdly, the attitudes of the local population towards returnees can significantly impact reintegration. Stefansson's (2004) work highlights the importance of stayees in the reintegration process in Bosnia wherein returnees were called pogjeclice by locals meaning: "those who ran away scared for no reason, implying cowardice" (58). Stayees felt that returnees were economically privileged and conflicts emerged over access to property, land rights, and jobs (Stefannson, 2004). Returnees also brought new ideas and customs that made them stand out and clash with local culture. The result was the social exclusion of returnees and the development of the 'return identity' and return 'enclaves' (a distinctly bounded area within a larger unit) wherein returnees only interacted with each other (Stefannson, 2004). The term 'immigrant enclave' was termed by Wilson and Portes (1980) in their work on the Cuban enclave in Miami. Their work led to the 'ethnic enclave hypothesis', which showed that it was more beneficial for Cubans to work for co-ethnics in immigrant entrepreneurship than for refugees to work for whites (Waldinger, 1993). This case study highlights the importance of reintegration occurring at a community level to ensure cohesion for the long-term.

In addition to clashes between stayees and returnees, clashes can also arise amongst different groups of returnees. Horst (2007) found that in return migration to Jamaica the different reintegration processes of returnees from the UK and returnees from the US led to conflict between the groups. Returnees from the UK believed that return required a strong commitment, participation in local returnee organisations and social life in Jamaica, whereas returnees from the US tended to spend half their time in the US and did not engage in organisations and social life in Jamaica (Horst, 2007). This led to resentment of the US returnees from the UK returnees and clashes amongst the returnees themselves due to their different reintegration processes and strategies.

Finally, an important distinction must also be made between short-term and long-term reintegration. It can be expected that the reintegration of a return migration within 12 months of return will be different than their reintegration after five years. As an example in a survey of 135 return migrants to a Barbadian village 53 per cent of respondents were so dissatisfied after their first year at home that they believed they would have been happier abroad, however, after three years in Barbados the level of dissatisfaction dropped to 17 per cent (Gmelch, 2004). Reintegration is thus a process that takes time.

It is evident that the term reintegration has different applications for different types of return migrants, thus explaining the challenges in establishing an 
all-encompassing definition of reintegration. Furthermore there are several factors that determine an individual's level of reintegration such as economic, social, political, and environmental conditions. Perhaps it is due to these complexities that a systemic approach to defining levels of reintegration is not established at present. This thesis will attempt to contribute to this gap through the reintegration strategies, which provide a typology for understanding how people reintegrate.

\section{Learning from Integration}

Integration is the process that occurs when a migrant moves from their country of origin to the country of migration. Although there are many differences between the processes of integration versus reintegration, there are also similarities as in both contexts the individual undergoes a process of adaptation to the new environment. The integration literature is more developed theoretically than the reintegration literature and offers some insights that can be applied to the return context.

Initial theories of immigrant incorporation, especially in the United States, assumed migrants to uproot themselves from their country of origin and begin a process of assimilating to the country of migration. Assimilation was viewed as a process wherein "immigrants were incorporated into society through a one-sided process of adaptation" (Castles and Miller, 2009: 247). From assimilation, the concept of multiculturalism gained popularity, which encourages migrants to maintain their cultural identities. Integration came to be understood as a two-way process that requires adaptation on the part of the migrant, but also the host society (Castles et al., 2003). Integration may thus be understood as a "process through which the whole population acquires civil, social, political, human and cultural rights, which creates the conditions for greater equality" (Castles et al. 2003: 118). This approach argues that immigrants should be given support to maintain their cultural and social identities.

Two approaches to integration highlight differences from reintegration approaches. The first approach by Heckmann (2001) is an examination of integration in European countries. Heckmann identifies four dimensions of analysis: structural, cultural, social and identificational integration. Structural integration refers to the acquisition of rights, access to positions and statuses in the core institutions of the country and these rights can only be achieved if the immigrant participates in learning and socialization processes. This follows to cultural integration, which refers to the cognitive, behavioural, and attitudinal change of individuals. This process also affects the receiving society. Social integration refers to membership of individuals in the society and private sphere including friends, marriages, social relations and participation in associations. Finally, individuals' subjective position is given importance in identificational integration meaning the individual's sense of belonging and identification. This approach highlights the importance of rights, networks, acceptance by the receiving society, and one's own personal sense of 
identification. Although the majority of these points are discussed in the reintegration literature, Heckmann's approach provides a nice summary of the key factors for reintegration.

The second approach is from Berry's model of assimilation in cross-cultural psychology (1997). Berry's assimilation model adopts the four categories of: integration, assimilation, segregation, and marginalization, as shown in Figure 1. Two questions (presented as issues) shape the model, the first being: "Is it considered to be of value to maintain one's identity and characteristics", and the second being "Is it considered to be of value to maintain relationships with larger society?" Within this model each category is then an interplay between cultural maintenance and contact and participation.

\section{Figure 1: Berry's Model of Assimilation}

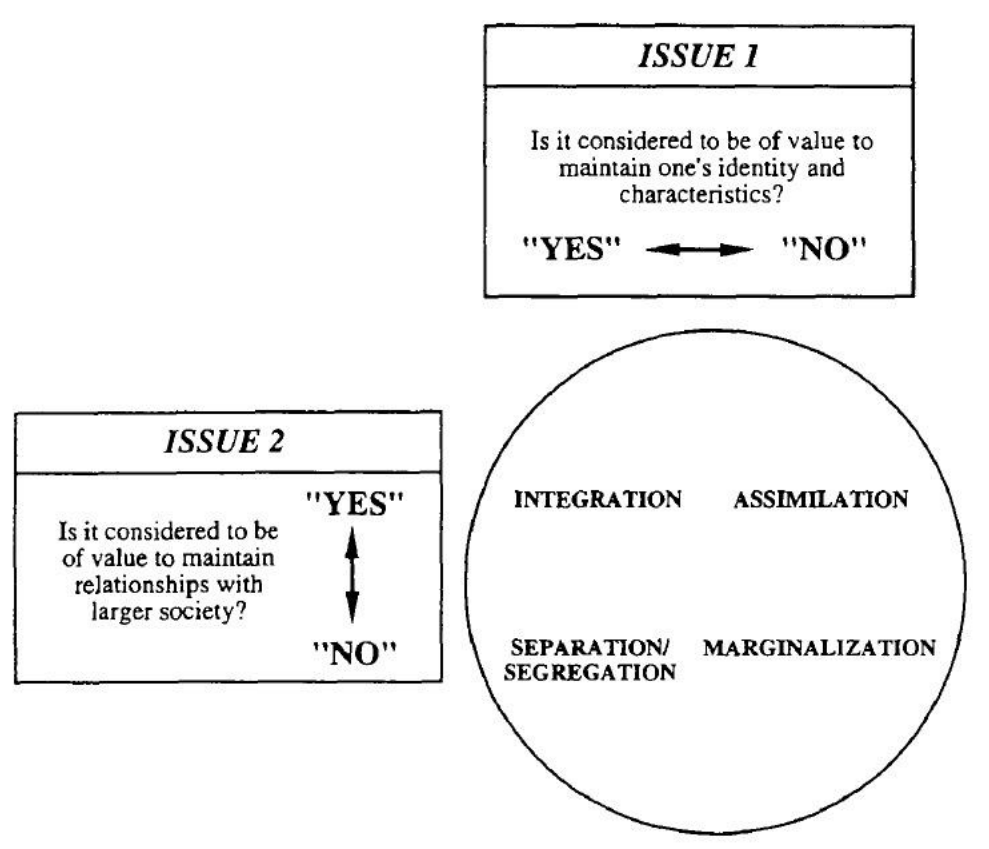

Source: Berry,1997

Cultural maintenance is defined as "to what extent are cultural identity and characteristics considered to be important, and their maintenance strived for" (Berry, 1997: 9). Contact and participation essentially refers to the migrants' social network and examines the extent to which migrants should become involved in other cultural groups or remain amongst their own cultural group.

The spheres of Berry's model are thus depicted further in Figure 2, where integration illustrates a combination of immigrant adaptation to the dominant 
culture and maintenance of their own culture, assimilation is a rejection of ones' own culture and full adaptation to the dominant culture, segregation is a rejection of the dominant culture and maintenance of ones' own culture, and marginalization is a dual rejection of both cultures.

Figure 2: Pictorial of Assimilation Strategies (Berry, 1997)

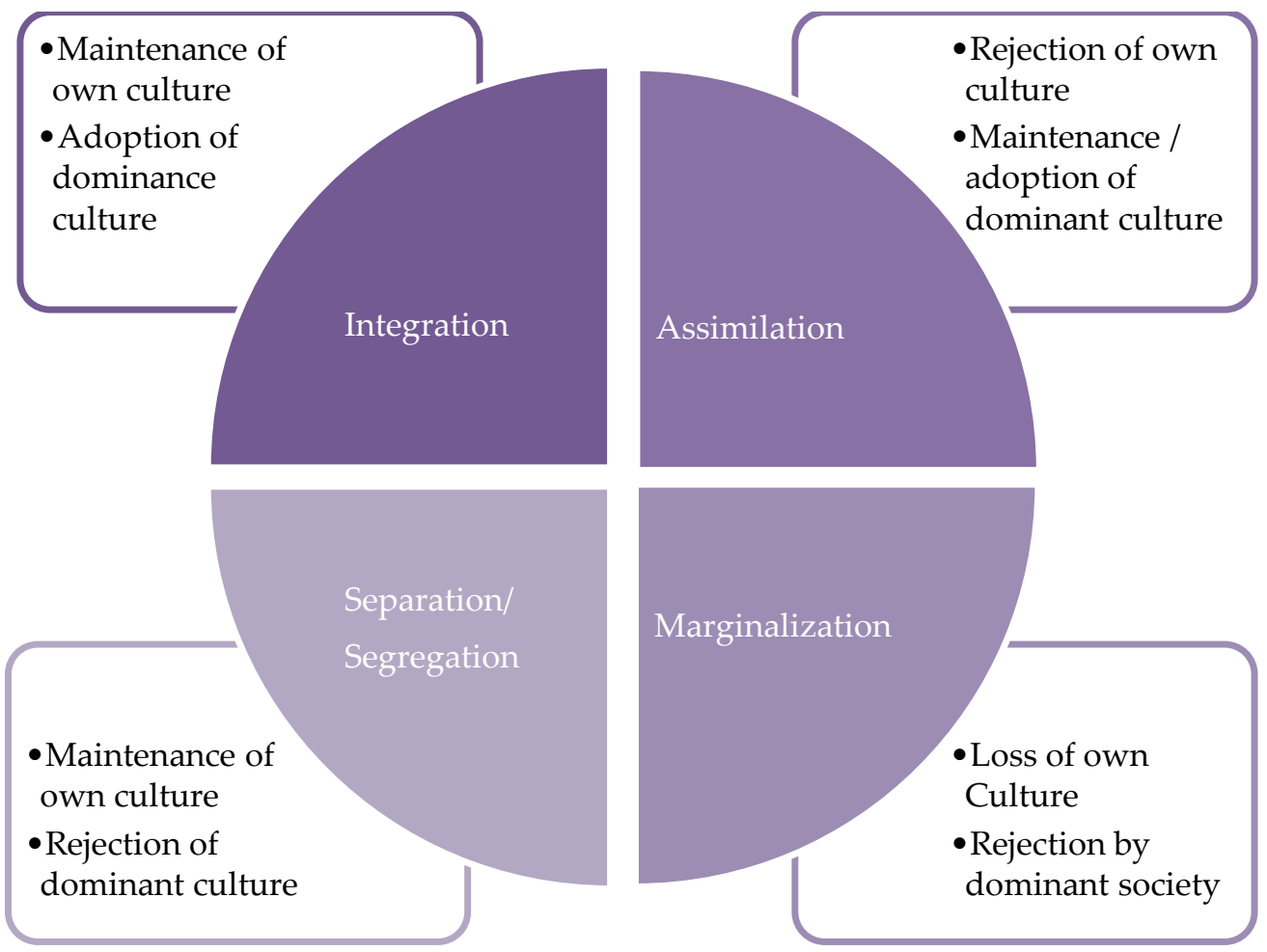

Berry's approach highlights the importance of cultural maintenance and social networks in immigration and the choices that an individual makes in their acculturation strategy. The model recognizes that structural factors also inhibit the ability of migrants to integrate and underscores that integration can only be attained when there is mutual accommodation and acceptance from the receiving population (Berry, 1997). This reflects Castles et al. (2003) definition of integration as a 'two-way process'.

The integration literature thus has a contribution to make to understandings of reintegration. The acquisition of rights and the incorporation of returnees into the core institutions of the return environment are essential components of successful reintegration. This is dependent upon the structural environment, government 
policies, and the attitudes of the local population towards the reception of the returnees. Secondly, returnees' decisions regarding cultural maintenance are an integral component to reintegration. Return migrants have to re-adapt to the local culture and can choose different balances between the culture of the country of migration and the culture of the country of origin/return. This highlights the importance of the return migrant undergoing what Heckmann terms a "learning and socialization process" to re-understand the local culture. Third, returnees' social networks are vital in their ability to reintegrate. There is a difference between return migrants only interacting with other returnees versus interacting with the local population, as is reflected in Berry's model of assimilation. Finally, as highlighted by Heckmann, self-identification is important in the reintegration process. Individuals may identify themselves as having dual or multiple allegiances or dual or multiple identities that may be maintained by dual lives in both the country of migration and country of return. This leads to an important discussion of the concept of transnationalism.

\section{Transnationalism}

Limited research exists on the impact of transnationalism on reintegration. Incorporating learnings from research on integration and transnationalism, however, it can be argued that transnationalism may reinforce processes of reintegration. This will be further explored in later chapters and this section will provide a brief overview of transnationalism theory and its relevance for return and reintegration.

The theory of migrant transnationalism emerged in the 1990s and since has gained increasing popularity. The central premise of the theory is that migrants are involved in dual lives with activities in both the country of migration and the country of origin/return. Portes et al. (1999) delimit the concept of transnationalism to "occupations and activities that require regular and sustained social contacts over time across national borders" (219). Not all migrants are transnational, only those that have significant and sustained cross-border connections with the country of origin/return. The basis of the theory is thus in the maintenance of cross-border social networks, however transnationalism goes beyond social network theory to argue that the connections create new transnational social fields and transnational communities impacting communities at home and abroad.

Levitt and Glick Schiller (2004) define social fields as: "A set of multiple interlocking networks of social relationships through which ideas, practices, and resources are unequally exchanged, organized, and transformed" (9). They further distinguish between ways of being versus ways of belonging. Ways of being refer to social relations and practices individuals engage in whereas ways of belonging refers to practices that signal an identity that demonstrates a connection to a particular group. Therefore: 
"If individuals engage in social relations and practices that cross borders as a regular frame of everyday life, then they exhibit a transnational way of being. When people explicitly recognize this and highlight the transnational elements of who they are, then they are also expressing a transnational way of belonging. Clearly, these two experiences do not always go hand in hand."

- Levitt and Glick Schiller, 2004: 12

Notions of identity and belonging are thus central to the field of transnationalism.

Transnational social spaces can exist at the kinship level, as circuits, or as transnational communities (Faist, 2008). These interactions are based on notions of reciprocity, exchange, and solidarity. Transnational communities are rooted in solitary ties that reach beyond kinship and through reciprocity and solidarity create a "high degree of social cohesion and a common repertories of symbolic and collective representations" (Faist, 2008). Transnational communities may or may not have a diaspora identity. A diaspora can be defined as a population "which has originated in a land other than which it currently resides, and whose social, economic and political networks cross the borders of nation-states or, indeed, span the globe" (Vertovec, 1999). Only diaspora's that have a strong connection to the country of origin can be considered transnational (Faist, 2008).

Initial research on transnationalism saw the process as opposing to integration. Recent research has indicated, however, that the processes are not mutually exclusive and can be intertwined (Vertovec, 2007). It has also been further argued that not only may the processes be intertwined they may be mutually reinforcing so that greater transnational engagement leads to higher levels of integration (Oeppen, 2009).

This leads to emerging discussions of the area of 'post-return transnationalism' (PRIO, 2012) and a debate as to if and how engagement in transnational activities upon return may or may not assist in the reintegration process. The examination of transnationalism from a return perspective is an emerging area that is currently being developed. The next section returns to a central component of integration theory and the basis of transnationalism theory, that is, social networks.

\section{Social Networks}

Engaging with concepts of social networks is important for this thesis as networks are essential for understanding concepts of integration and transnationalism, and therefore also reintegration. Key concepts of social networks including: resources, social structure, and social capital will be addressed in this section. All of these concepts are essential to understand how people are positioned upon their return in 
terms of access to resources and capital. The section will then discuss the application of network theory to migration studies and return migration.

A network can be defined as "a specific type of relation linking a defined set of persons, objects, or events" (Knoke and Kuklinski, 1982:12 from Mitchell, 1969). Network analysis bridges the micro and macro level of analysis that is the structural environment and the individual and household. It moves beyond looking at attributes of individuals to looking at the relationships and connections between individuals.

The central importance of networks is the access to resources that they provide. Resources can be defined as "material or symbolic goods" (Lin, 1982). Lin argues that there are three principles regarding how individuals assign meaning to resources. The first principle is "differential values are assigned by consensus or influence to resources to signal their relative significance" (Lin 1982). This relates to supply and demand of the resource available, but also the value of the resource can change due to events or over time. The second assumption is "all actors will take actions to promote their self-interests by maintaining and gaining valued resources if such opportunities are available." Generally, those with more valued resources will work to protect their resources, and those with less valued resources will try to gain more valued resources or change the values assigned to resources. Appropriation of resources can occur in legitimate ways such as education, or in illegitimate deviant behaviours such as stealing. The third principle regarding resources is that "maintaining and gaining valued resources are the two primary motives for action, with the former outweighing the latter" (Lin 1994a).

The acquisition of resources is embedded within a social structure. Here there is a distinction between resources that are attached to an individual versus resources that are attached to a position. Power, hierarchy, authority, and rules all become embedded in the social structure and regulate the access to resources of individuals depending on their position and network connections within the social structure. Individuals have limited resources themselves and thus use social ties and connections within the structure to access resources. Social capital is thus a critical component of the network approach.

Social capital according to a network perspective is the resources accessible and embedded through social connections or social networks (Lin, 2001; Burt, 2002). This contrasts the theories of social capital put forth by Bourdieu, Coleman, and Putnam in that social capital exists on a group level and can be examined through solidarity and reproduction of the group (Lin, 2001). Bourdieu, Coleman, and Putnam argue that a requirement for social capital is the density or closure of social networks (Lin, 2001). Dense networks are those that consist of strong ties wherein "members know one another, interact on a routine basis, and are privy to the same 
information regarding the social environment, including job opportunities" (Wilson, 1998; 397).

Network theorists approach to social capital argues that weak ties in networks can be more beneficial for accessing new resources not currently possessed, such as information regarding new job opportunities. Granovetter (1973) has illustrated that information regarding job opportunities is often best found outside of dense networks ties through weak ties that thus act as an information bridge from structural holes (absence of ties). Building on Granovetter, Burt argues "Dense networks tend to convey redundant information, while weaker ties can be sources of new knowledge and resources" (From Portes, 1998: 6). In terms of maintaining resources, denser networks have an advantage as they prevent entry for others; such as occurs with the privileged class (Lin, 2001). For those looking to obtain new resources, such as a job, weak ties and extending bridges can be more helpful.

Putnam (2000) termed the differences in weak ties and dense ties access to social capital as bridging and bonding social capital. Bridging social capital is defined as networks that are "outward looking and encompass people across diverse cleavages" and bonding social capital as "inward looking [networks that] tend to reinforce exclusive identities and homogenous groups" (Putnam, 2000: 22). Nannested and Svendesen (2008) further the explanation to equate with trust where bridging social capital is based on general trust and refers to trust in strangers and bonding social capital is based on concrete trust and refers to trust in people you already know. Bonding social capital can also turn negative when it becomes excessive in groups that form units such as al-Qaida and the mafia (negative social capital is explored further below).

Upon accessing social capital, Lin (2001) argues that social capital can lead to two types of returns: instrumental returns and expressive returns. Instrumental returns are based on instrumental action, which is taken to obtain resources not already possessed by the actor. Instrumental returns include economic, political, and social returns. Economic and political returns are self-explanatory. Social returns can include reputation, that is, the unfavourable or favourable opinion regarding an individual in a collective. Expressive action refers to a method to consolidate resources and defend against resource losses. Expressive returns include physical health, mental health, and life satisfaction. Expressive returns reflect the theory of homophily, also known as the 'like-me hypothesis', which states that people with similar characteristics, attitudes and lifestyles tend to congregate.

Through social networks individuals can mobilize resources and gain social capital that offers the individual different types of returns. In general, it is assumed that returns acquired through networks and social capital are positive and can lead to economic, political, and social gain, or improvements in health, happiness, and life 
satisfaction. There can be however, negative elements to social capital and network membership.

Portes (1998) highlights four negative aspects of social capital: exclusion of outsiders, excess claims on group members, restrictions on individual freedoms, and downward levelling norms. Portes states "Social ties can bring about greater control over wayward behaviour and provide privileged access to resources; they can also restrict individual freedoms and bar outsiders from gaining access to the same resources through particularistic preferences" (Portes, 2008: 21). Downward levelling norms refers to groups where solidarity is created and maintained based on opposition to mainstream society. When one individual is able to create success in mainstream society this undermines group cohesion as the group is rooted in the impossibility of such successes. Therefore that member generally exits the group and the remaining group members focus on downward levelling norms that maintain their group dynamics.

The negative aspects of social capital highlight an important component of the network debate as network membership may have negative influences on its members. Therefore, simply being a member of a network is not enough; it is the characteristics and dynamics within the network, and the access to resources that the network provides that is important. Finally, it is essential to note that networks are not static entities that are constantly changing and adapting (Cassarino, 2004).

\section{Migration Networks}

It is essential to note that network theory has only been partially applied in migration studies. A network approach to migration studies gained increasing popularity in the 1980s. Prior to this research conducted in the 1960s and 1970s also focused on the importance of social networks in theories of chain migration (MacDonald and MacDonald, 1964; Boyd, 1989). Current migration research emphasizes social networks in various stages of the migration process including: 1) decisions to migrate 2) direction and persistence of migration flows 3) transnational links and 4) settlement patterns and incorporation (Hagan, 1998).

Massey et al. define migrant networks as "sets of interpersonal ties that connect migrants, former migrants, and non-migrants in origin and destination areas through ties of kinship, friendship, and shared community origin" (1993, 448). Migrant networks are theorized to increase migration because they lower the risks and costs of migration and increase the returns from migration (Massey et al, 1993). Migrant networks can aid the migrant at the destination in multiple ways, such as: "the provision of food and housing for a temporary period, assistance in finding housing and work, orienting the migrant to life in the receiving community, and often constituting the primary source of continuing social relationships and moral support once the migrant has established himself/herself in their destination" 
(Wilson, 2010: 13). Once established, migrants can send back remittances and information to members of their networks to assist them in facilitating migration. This creates what has also been termed chain migration. MacDonald and MacDonald (1964) defined chain migration as "that movement in which prospective migrants learn of opportunities, are provided transportation, and have initial accommodation and employment arranged by means of primary social relationships with previous migrants" (82).

Network theory in migration studies has primarily focused on the facilitating role of migrant networks (de Haas, 2010). The approach has assumed a dense network that provides privileged access to information on how to migrate and then self-perpetuates migration. Migrant network theory has largely ignored three important aspects of network theory (de Haas, 2010). First, the importance of access to resources remains largely unaddressed in migration theory which assumes that networks simple existence will lead to migration, while only the resources provided from the network ties can facilitate access to migration. Secondly the forms of social capital are not assessed in the migration network approach, which assumes dense networks and does not examine the potential to migrate through bridging social capital or weak ties. Thirdly, the negative aspects of social capital are generally excluded from the migration network approach, which is significant as it is highly probable that outsiders (based on kin or class) are excluded from migration opportunities due to lack of membership (de Haas, 2010). De Haas (2010) argues that building on Portes (1998) argument the fifth downside of social capital is that strong bonding and weak bridging social capital leads to the exclusion of individuals from new information and ideas that may be critical for migration. In summarizing the network effects on migration and accounting for previous shortages in the theory de Haas states:

"Large-scale migration diffusion through network effects seems most likely to occur among relatively poor, low-skilled migrant groups with a 'moderate' level of group identity, cohesion and 'strong ties', which should be strong enough to guarantee clustering and prevent rapid assimilation, but also loose enough so that group norms do not prevent the establishment of 'weak ties'. This seems to apply to many rural communities in relatively poor but rapidly modernizing and transforming societies" (de Haas, 2010: 1610).

This highlights the continued importance of the social structure (hierarchy, power, authority) in the access to resources that the network can provide. Building on these arguments, this thesis will utilize the full application of social network theory to 
migration studies, moving beyond the limited application of the 'network approach' commonly utilized in migration studies.

Finally, Epstein (2008) puts forth that a distinction must be made between migration network effects and migration herd effects. Network effects account for the individual receiving personal information regarding the migration, whereas herd effects account for individuals who make their migration decisions based on observations of others. In the herd model emigrants "may have some private information, but are imperfectly informed about the attributes of alternative foreign locations, and pay attention to previous emigrants' decisions" (Epstein, 2008: 568). Individuals may discount private information to follow the herd model and the result can be a negative migration experience, due to the discounting of private information that was accurate. This model differs from network effects where migrants have a connection at the destination that will assist them in their initial settlement.

\section{Social Networks and Return Migration}

The application of the social network approach to return migration is less well studied than in the migration literature. From a return migration perspective it is anticipated that the migrant will acquire social capital while abroad that can be transferred upon return. Cassarino (2004) states "social network theory views returnees as migrants who maintain strong linkages with their former places of settlement in other countries" (265). Thus, successful returnees would have generally expanded their social network due to migration, thus granting them further access to resources and providing positions of power upon returns from their expanded social capital.

In addition to expanding the network through migration, social networks are vital in the process of return migration and the individual's resource mobilization and preparedness for return (Cassarino, 2004). Resource mobilization refers to the tangible (ie: financial resources) and intangible (contacts, relationships, skills, acquaintances) resources that have been mobilized while abroad. Preparedness refers to "not only the willingness of migrants to return home, but also their readiness to return home" (Cassarino, 2004: 271). A high level of preparedness refers to an individual who has strong incentives and opportunities in the origin country to encourage return, has acquired savings and new acquaintances, maintained contacts in the origin country, and has knowledge, skills and expertise mobilized for return. Their reintegration is thus a process of adaptation and negotiation and the rediscovery of the true characteristics of the origin country (Cassarino, 2004). Cassarino's preparedness theory highlights that networks and resource mobilization are not the only central component in return migration, as the willingness and readiness of the migrant to return is also central to their ability to reintegrate. 
Both preparedness and resource mobilization for return can be supported through social networks in the host and origin country. Temporary visits allow the individual to see the country of return and preliminarily assess the conditions of return. Networks in the country of return can assist in providing access to valuable resources of information, housing, employment and business opportunities, and social support in the reintegration process. Networks abroad can also continue to provide information on opportunities and access to potentially broader networks in the country of return, as well as providing social support in the reintegration process.

Social networks are a vital component to successful return and reintegration. Networks provide access to resources and social capital that can play essential roles in the process of reintegration. This includes leading to instrumental returns in the reintegration process such as access to employment, information for business development, or political positions. Networks and social capital can also lead to expressive returns such as mental health and life satisfaction in the return experience. The establishment of return migrant networks that perpetuate further return from networks in the country of migration is also a possibility that has yet to be explored. Finally, the social structure impacts the capacities of the return migrants network in return and the migrant's agency is paramount in determining their preparedness for return. All of these factors combine to impact the ability of the return migrant to affect social change in their communities of return.

\section{Social Change}

Migration can be both a form of change and a cause of change that has different effects on the sending and the receiving society. Social change is discussed in this section as it is important to note the potential impacts of return migrants on their communities of return. The short-term effects of migration on the sending society include remittances and investments and the development potential depends on the countries governance. Long-term effects include the possible depopulation of sending regions, transnationalisation of local culture; economic remittances alleviate poverty and potential political transformations via mass voting from abroad. Shortterm effects on the receiving society include surface level social and political adaptions and the meeting of labour market needs. The long-term effects in receiving societies include the emergence of working class settlements and enclaves, increasing ethnic diversity in working-class, some social and political transformations to accommodate diversity, and the emergence of specialized institutions to handle marginalized groups (Portes, 2010). 


\section{Return Migration and Social Change}

In terms of return migration, it is possible to conceptualize that all of the changes mentioned above for both the sending and receiving society become feasible in the country of return. The key impacts for the country of return can be categorized as economic impacts and social, cultural and political impacts. In terms of economic impacts, the primary economic impact of migration generally discussed is the impact of remittances. Upon return, the migrant is of course no longer able to send remittances, however, decided returnees often return with financial resources acquired abroad. These resources may be invested into the local economy. This can be on a small scale such as purchasing a house or items for the return migrant and their family, or a larger scale such as investing in a new business or large project.

The impact of new business creation from return migrants can be significant in countries of return. A prime example of this is the case of India, wherein highly skilled migrants from the United States began to return to India and re-vitalize the information technology (IT) sector in India (Hunger, 2004). According to Hunger (2004:102), in 2000, ten of the twenty most successful software companies in India were set up and/or managed by return migrants from the US. The software boom in India has led to development gains and increased the economic position of the country.

In terms of social, cultural, and political impacts, return migrants that have themselves undergone a process of cultural change and adaptation to the country of migration may return with new values, cognitive frameworks and knowledge. These new cultural elements interact with the local culture and may create clashes or over the long-term the increased diversity and social and political transformations to accommodate the new diversity. Especially when those that return are the elite who hold the power in the country the processes of social change may occur more rapidly.

Finally, Ammassari (2009) argues that development through return migration can occur at the micro, meso, and macro level. At the micro level social change includes the individual themselves and their immediate family. Social change can occur through human and financial capital accumulation, thus including an increase in knowledge or wealth for the individual and/or family unit. Social change occurs at the meso level through the return migrants behaviours and the spreading of new ideas within their social environment and work place. Finally, macro level social change occurs through the development of new businesses and entrepreneurial activity and through community development, the mobilization of civil society and public advocacy. This section has illustrated that there is a gap in the evidence on the relationship between return migration and social change, which will be explored in this research, however, requires further attention beyond the scope of this thesis. 


\section{Return Migrants' Potential to Affect Social Change}

A distinction can be highlighted between diffusion effects caused by return migration (such as through business creation) and direct social changes initiated by individual return migrants. Several factors contribute to the ability of return migrants to affect social change including their skill sets, the duration of time abroad, skill acquisition in the country of migration, and their networks and preparedness for return. Portes (2010) argues that the power of migration to affect change depends on three factors: the size of the movement, the duration of the movement, and its class composition. Thomas Hope (1999) states that return migrants must have not only the skills, but also the experiences and attitudes to impact the country of return. This also relates back to Bovenkerk in that large numbers of returnees will have the critical mass to create reforms whereas small numbers have limited capacity for influence (Gmelch, 1980). It is argued that circular migrants who move for a short period with intended return are unlikely to affect change as compared to highly skilled migrants who have been abroad for a longer duration (Portes, 2010).

Furthermore, having the potential to elicit social change does not mean that one will lead change to occur. Gmelch (1980) found that the innovation influence of return migrants often does not occur and cited the example of Ireland where returnees felt that in order to gain acceptance with locals they could not force their ideas or foreign experiences on local people. This highlights the importance of the conditions in the country of origin as noted by Thomas Hope (1999).

Levitt and Merry (2009) argue that diffusing practices (the basis of social change) do not occur through merely the existence of social networks and linkages, but that linkages, practices, and identities are inherently cultural. They term the process of appropriation of international ideas into a local context for local adaptation vernacularization. According to Levitt and Merry (2009) "Vernaculizers take the ideas and practices of one group and present them in terms that another group will accept" (446). Levitt and Merry (2009) apply this model to the international human rights and women's movement regime to see how international human rights ideas are translated on the ground.

Bridging the above theories, in order to create social change return migrants can affect culture by bringing with them new values, cognitive frameworks and knowledge. In order to have these new values become adopted by the local population the return migrants must be vernaculizers who have the capacity to translate the new values and knowledge into terms that the local population will accept. When this occurs, provided the country has constructive structural factors, the return migrant as an individual has the capacity to affect social change.

In this study, it is not possible to measure the impact of return migrants to affect social change, or to assess if locals have embraced the messages of return migrants. For these reasons, the study will focus on the potential of return migrants 
to vernacularize. As illustrated above, vernacularizers can be powerful agents of change upon their return. This study will thus examine the potential of return migrants to vernacularize upon their return.

\section{The Reintegration Strategies: A Framework for Analysis}

Following from the definition of reintegration used in this study: "the process in which return migrants are supported in maintaining their cultural and social identities by the host society and the whole population acquires equal civil, social, political, human and cultural rights", return migrants reintegration will be assessed in two parts: the structural environment of return, and the returnees' reintegration strategy. The structural environment of return refers to the first half of this definition in that "migrants are supported in maintaining their cultural and social identities by the host society". The structural environment in this study characterizes the host societies attitudes toward the returnees and their level of welcomeness to the cultural diversity returnees may bring with them upon return. The structural environment of return is therefore based on the three elements of: government policies, the number of returnees, and locals perspectives towards returnees.

The second part of the definition refers to the returnees' reintegration strategies- that is, how in fact, they reintegrate. The approach recognizes the critical importance of integration and culture in the life cycle of the return migrant. Having had the opportunity for integration abroad, migrants may change their cultural orientation and bring this with them in return. Reintegration is therefore not only an insertion back into the culture and life of the country of origin, it is a process. Much like integration, return migrants must go through a process of reintegration, and how they reintegrate will be dependent upon their experiences and choices. Agency and the life cycle of the migrant are critical elements in determining the returnees' reintegration strategy. Networks have a critical role in this process as they provide access to resources and information regarding return and reintegration. The returnees' reintegration strategy is thus based on the four categories of: cultural maintenance, social networks, self-identification, and access to rights, institutions and labour markets.

Taken together, these two parts of the structural environment and the reintegration strategies, comprise the four categories of integration classified by Heckmann (2001). However, as structural factors are outside the realm of the individual return migrants control, I have addressed them separately. The return migrants reintegration strategies and the conditions of the structural environment are then combined to assess the potential of return migrants to act as vernacularizers.

\section{Structural Conditions}

Structural conditions of the return environment include government policies towards return migrants, the attitudes of locals towards return migrants, the 
approach of the private sector to return migrants and return migrant flows. It is important to note that as return migrants are heterogeneous the structural conditions at any one time may differ for different categories of return migrants. For instance, the government may have a pro-return stance for highly skilled migrants and an anti-return stance for low-skilled migrants, or locals may be welcoming towards highly skilled migrants and negative towards deportees.

The structural environment of return can thus be categorized as favourable, adverse, or neutral as illustrated in Table 3. Favourable return environments include an official government position welcoming and encouraging return, conducive government policies towards returnee business creation, positive attitudes of locals and the private sector towards returnees and a medium number of returnees that does not overwhelm the local environment.

An adverse return environment would be characterized by government policies that do not encourage return or provide support to returnees, negative attitudes of locals and the private sector towards returnees and return that is in large numbers that overwhelms the local population. The conditions of the structural return environment can have a significant impact on the reintegration experience of the return migrant.

\section{The Reintegration Strategies}

The reintegration strategies represent a multidimensional approach to the process of reintegration based on the four dimensions of: cultural maintenance, social networks, self-identification, and access to rights, institutions and the labour market in the country of return. Cultural maintenance reflects the value systems of the return migrant and their orientation towards the values of the country of migration or the values of the country of origin/return. The choice of cultural orientation reflects the desire or not for cultural maintenance of the values adopted from the country of migration (Berry, 1997). Social networks reflect the type of network of the return migrant: if it is comprised of returnees, locals, cross-border networks or a combination of the three groups. 
Table 1: Structural Environment for Return

\begin{tabular}{|l|l|l|l|}
\hline \multicolumn{1}{|c}{ Favourable } & \multicolumn{1}{c|}{ Adverse } \\
& $\begin{array}{l}\text { - encourage return } \\
\text { migration } \\
\text {-implement policies to } \\
\text { support returnees } \\
\text { reintegration/ } \\
\text { participation }\end{array}$ & $\begin{array}{l}\text { - discourage return } \\
\text { migration } \\
\text { - no policies to } \\
\text { support returnees }\end{array}$ & $\begin{array}{l}\text { - ambivalent towards } \\
\text { returnees }\end{array}$ \\
\hline Local Population & $\begin{array}{l}\text { - inclusive attitude } \\
\text { towards returnees } \\
\text { - open towards } \\
\text { cultural diversity }\end{array}$ & $\begin{array}{l}\text {-exclusive attitude } \\
\text { towards returnees } \\
\text { - closed towards } \\
\text { cultural diversity }\end{array}$ & $\begin{array}{l}\text {-ambivalent towards } \\
\text { returnees }\end{array}$ \\
\hline Private Sector & $\begin{array}{l}\text { - inclusive attitude } \\
\text { towards returnees }\end{array}$ & $\begin{array}{l}\text {-exclusive attitude } \\
\text { towards returnees }\end{array}$ & $\begin{array}{l}\text {-ambivalent towards } \\
\text { returnees }\end{array}$ \\
\hline Return Migrant & $\begin{array}{l}\text { - medium flow of } \\
\text { return migrant }\end{array}$ & $\begin{array}{l}\text { - flow is too large and } \\
\text { overwhelms local } \\
\text { population } \\
\text { - flow is too small to } \\
\text { be noticed }\end{array}$ & $\begin{array}{l}\text { - small to medium } \\
\text { flow of returnees } \\
\text { (does not affect local } \\
\text { populations daily } \\
\text { lives) }\end{array}$ \\
\hline
\end{tabular}


Table 2: Typology of Reintegration Strategies

\begin{tabular}{|c|c|c|c|c|}
\hline & Reintegrated & Enclaves & Traditionalists & Vulnerable \\
\hline Return Migrant & $\begin{array}{l}\text {-abroad for } \\
\text { longer duration } \\
\text { - decided return } \\
\text {-high return } \\
\text { preparedness } \\
\text { - economic } \\
\text { success }\end{array}$ & $\begin{array}{l}\text {-abroad for } \\
\text { longer duration } \\
\text { - decided return } \\
\text { - high return } \\
\text { preparedness } \\
\text { - economic } \\
\text { success }\end{array}$ & $\begin{array}{l}\text { - abroad for } \\
\text { shorter duration } \\
\text { - decided return } \\
\text { - medium } \\
\text { preparedness } \\
\text { - economic } \\
\text { stability }\end{array}$ & $\begin{array}{l}\text {-abroad for } \\
\text { shorter duration } \\
\text { - forced return } \\
\text { (deportees) } \\
\text { - no return } \\
\text { preparedness } \\
\text { - economically } \\
\text { vulnerable }\end{array}$ \\
\hline $\begin{array}{l}\text { Cultural } \\
\text { Orientation }\end{array}$ & $\begin{array}{l}\text { - value both the } \\
\text { culture of the } \\
\text { country of } \\
\text { migration and } \\
\text { country of } \\
\text { origin/ return }\end{array}$ & $\begin{array}{l}\text { - value the } \\
\text { culture of the } \\
\text { country of } \\
\text { migration }\end{array}$ & $\begin{array}{l}\text { - value the culture } \\
\text { of the country of } \\
\text { origin/ return }\end{array}$ & $\begin{array}{l}\text { - rejection of } \\
\text { culture of } \\
\text { country of } \\
\text { migration } \\
\text { - rejection from } \\
\text { dominant } \\
\text { society in } \\
\text { country of } \\
\text { origin/return }\end{array}$ \\
\hline Social Network & $\begin{array}{l}\text { - locals, } \\
\text { returnees and } \\
\text { cross-border ties }\end{array}$ & $\begin{array}{l}\text { - returnees and } \\
\text { cross-border ties }\end{array}$ & - locals & $\begin{array}{l}\text { - ties to kin and } \\
\text { other vulnerable } \\
\text { groups }\end{array}$ \\
\hline $\begin{array}{l}\text { Self } \\
\text { Identification }\end{array}$ & - transnational & - transnational & - unidirectional & - unidirectional \\
\hline $\begin{array}{l}\text { Access to } \\
\text { Rights, } \\
\text { Institutions, } \\
\text { and the Labour } \\
\text { Market }\end{array}$ & $\begin{array}{l}\text { - limited or full } \\
\text { access to rights } \\
\text { in country of } \\
\text { return (depends } \\
\text { on citizenship } \\
\text { choices) } \\
\text { - limited access } \\
\text { to key } \\
\text { institutions in } \\
\text { country of return }\end{array}$ & $\begin{array}{l}\text { - limited access } \\
\text { to rights in } \\
\text { country of return } \\
\text { - limited access } \\
\text { to key } \\
\text { institutions in } \\
\text { country of return }\end{array}$ & $\begin{array}{l}\text { - full access to } \\
\text { rights in country } \\
\text { of return } \\
\text { - full access to key } \\
\text { institutions in } \\
\text { country of return }\end{array}$ & $\begin{array}{l}\text { - full access to } \\
\text { rights in } \\
\text { country of } \\
\text { return } \\
\text { - limited access } \\
\text { to institutions in } \\
\text { country of } \\
\text { return }\end{array}$ \\
\hline
\end{tabular}


The network of the return migrant will determine the access to resources and social capital that the network can provide. Self-identification is the returnees' subjective view and self-definition of their own identity. Return migrants can identify themselves as one of the following: unidirectional orientation towards the country of origin/ return, unidirectional orientation towards the country of migration, or a transnational bidirectional orientation towards both the country of migration and origin/ return. Levitt and Glick Schiller (2004) term the last option a transnational way of belonging. The final component is the access to rights and institutions in the country of return that are available to the return migrant. This includes the position and statuses that the return migrant can achieve in institutions such as the labour market, citizenship rights, political institutions, housing rights, and within the education system (Heckmann, 2001). All of these factors are not absolutes and can be envisioned as different degrees along a spectrum.

From these four dimensions the reintegration framework puts forth four reintegration strategies as illustrated in Table 4. The first strategy is termed 'reintegrated'. The reintegrated returnee has been abroad for a longer duration (more than five years), has a high preparedness for return, and possesses skills or a comfortable level of wealth. In this strategy the return migrant has maintained aspects of the culture from the country of migration, but has also adjusted to the culture of the local context. The return migrant has a vast social network that includes locals, other returnees, and the maintenance of their cross-border network from the country of migration. The vast social network allows the return migrant access to both bridging and bonding social capital, thus being able to access a wide array of resources. The return migrant identifies himself or herself as being transnational or belonging simultaneously to two cultures and country contexts. From this reintegration strategy the return migrant is able to acquire limited rights in the country of return. The ability to acquire rights will be largely dependent on the country of returns citizenship policies. For instance, if the country of return allows for dual citizenship than the return migrant will have the same rights as citizens. If the country of return does not allow for dual citizenship and the return migrant opts to maintain their citizenship from the country of migration, although being a resident of the country of return, their rights in the country of return will be limited. In terms of access to the labour market, the reintegrated should have strong access due to their skills and adaptability. Finally, their access to the core institutions of the country will also be dependent upon their citizenship choices, and thus may be limited.

The second strategy is termed the 'enclave' strategy. Return migrants in the enclave strategy are similar to those in the reintegrated strategy in that they have been abroad for a longer duration (more than five years), have a high preparedness for return, and possesses skills or a comfortable level of wealth. The enclavists, 
however, maintain the culture of the country of migration and do not adapt to the local culture. The enclavists are most likely to have cultural clashes with the local population. The social network of the enclavists is primarily comprised of other returnees and the maintenance of their cross-border network with limited ties to the local community. The enclavists thus have strong bonding social capital, but weak bridging social capital. They maintain an exclusive network that is difficult to gain access to for outsiders. The enclavists define themselves as transnational. Similarly to the reintegrated, the enclavists would have limited rights in the country of return if the country does not allow for dual citizenship. Unlike the reintegrated who may opt to give up their citizenship from the country of migration, the enclavists would not give up their citizenship from the country of migration as they identify with the country of migration and ensure the maintenance of the connection with the country of migration. Thus their rights would be limited in a country of return that does not allow for dual citizenship. Therefore, the enclavists would also have limited access to key institutions in the country of return, such as political membership (if this is not allowed for non-citizens); however, they should have access to the labour market, educational institutions and housing.

The third strategy is the 'traditionalist'. The traditionalist typically has been abroad for a shorter amount of time (3-5 years), has a medium level of preparedness for return, and had less social status than the enclavists or reintegrated, but enough status that they can acquire positions of medium power upon return. The traditionalist has fully adapted to the local culture and rejects the culture of the country of migration. Either the traditionalist does not maintain the cultural changes that they adopted from the country of migration and rejects these changes in the return migration strategy, or the traditionalist adopted a segregated integration approach in the country or migration wherein they had limited contact with locals and did not venture beyond their cultural environment, thus not adopting new cultural capital in the country of migration. The traditionalists' social network is primarily comprised of locals with minimal to no interaction with other return migrants and the cross-border networks from the country of migration. The network thus has limited access to resources and the traditionalist has weak bridging social capital due to the lack of maintenance of transnational ties. The traditionalist defines himself or herself as entirely oriented towards the country of return. The traditionalist has typically maintained the country of origin/return citizenship and would have full access to rights and institutions in the country of return.

The final reintegration strategy is the 'vulnerable'. The vulnerable have been abroad for a shorter duration (less than 2 years), have a low preparedness for return, and often are low skilled with low social status. The vulnerable generally have had an unsuccessful migration experience and may have been forcibly returned as a deportee. The vulnerable do not associate with the culture of the country of 
migration. Simultaneously, the vulnerable are often rejected by the dominant culture in the country of origin/ return. This is due to the lack of social acceptance of deportees in the country of origin/ return. The low social position of the vulnerable places them on the periphery of society and leads to social exclusion. This places them in a position of vulnerability where they have low access to local institutions for employment and low rights within the country of origin/ return, although they are full citizens of the country of origin/ return. The vulnerable have limited social networks that are comprised of locals or other returnees and do not maintain crossborder networks developed during migration, as they generally do not have a network in the country of migration to maintain. The vulnerable are at risk of experiencing the negative aspects of social capital, such as 'downward levelling norms' as their network is comprised of other vulnerable people. The vulnerable identify themselves with a unidirectional orientation towards the country of origin.

The reintegration strategies are not permanent and return migrants may adopt different strategies at different stages of their return. For example, upon initial return an individual might adopt the enclave strategy, however with time as they become accustomed to the culture and country of return they may change to adopt a reintegration approach. Factors that can impact a change in a reintegration strategy would include a shock to the economic position of the individual, a change in the family situation, a negative or positive experience with the country of origin/ return, or a change in the relationship with the country of migration. For instance, the relationship with the country of migration could decrease over time and the returnee may choose to move from a reintegrated strategy to more of a traditionalist strategy as they lose connections with the country of migration. On the other hand, the connection with the country of migration may strengthen and a returnee that was initially a traditionalist may re-engage with the country of migration and move to the reintegrated strategy. The returnee may even choose to re-migrate, thus no longer maintaining return status. Finally, the reintegration strategies are conceptualized to provide overall categorizations and it is possible that individuals may portray aspects representing different categories, thus the categorizations may not be mutually exclusive.

\section{Reintegration Strategies and the Potential to Vernacularize}

The potential of return migrants to vernacularize depends, among others, upon their reintegration strategy. The reintegration strategies presented in this study define the process of how people reintegrate across the four dimensions of cultural orientation, social networks, self-identification, and access to rights, institutions and the labour market. In order to act as a vernacularizer, one must first have gained new ideas and values that they bring with them in return, and secondly, be able to gain the trust of locals and frame issues in a way that is socially acceptable. Therefore, the reintegrated have the highest potential to vernacularize as they are comfortable 
within both cultures and are networked between locals, returnees, and transnational ties. Enclavists have the second highest potential as they meet the first condition of bringing with them new ideas and values in return. Their limited networks with locals upon return limit their potential to vernacularize. Both traditionalists and vulnerable have no potential to vernacularize as by rejecting the culture of the country of migration they do not bring with them new ideas and values in return. Table 3 depicts this relationship illustrating the potential to vernacularize among the different reintegration strategies.

Table 3: Reintegration Strategies and Potential to Vernacularize

\begin{tabular}{|l|c|c|c|c|}
\hline \multicolumn{2}{|c}{ Reintegrated } & Enclaves & Traditionalists & Vulnerable \\
\hline $\begin{array}{l}\text { Potential to } \\
\text { Vernacularize }\end{array}$ & High & Medium & None & None \\
\hline
\end{tabular}

\section{Structural Environment, Reintegration Strategies and Potential to Verncaularize}

A return migrants' reintegration strategy is essential in their potential to vernacularize, however the structural environment will also significantly determine the ability of the return migrant to vernacularize. Table 6 combines the potential to vernacularize of the return migrant according to their reintegration strategy in a favourable versus adverse structural environment.

Table 4: Potential to Vernacularize based on the Reintegration Strategy and Conditions of the Structural Environment

\begin{tabular}{|l|c|c|c|c|}
\hline Structural & Reintegrated & Enclaves & Traditionalists & Vulnerable \\
Environment & High & Medium & None & None \\
\hline Favourable & Medium & Low & None & None \\
\hline Adverse & Mdium
\end{tabular}

In situations of a favourable structural environment for return migration individuals who are reintegrated have a high potential to vernacularize. Locals are open to return migrants and are thus willing to learn new ideas and accept cultural diversity. In addition, reintegrated returnees can engage in social structure positions that are supported by the government and can share new ideas through developing businesses, joining political organisations or advocacy movements. Reintegrated returnees possess both the power positions and cultural orientations to be highly effective change agents in the favourable environment.

In an adverse structural environment for return migration reintegrated returnees still have the greatest potential to vernacularize, but the constraining 
structural environment limits their capacity to be effective. Strong vernacularizers will be able to integrate with the local population and still disseminate some new ideas, despite the closed attitudes towards returnees. The adverse environment may also push returnees who would generally opt for a reintegrated strategy towards an enclave strategy due to the clashes with the local population.

In a favourable structural environment enclavists would have a medium potential to vernacularize as they return with different cultural values and if they are highly skilled can occupy positions of power that lead to indirect diffusion effects. That is, locals may indirectly learn from their behaviour, emulate their cultural differences, or desire to migrate due to their example. In an adverse structural environment for return, enclavists would have a low potential to vernacularize due to the cultural clashes between returnees and locals. The enclave strategy may no longer be chosen in an adverse structural environment, but it may be forced if locals ostracize returnees. The adverse structural environment may lead to high levels of re-migration if enclavists cannot establish themselves.

In both a favourable and adverse structural environment traditionalists and vulnerable have no potential to vernacularize. A favourable structural environment would, however, be more supportive towards the vulnerable and offer them services for assistance. An adverse structural environment would ostracize the vulnerable leading to further marginalization from society.

This section has highlighted the importance of both the structural environment and the return migrants reintegration strategy in determining the potential of return migrants to vernacularize. Clearly, not all returnees have the capacity to act as vernacularizers and not all return environments are open to return migration.

\section{Assumptions of the Model}

There are several key assumptions associated with the reintegration strategies. First, it is recognized that return migrants are not always in a position to make choices regarding their reintegration. Therefore, return migrants may or may not choose their reintegration strategy (as an exercise of their agency). Secondly, return migrants reintegration strategies can change over time, that is, over the short and long term, depending, among others, on the type of networks in which return migrants are involved and on the resources they mobilise. Thirdly, the structural environment can change over time (to or from favourable/ adverse) and can differ for different return migrants. Fourth, the potential and ability of return migrants to vernacularize can also change over time with returnees going from a high to low or low to high potential to vernacularize. These assumptions reflect that situations change over time and are never static. In addition, it reflects the agency of the individuals within the process of reintegration. 


\section{Summary}

This chapter provides the foundation for this thesis through a discussion of the key notions of return, reintegration, social networks, and social change and finally the presentation of the reintegration strategies typology. The typology is informed through the multidisciplinary literature review and encompasses elements from the return migration, integration, transnationalism, social networks, and social change literature. The objective is to draw attention to the multiple facets and dimensions influencing return migration and reintegration; the need to widen the definition of reintegration to reflect learning from integration; and the introduction of the reintegration strategies to examine how people reintegrate. The framework recognizes the structure and agency of return migration and how these two factors impact the ability of return migrants to vernacularize.

This chapter forms a substantive base for the remainder of this thesis. Chapter 4 examines the structural environment of return migration in Ethiopia, based on the approach to the structural environment of return addressed in this chapter. Chapter 5 explores the life cycle of return migrants to Ethiopia as the life cycle, opportunities for integration abroad, preparedness and process of return all have a significant impact on a returnees resulting reintegration strategy. Chapter 6 provides an in-depth examination of the dimensions of the reintegration strategies in comparison to the analytical groups of returnees. Chapter 7 then addresses the returnees' reintegration strategies and the relationship between the reintegration strategies and the potential to vernacularize. 


\section{Chapter 3: Research Methodology}

\section{Introduction}

This chapter will present the methodology utilized in this study and ethical considerations made in the fieldwork. I collected empirical data collected in Ethiopia as existing information on returnees in Ethiopia was not sufficient for analysis. There are no official statistics on returnees to Ethiopia and no datasets that would provide the necessary information on the return and reintegration experiences of returnees.

As a part of my PhD I was engaged in the IS Academy: Migration and Development project, for which I was leading the data collection of 1282 household surveys in Ethiopia. From initial scouting trips to Ethiopia wherein we met with migration experts in Ethiopia, it became evident that returnees were a smaller population and would be difficult to find for the survey analysis. This was the case wherein we found in the household listing conducted for Ethiopia on average only 2.7 per cent of households had a return migrant. It was evident that the number of return migrant households surveyed would be too small for a robust quantitative analysis. This contributed to my decision to conduct semi-structured interviews with returnees.

I decided to conduct semi-structured interviews with female returnees in order to be able to grasp the complexities and nuances of their migration decisions, experiences, return decisions and experiences of reintegration. As identified in the introduction, my research questions address "how" and "whys", which are best answered by qualitative research. The empirical work in this study is meant to be an exploration of how women reintegrate, and how and why they make certain decisions regarding their reintegration. I decided to use interviews (not focus groups) as the information being collected is of a personal nature, wherein trust was essential to develop and depth of information was also critical for the analysis.

This chapter has been divided into four sections. The first section provides details on the field site used in this study. The second section explains the approach and sampling strategy and the third section explains the methodology used for the analysis. The fourth section discusses ethical considerations made in the research study and finally the section concludes with a brief summary.

\section{Field Site}

The fieldwork for this study was completed in the capital of Ethiopia, Addis Ababa. Figure 3 shows a map of Ethiopia with the capital of Addis Ababa located roughly in the centre of the country. 


\section{Figure 3: Map of Ethiopia}

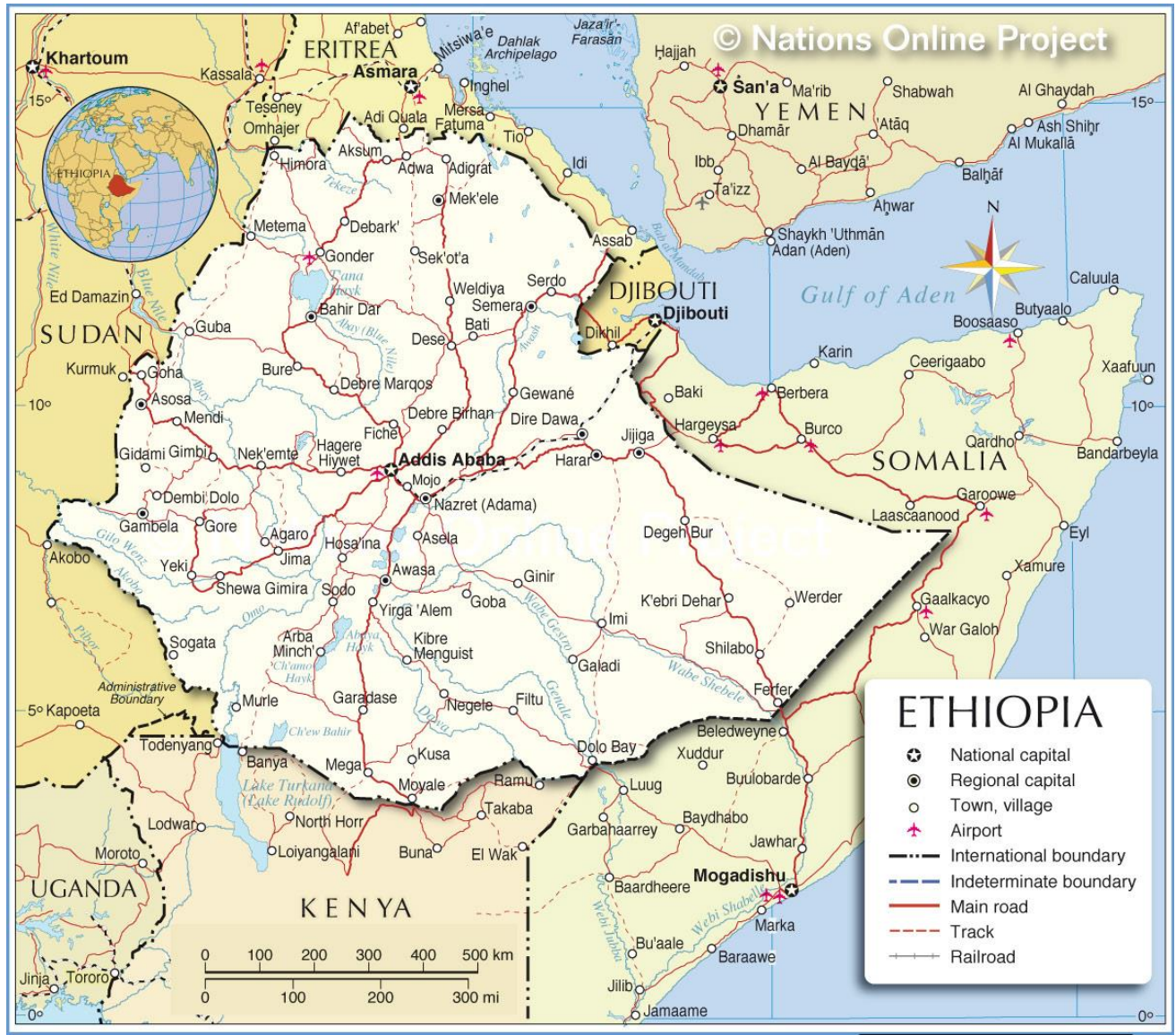

Source: http://www.nationsonline.org/oneworld/map/ethiopia-political-map.htm

According to the 2007 Ethiopian Census the population of Addis Ababa was 2.7 million (CSA, 2008), however it is estimated that the population is growing each year. It is important to note that Addis Ababa presents many differences from the rest of the country. Addis Ababa is more modern than the rest of the country and is the largest urban area whereas the majority of Ethiopia's population lives in rural areas (83\%) (UNDP, 2012).

It would have been ideal to expand the fieldwork to rural areas of Ethiopia; however, I decided that this was not feasible. In rural communities there are large difference between ethnic groups, highland and lowland areas, and proximity to urban areas. Therefore, in order to be inclusive of the multiple differences in rural areas, several different rural communities would need to be included. I decided this was not feasible within my resources and focused on returnees to Addis Ababa. 
The fieldwork in Addis Ababa was completed in two primary trips, and complemented by interviews and site visits on two secondary trips. The majority of the fieldwork took place between February-May 2011, followed by a second followup visit in November 2011. Prior to this, two previous visits were made to Addis Ababa in April 2010 and November 2010 wherein preliminary scoping work was conducted for the IS Academy survey that led to useful contextual information and contacts for the primary fieldwork.

During the primary fieldwork in Addis Ababa, the research partner for the IS Academy survey was the Ethiopian Development Research Institute (EDRI). I was provided an office at EDRI that could be used for conducting interviews. In addition, the office provided an opportunity to gain connections for further interviews.

Interviews were conducted in several different locations in Addis Ababa. Participants were given the choice to choose the location based on their level of comfort. Interviews were thus conducted in local cafes, at the participant's office, at the researcher's office, or in the interviewee's home. Not all locations were ideal due to noise and sometimes lack of privacy; however, the office environment was often not comfortable for interview participants. All efforts were made by the interviewer to ensure the comfort of the participant at the interview locations.

\section{Approach and Sampling Strategy}

Return migrants can be viewed as a hard to reach population. 'Hard to reach populations' can be described as populations that are difficult to locate and have an unusual or stigmatized condition (Atkinson and Flint, 2001). Although not necessarily stigmatized, return migrants do represent a specific segment of the population that can be difficult to locate as they may be spread out in different clusters within the overall population. Furthermore, in Ethiopia there is no list of return migrants or one central organisation assisting returnees. For these reasons, the only viable method for sampling was snowball sampling. In snowball sampling a gatekeeper introduces the researcher to participants and essentially uses referrals from one participant to find new participants. Multiple entry points were used to find participants and these varied slightly by the type of returnee to be sampled. For the domestics, the consortium of $\mathrm{NGOs}^{1}$ working with returnees and IOM were initially very helpful in referring participants. In the professional category, the Ethiopian Investment Agency (EIA) shared the phone number of diaspora investors, which included some female returnees. The majority of participants, however, were found through the researcher's network connections. This included colleagues at EDRI (who were able to refer all categories of returnees), colleagues through other

\footnotetext{
${ }^{1}$ The consortium includes Agar, Ethiopian Orthodox Church, Association for Forced Migrants, and Stichting Dir. Each of their roles with regards to return migrants in discussed in the next chapter.
} 
organisations in Addis Ababa, staff and other guests at the researchers guesthouse, and other expats working in the city. In addition, the researcher went to areas where high numbers of returnees apparently congregated, such as international churches and cafes and worked to make connections with returnees. Finally, in finding domestics, assistant researchers were sent to neighborhoods known to have high numbers of returnees and spoke to people in the local community to find returnees from the Middle East. Through the above methods, a total of twelve different entry points were obtained for finding the returnees.

One of the key benefits of the snowball sampling approach is being able to obtain participants where "some degree of trust is required to initiate contact" (Atkinson and Flint, 2001: 3). This was the case in the research that many participants were only willing to participate due to the individual that referred them, especially with the professionals. In general, the professionals represent an urban elite class where it is more difficult to gain interview access. One participant invited the researcher to attend meetings of their professional organisation, which proved to be essential to gaining trust and further contacts within the professional group. Domestics were also often cautious about participating, but when referred from a friend that had participated and were assured regarding the process, they were more willing. In some cases, due to hesitancy, domestics also brought a friend with them to the interview for moral support.

An important drawback to the snowball sampling approach is that the "researcher relinquishes a considerable amount of control over the sampling phase to the informants" (Noy, 2008: 332). I worked to be very clear with the participants regarding who did and who did not qualify for participation. This did lead to some confusion and in one instance I was referred to a second-generation returnee that did not fit the sampling criteria. In addition, at times it was difficult to encourage the participants to refer more participants.

A final note regarding snowball sampling is that those who are willing to share informants with the researcher are members in social networks (Noy, 2008). This is important to note for the analysis, wherein social networks are one of the elements of the reintegration strategy. Not all participants referred further participants for interviews, which could also be an indicator of their social networks, but was not included in the analysis as referrals were voluntary. However, being able to make referrals indicates that the respondent is involved in a social network inclusive of other returnees.

\section{Interviewee Characteristics}

The defining characteristic that separated the interviewees was intended to be the country/ region of migration. In the initial research design, I planned to interview 30 returnees from the north, 30 from the Middle East, and 30 from Africa. Early into the interview process it became evident that female return migration from African 
countries to Addis Ababa was limited and the interviews would not be obtainable. This was also evidenced in the IS Academy survey data, wherein only 21.4 per cent of return migrants from African countries were female. Of these female returnees from Africa, only 18 per cent returned to Addis Ababa, totaling 3.9 per cent of the total returnee sample in the survey. Due to this challenge, I decided to distinguish between professional returnees from the North and student returnees from the North. I aimed to have a representative sample of each type of interviewee group in the final sample. The result was a total of 43 returnees from the Middle East, 17 student returnees, and 21 professional returnees. Although not equitable, there is enough representation in each group for analytical categories.

\section{Research Techniques}

The research techniques employed in the study included semi-structured interviews, key stakeholder interviews, field notes, reviewing local media sources, and supplementary quantitative sources.

\section{Semi-structured Return Migrant Interviews}

Semi-structured interviews allow for a mix of standardization and comparability, as well as allowing the participant freedom to speak from their own frame of reference (May, 2004). The interview guide used in the research evolved through the interview process and the most recent version is included in Appendix 1. The interview guide focuses on six specific themes: 1) life before migration, 2) the decision to migrate, 3) life in the country of migration, 4) the decision to return, 5) the return experience, and 6) the reintegration experience.

All interviews began with an explanation as to the purposes of the research, an overview of what the interview would entail and gaining informed consent to participate. Informed consent was gathered verbally. Permission was also sought to record the interview using a voice recorder. All except for one interview was recorded.

Forty of the interviews were conducted in English and the remaining interviews were conducted with the assistance of a translator or by a research assistant. Three research assistants were hired and trained to conduct interviews in Amharic with returnees from the Middle East. The research assistants conducted 30 interviews, and 14 interviews were conducted with the researcher through translation. All research assistants and the translator were female and spoke both English and Amharic. The majority of interviews lasted 45 minutes to one hour and overall interviews ranged from 30 minutes to two hours in duration.

\section{Key Stakeholder Interviews}

The key stakeholder interviews were less structured than the participant interviews and questions were targeted towards each stakeholder's role in regards to return 
migration. The key interview objective of the stakeholder interviews was to understand: 1 ) their current role; 2) their role in relation to return migration; 3 ) the role of the overall organisation in relation to return migration; and 4) their perspectives on return migration in Ethiopia. Key stakeholders were interviewed from the Government of Ethiopia, international organisations, local NGOs, and other local institutions dealing with return migrants, such as the Addis Ababa Airport Authority and the Mental Health Hospital.

A total of 19 interviews were conducted with key stakeholders. These interviews were not recorded as often the researcher was informally referred to the organisation and in order for participants to feel comfortable with recording they would need to receive permission from the communications department or director of the organisation. Thus, in order for interviewees to speak freely, detailed notes were taken from the interviews. Key stakeholder interviews ranged from 30-90 minutes.

\section{Field Notes}

I kept field notes during the fieldwork based on observations made before and after interviews, at events regarding migration and return migration, and from general interactions with locals regarding their views of return. These notes were not meant as formal ethnography and were made in an effort for further reflection on understanding the situations of the participants and return migration in Ethiopia. The field notes were unstructured and open-ended and allowed for regular reflection on the situation of return migration in Ethiopia.

\section{Local Media Sources}

Local media sources were reviewed in an effort to gain an understanding as to how the local media portrays return migrants. This was not meant as a formal content review, but as a method to gain further insight into the local dialogue regarding return. The review was, however, limited to media sources in English, thus not being fully representative of the local dialogue. Ethiopia has two newspapers that are printed in English: the Reporter and the Addis Fortune. Both of these newspapers can be searched online. In addition, other online Ethiopian information sources were searched such as the walta information source and nazret.com. The key search terms utilizes were 'return migration; returnees; diaspora; and deportation'.

\section{Supplementary Quantitative Data Sources}

Quantitative data sources have supplemented the research. The IS Academy Survey, funded by the Dutch Ministry of Foreign Affairs, conducted in 2011 presents the only survey data on return migrants in Ethiopia. An in-depth household survey was administered with 1282 households in Ethiopia across five different regions of the country from March to May 2011. Surveys were conducted with households who 
currently had a household member living abroad; households who had a member who had lived abroad and returned; and households that had no experience with international migration. A total of 154 return migrants were surveyed. The surveys were conducted in five regions of Ethiopia: Amhara, Oromia, Southern Nations Nationalities and People's Region (SNNPR), Tigray, and Addis Ababa, which together account for 96 per cent of the population. In each region, three different Woreda's (districts) were selected for sampling, two rural and one urban, totalling 15 data collection sites.

The sampling strategy was based on a two-stage approach. First a listing was conducted at each site to identify households as a migrant, return migrant, or non-migrant household. Based on this identification, households were randomly selected for enumeration in each site, with a purposive over sampling of migrant and return migrant households. In each site, as many return migrants were sampled as possible, however, compared to migrant and non-migrant households there were low numbers of return migrant households across Ethiopia. The data is not nationally representative and cannot be generalized to be representative of all Ethiopian migration, however, aims to provide insight into the dynamics of return migration to Ethiopia.

Other quantitative data that is available on return migration to Ethiopia includes: the number of assisted voluntary returns (provided by The International Organisation for Migration); the number of vulnerable laissez- passé returnees that require assistance at the airport (from the Bole Airport Administration, Addis Ababa); and the number of diaspora investors opening a new business in Ethiopia. All of this data came from secondary sources and most of this data is utilized in the next chapter on the structural environment of return migration to Ethiopia.

\section{Analysis}

The analysis was conducted over two stages. The first stage was the initial coding phase, wherein the approach of an issue-focused analysis was conducted. The second stage is based on a deductive analysis completed to assess the reintegration strategies. Each of these is discussed in further details below.

\section{Issue Focused Analysis}

The analysis followed what Weiss calls an 'issue-focused analysis', meaning that the aim of the analysis was to learn from all respondents about specific issues, events, or processes (1995). The issues of interest in this study include return migration, reintegration, and social change. Following from the theoretical framework in Chapter 2, each chapter following this chapter addresses a particular aspect of the framework for the case analysis. 
Weiss furthers that in issue-focused analysis there are four stages: coding, sorting, local integration, and inclusive integration (1995). Coding was done using the qualitative software Nvivo. All transcribed participant interviews were coded using a mix of pre-defined nodes based on the framework, and free nodes that emerged as the coding progressed. Once the participant files are coded (referred as nodes in Nvivo), they need to be organized, which is what Weiss terms the sorting phase (1995). This essentially referred to grouping together the nodes relevant to each chapter and section for analysis. Local integration then refers to bringing in the other sources of data collection including notes and observations made the researcher. Inclusive integration then brings together all aspects of the analysis to create a coherent story. This process was not necessarily followed as strictly as described above and evolved slightly more organically, but essentially each of the steps of coding, sorting the files, integrating notes and observations with the sorted material, and bringing all aspects together to create the coherent story of each chapter was the process of analysis.

\section{Deductive Analysis of the Reintegration Strategies}

Following from the issue focused analysis, a specific analysis was conducted for assessing the reintegration strategies of each participant. A deductive analysis was conducted wherein first, each return migrant was assessed across the four dimensions (cultural orientation, social networks, self-identification, and access to rights, institutions and the labour market) and secondly, based on this analysis, each participant was placed into a reintegration strategy. This methodology allows for the identification of variations within the analytical groups, key trends and anomalies. For the most part the dimensions within the reintegration strategies corresponded to one another to result in a clearly defined reintegration strategy of the participant. However, there were a few cases where the reintegration strategy was not clear.

In the case of students, for both cultural orientation and social networks they were frequently placed in the reintegrated strategy, however for self-identification and access to rights and institutions they were placed in the traditionalist strategy. This meant that along the dimensions the students were equally split between two reintegration strategies. In this situation, students were placed in the reintegrated strategy when they stated differences in their values and behaviours from migration that were brought with them in return and maintained upon their return. This reflects a heavier weighting of cultural orientation in determining the overall reintegration strategy. In general the four categories are supposed to be seen as equally weighted; however, in determining a final strategy, cultural orientation was viewed as the most influential category for the reintegration strategy.

For the reintegration strategy of vulnerable, the dimensions had to be slightly expanded in terms of self-identification. For this group, self-identification 
was less focused on national/cultural/ethnic identity, but more on state-of-being, in that the vulnerable self-identify themselves as not being 'okay'. Therefore, based on the reintegration strategies the vulnerable have been identified as meeting at least one of the following criteria: 1) poverty to a degree that one does not have the ability to access rights and institutions; 2) experiencing some level of social exclusion; and 3) self-identify themselves as not being okay. In terms of the first criteria, it is arguable that an individual that lives in acute poverty does not have the ability to go beyond their daily needs of food and shelter. Therefore, they do not have the capacity to access rights and institutions within their culture. Secondly, social exclusion is viewed as those that have limited access to social networks (which may be selfimposed) and do not engage with society. Finally, women that self-identified that they were not 'okay' include statements regarding unbearable stress since their return, depression, or not being able to cope with their lives. These forms of situations led to returnees being categorized as vulnerable.

Finally, there is one case of a professional who did not fit within the reintegration strategies and for this reason was left out of this analysis. This individual identified most strongly with the country of migration, but was isolated upon return and therefore not engaged in returnee or local networks. She was thus seemingly vulnerable due to lack of ties, however, was not vulnerable in any other dimension. Her self-identification was fully Ethiopian, but simultaneously she reacted negatively to the culture. She therefore cut across several of the reintegration strategies and did not fit into one category. What is interesting about this case, however, is that she was most likely to re-migrate as she felt that she could not be successful in Ethiopia. It was commonly discussed with the professionals that far more women came and went back than that came and actually stayed in Ethiopia. Perhaps this is actually then a fifth category of unsuccessful reintegration, which this woman was currently in the midst of experiencing. Further research in the countries of migration with women that returned and re-migrated would be required to provide reflections on this hypothesis.

\section{Ethical Considerations}

Migration research leads to several ethical considerations, particularly research with refugees. Refugees are vulnerable as research subjects due to their political status, human rights abuses they may have been exposed to, and their current situations, particularly in refugee camps (Leaning, 2001: 1432-33). This vulnerability is one of the reasons that research with refugees is so ethically laden, as "those who have been displaced or forced to migrate have often suffered serious physical, psychological and emotional trauma" (Mackenzie, McDowell, and Pittaway, 2007: 4). The former refugees interviewed in this study are no longer vulnerable in the ways described above; however the interview questions could bring about memories of physical, 
psychological and emotional trauma from the conflict period in Ethiopia and the refugee experience. In addition, the domestics represented a group that needed increased consideration due to physical, psychological and/ or emotional trauma that may have been experienced during their recent migration to the Middle East. For these reasons, principles from refugee research were adopted for this research study.

\section{Informed Consent and Confidentiality}

Informed consent is perhaps the greatest cornerstone of research with human participants. The preamble for the study included the key components for informed consent listed by the US Government Office for Human Research Protection (OHRP, 2005). This included an introduction to the study, the participant's role, an explanation of confidentiality and voluntariness, and an understanding that the interview could be stopped at any time and participation withdrawn. Further, after the preamble, the researched confirmed comprehension from the participant and asked if they had any questions regarding the interview process. Once this was confirmed, informed consent was gathered verbally. Due to the fact that for many participants, particularly domestics, this was their first interview situation and there was already apprehension, the signing of an informed consent sheet would have been even more intimidating and created a further business environment, than a relaxed interview setting. For this reason, it was decided not to use a written informed consent form.

After informed consent was granted, than permission was also asked to record the interview with an explanation as to how the recording would be used. It is essential to ensure confidentiality when recording interviews. No names were mentioned on the transcripts; only the participant number of the individual and only the researcher had access to the file linking names and participant ids. The files were also labelled according to participant ids. Furthermore, it was stressed that only the research assistant and researcher had access to the recording and transcription. The research assistants, however, were not given the identity of the participant and were instructed to transcribe without using individuals names that may have been mentioned during the interview phase. After the research assistant had completed their work, they were instructed to permanently delete all files regarding this study.

\section{Do No Harm}

Research with refugees generally aims to 'do no harm', which includes protection aspects such as physical security, mental health and protection within the community. Do no harm also goes beyond this to debates regarding if the re-telling of the refugee story is traumatic or empowering. For the purposes of this research study, several strategies were employed to respect the principle of do no harm.

First, questions that were not necessary for the research were not asked. For instance, when asking domestic workers about their experiences of migration, many 
probing or follow-up questions could have been asked of participants who had a negative experience, such as: what kind of abuse did you experience? This information, although relevant to the overall study, was not the purpose of the study and questions specifically regarding abuse, rape, or other negative experiences were never asked to the participant as they could be unnecessarily traumatic for the participant. On the other hand, if participants chose to volunteer this information and appeared to want to discuss these forms of issues, the researcher listened and did not provide reaction, sensing that for these individuals it was a relief to be able to speak about these issues. Abuse is not a culturally appropriate topic of conversation in Ethiopia. Thus, for some of the interviewees who had experienced abuse they did not have people to discuss this with and speaking to the researcher was a unique opportunity to let out these experiences. Based on this approach, it is possible that instances of abuse and specific forms of abuse, such as rape, are underreported in this study.

Secondly, at any time during an interview when a participant became upset, the researcher offered a moment to stop the interview and take a break. The researcher told the participant that they did not have to continue the interview, and if they were upset, the interview could be concluded without any problems or concerns and that it was their decision on how to proceed. In one instance the participant wanted to continue, but needed a few moments, so I suggested that we take a break and go have a coffee and then return to the interview. This strategy worked well to allow the participant some time to relax and move beyond the difficult part of the interview. When returning to the interview, I moved to the next stage of the interview, thus not having to recount any of the parts of the interview that led to distress. In all interviews, respect for the participant and their mental health was a vital concern of the researcher, who worked to ensure the comfort of the participant throughout the interview process.

\section{Reciprocity and Compensation}

Mackenzie, McDowell, and Pittaway (2007) argue that although the principles incorporated under 'do no harm' are critically important, they are not enough and "that researchers need to move beyond harm minimization as a standard for ethical research and recognize an obligation to design and conduct research projects that aim to bring about reciprocal benefits for refugee participants and/ or communities" (12-13). A good example of this approach (although not termed reciprocity) would be Verdirame and Harrell-Bond's research in Kenya and Uganda wherein they worked to assist interviewees whenever possible by offering free legal advice at their legal aid clinic, or providing information to interviewees (2005). This view of reciprocity has informed this research, wherein the researcher tried to the best of her ability to assist interviewees when asked. This included providing information on organisations providing assistance to returnees, training programmes for returnees, 
connecting job-seekers with networking opportunities and people in the researcher's network who might be able to assist them, and providing other information requested to the interviewees. I was not always able to gather the information requested by the interviewee, but ensured to follow-up with the participant to let them know the situation.

In the case of domestics, it was decided to offer compensation at the end of the interview. This was done for several reasons. First, the majority of surveys in Ethiopia ${ }^{2}$ now offer compensation to participants in recognition of the time that participation takes away from their jobs and ability to make livelihoods. Secondly, it is recognized that transport for participants to interview sites is often expensive for participants. Third, the offer of small compensation is perceived as a culturally appropriate thank you for participation. In this study, as the majority of domestics travelled for the interview, it was decided to offer a small compensation in recognition of the cost of participants to the interviewee. The amount given was 50 birr (roughly US \$2.50). It was offered at the end of the interview as a thank you and was never mentioned to the interviewee before this stage to ensure it was not acting as an incentive for participation. In a few cases, participants refused the compensation, but in most cases, it appeared to be genuinely appreciated.

\section{Translation and the use of Local Researchers}

Ethical and methodological issues can both arise when working through translation and with local researchers. It was integral to have translation for interviews with domestics as very few spoke English. The selection of the translator (who also acted as the research assistant) was done through referrals and interviews. The individual selected was chosen based on experience working with vulnerable groups and to have a non-threatening demeanour to the participants, as well as education and language ability. For interviews with domestics, being able to translate was not only important, but also being respectful and prepared for the potential challenges in the interview setting was critical. Furthermore, it was ensured that the participant selected had a fair distance from the return migration community such that they would not be in the same social network or in a position to use any of the information shared in the interviews against the participant, as is a concern in refugee research (Jacobsen and Landau, 2003).

Translation occurred slightly differently during the interview and the transcription process. During the interview, if the participant spoke in monologue, the translator could summarize the key points for the researcher, however for the transcription the translator transcribed the exact words of the participant during the

2 This includes the IS Academy Survey, The Young Lives Project, The Ethiopian Urban Household Survey (2009 round), and the Ethiopian Rural Household Survey (2004 round), amoung others. 
interview. At times, translation challenges arose as "the same words can mean different things in different cultures and the words we choose matter" (Temple and Edwards, 2002:3). One example of this was the use of the phrase "to transform myself". The domestics commonly gave this as the reason for migration and in Amharic is translated as a local saying; however, in English the literal translation "to transform myself" is slightly confusing. With discussion, it was agreed that the Amharic phase translates better in English as "to make something of myself". The researcher and translator discussed this phrase several times in order to deconstruct the different ways it could be interpreted and the intended cultural meaning of the Amharic phrase into English. At any time that the translator felt confused regarding a word the researcher and translator discussed it after the interview.

It is recognized that back-translation provides the most effective methodology for accurate translation. As there were over 40 interviews for translation, it was not feasible within the budget of this study to have all interviews back-translated. In any instances wherein clarity was required, the researcher was able to contact colleagues in Ethiopia to discuss the transcript and original recording to ensure proper interpretation of the participant.

\section{The Dual Imperative}

Jacobsen and Landau (2003) discuss a critical issue of importance and relevance to this study, which they term the 'dual imperative in refugee research'. This refers to the challenge of satisfying "the demands of academic peers and to ensure that the knowledge and understanding work generates are used to protect refugees and influence institutions like governments and the UN" (Jacobsen and Landau, 2003: 186). The dual imperative occurs within the context that research with refugees can be traumatic for refugees and should not only be undertaken for academic gain. Simultaneously, it does not go to the other extreme that the researcher should be an activist for refugees, but seeks to maintain a middle ground where the knowledge generated by researched is used for additional gains than academia.

The primary purpose of this research is for the PhD dissertation; however, the issue of the dual imperative was discussed with several interview participants and key stakeholders in the field. The information collected in this study can be used to provide further policy relevant information on the situation of Ethiopian domestic workers in the Middle East and their challenges in return and reintegration, as well as the challenges of professionals in returning and reintegrating in Ethiopia. This information can be viewed as valuable to share with international organisations, international governments and the Government of Ethiopia. For this reason, in addition to this dissertation, the research from this study will address these policy relevant issues in a separate venue of policy briefs for the IS Academy Project that will be widely distributed through all contacts established by the researcher in 
Ethiopia. The purpose of this manuscript is to focus on the academic relevance of this study.

\section{Summary}

This chapter has sought to outline the methodology utilized in this study and to present some of the methodological and ethical challenges encountered in the research. Care was taken at all points of the research process to protect the rights and interests of the participants. The study has aimed to utilize a mixed-methods approach that encompasses all existing data on return migration to Ethiopia and generates new knowledge regarding return migration to Ethiopia. 


\section{Chapter 4: The Structural Environment of Return in Ethiopia}

\section{Introduction}

As discussed in the first chapter, the structural environment of return plays a vital role in the ability of return migrants to reintegrate into their country of origin. Reintegration is a two way process that is highly influenced by the country of return. If the country of return is open and welcoming towards returnees, this will most likely make the reintegration process faster and easier for the returnee. For example, in the Philippines the government has established several programmes to support returnees, there is a positive perception of international migrants and the return flows are moderate (IOM, 2013). Return migrants still face challenges in their reintegration in the Philippines; however they receive much higher levels of support than in other countries. This is quite different than a case such as Bosnia, wherein returnees were viewed as deserters of the country and experienced clashes with locals and local government upon return (Stefansson, 2004). Presumably return migrants reintegration experiences are very different in these two contexts.

The four key elements utilized in this study to examine the structural environment of return are: 1) the governments' policies and approach towards returnees, 2) locals attitudes and perceptions towards returnees, 3) the private sectors attitudes and approach towards returnees and 4) the flows of return migration to the country. Combined, these factors determine if the structural environment is favourable or adverse to return migrants reintegration in their country of origin.

This chapter will provide an analysis of the structural conditions of the return environment in Ethiopia. The chapter will first provide a brief history of return migration to Ethiopia. The next section will examine the current forms and flows of return migration to Ethiopia. Third, the chapter will discuss the role of government policies and different institutions involved in return migration to Ethiopia. The fourth section will explore local attitudes and perceptions towards returnees. The final section will provide an assessment of the structural conditions of the return environment for each return group of interest in this study: professionals, students and domestics.

\section{A Brief History of Return Migration to Ethiopia}

Return migration to Ethiopia can be characterized in four phases. The first phase would include all return that occurred prior to 1991. Prior to 1974 the majority of returnees were the elite that went abroad for education (Tasse, 2007). From 19741991, there was little return migration to Ethiopia as people primarily fled the country. Few people were issued exit visas during this time to study abroad and many used this as an opportunity to claim asylum in a third country, however it is 
arguable that some people also returned during this time. The largest return flows to Ethiopia were thus in the post 1991 decade wherein after the end of the conflict in Ethiopia, migrants began to return to Ethiopia. In the 1990s, the primary return flows were repatriating refugees from neighbouring countries. By the end of the 1990s the period of refugee repatriation to Ethiopia was more or less complete. Return flows thinned out and began to change form as the majority of near refugees had returned. This leads to the third phase of return, which began around 2000 and saw the return of diaspora members who had received refugee status in the North. These numbers were much smaller than the repatriating refugee figures from the 1990s; however, the diaspora returnees have had an impact on modernizing Addis Ababa.

The final phase of return, is the current phase, which can be seen as beginning within the past 3-5 years, thus from 2008 onwards. This phase continues to see diaspora return, but is also comprised of increasing flows of returnees from the Middle East, and from other parts of Africa. This final phase of return migration is the most diverse, comprised of different flows as migration and return from Ethiopia has increased in recent years.

\section{Note on Return Terminology in Ethiopia}

In Ethiopia it is important to note that the term 'diaspora' is used to describe all individuals with a foreign citizenship- including individuals born in Ethiopia who have acquired citizenship abroad and have returned and settled in Ethiopia. Thus, an individual that would be considered a return migrant within this study is called 'diaspora' in common rhetoric in Ethiopia. This leads to some confusion, as diaspora returnees are not distinguished from diaspora non-returnees within the use of the term 'diaspora'. For the purposes of this study, the term 'diaspora returnee' will be utilized to refer to those individuals referred to by the Ethiopian Government as diaspora, but who have returned and settled in Ethiopia.

\section{Flows and Forms of Current Return Migration to Ethiopia}

There are no official figures on return migration to Ethiopia. The government of Ethiopia does not keep records on the number of citizens returning to the country at immigration. This section will provide information on available figures of return migration from three different sources. The first is a brief overview of the return migrants in the IS Academy survey. This information is useful in understanding the types of current return migrants to Ethiopia, keeping in mind that the survey is not nationally representative. The second is the number of investors recorded as diaspora by the Ethiopian Investment Agency, which provides an indication of the number of diaspora entrepreneurs in Ethiopia. The third source is information on returnees that are assisted by the Addis Ababa Airport Authority. This information specifically refers to returnees from the Middle East that require assistance. 


\section{IS Academy Return Migration Survey}

As discussed in the Methodology Chapter, the IS Academy Survey included information on 152 returnees in Ethiopia. The survey was not nationally representative, thus the information provided here is not reflective of the country as a whole, however it still provides insights into return migration in Ethiopia.

Table 5 shows the number of return migrants per region in Ethiopia, based on the geographical regions of the country of migration. The largest numbers of returnees were from the Middle East (62.18\%), followed by Africa (28.85\%), with less than ten percent of all returnees coming from the North $(6.41 \%)$. This highlights that the majority of return migration to Ethiopia is not from the North, but from SouthSouth migration streams. This is consistent with the data in the survey on current migration, wherein the largest current flows are migrants to the Middle East, followed by migrants to Africa (Kuschminder, Andersson, and Siegel, 2012). The majority of returnees from the North returned to Addis Ababa (60.0\%) and the majority of returnees from Africa returned to Amhara region (42.22\%). In Amhara region, one of the survey sites was the town of Metemba, which is a border city with Sudan. The high number of returnees in the Amhara region represents primarily return and circular migration to and from Sudan. Return migrants from the Middle East most commonly returned to Oromia (38.14\%), followed by Tigray $(26.80 \%)$, and Addis Ababa (20.62\%). This illustrates that migration and return from the Middle East is occurring in different regions of the country.

Table 5: Return Migrants per Region in Ethiopia

\begin{tabular}{|l|c|c|c|c|c|c|c|c|}
\hline \multicolumn{4}{|c|}{ Middle East } & \multicolumn{3}{c|}{ North } & \multicolumn{4}{c|}{ Total } \\
\hline & $\mathrm{n}$ & $\%$ & $\mathrm{n}$ & $\%$ & $\mathrm{n}$ & $\%$ & $\mathrm{n}$ & $\%$ \\
\hline $\begin{array}{l}\text { Addis } \\
\text { Ababa }\end{array}$ & 20 & 20.62 & 8 & 17.78 & 6 & 60.00 & 36 & 23.08 \\
\hline Amhara & 3 & 3.09 & 19 & 42.22 & 4 & 40.00 & 26 & 16.67 \\
\hline Oromia & 37 & 38.14 & 14 & 31.11 & 0 & - & 51 & 32.69 \\
\hline SNNP & 11 & 11.34 & 1 & 2.22 & 0 & - & 14 & 8.97 \\
\hline Tigray & 26 & 26.80 & 3 & 6.67 & 0 & - & 29 & 18.59 \\
\hline Total & 97 & 100.00 & 45 & 100.00 & 10 & 100.00 & 156 & 100 \\
\hline
\end{tabular}

Source: Authors own calculations.

Overall, there was a fairly equitable distribution of male and female return migrants at 55.33 per cent male returnees. However, in looking at return from the specific regions, there was a lower percentage of female return migrants from African countries $(21.43 \%)$ and a slightly higher percentage of female return migrants from 
the Middle East (53.61\%), whereas female return migration from the North was equitable $(50 \%)$.

In terms of returning to urban versus rural areas, there was also a fairly equitable split within the return migrants where 54 per cent returned to urban areas. In general, it is expected that return migrants return to urban areas, so the high number of returnees to rural areas is fairly unique. Furthermore, it is primarily males that return to rural areas at 64 per cent, whereas females return to urban areas. The explanation for this is not known, but could be in part that females returning from the Middle East generally arrive first in Addis Ababa and may choose to remain in the city. For those in need there are some services in Addis Ababa that they can access, which are not available in other parts of the country. Males on the other hand migrating to different parts of Africa may choose to return to their family and rural area in an effort to provide their families with support. On average, return migrants spent 4.2 years in the country of migration.

The primary reason for leaving Ethiopia for the majority of returnees was to find employment opportunities (75.3\%). Reasons for return were more varied and are represented in Figure 4. It is noteworthy the change in reasons for return from the post-conflict period in the 1990s and up to 2005 where people frequently cited the changing political situation as the main reason for return, however post-2005 this is no longer the case. The country of return also changes over time as from 1990-1999, 61 per cent returned from African countries, suggesting that they were repatriating refugees, whereas from 2006-2011 78 per cent returned from the Middle East. Overall, the most frequently cited reason for return was a desire to be closer to friends and family (18.6\%), followed by being repatriated/deported (16.6\%).

Post-2005 there is a large increase in the number of returnees that report being repatriated/deported within the last five years. Seventy-five percent of the respondents citing deportation were returning from Saudi Arabia. This most likely reflects both an increase in migration to Saudi Arabia and an increasing migration management political strategy in Saudi Arabia. According to the Guardian from November- 8 December 2013, over 115,000 Ethiopians were deported from Saudi Arabia to Ethiopia in the Kingdoms of Saudi Arabia's crackdown on illegal migration (Jobson, 2013). 


\section{Figure 4: Year of Return and Reason for Return}

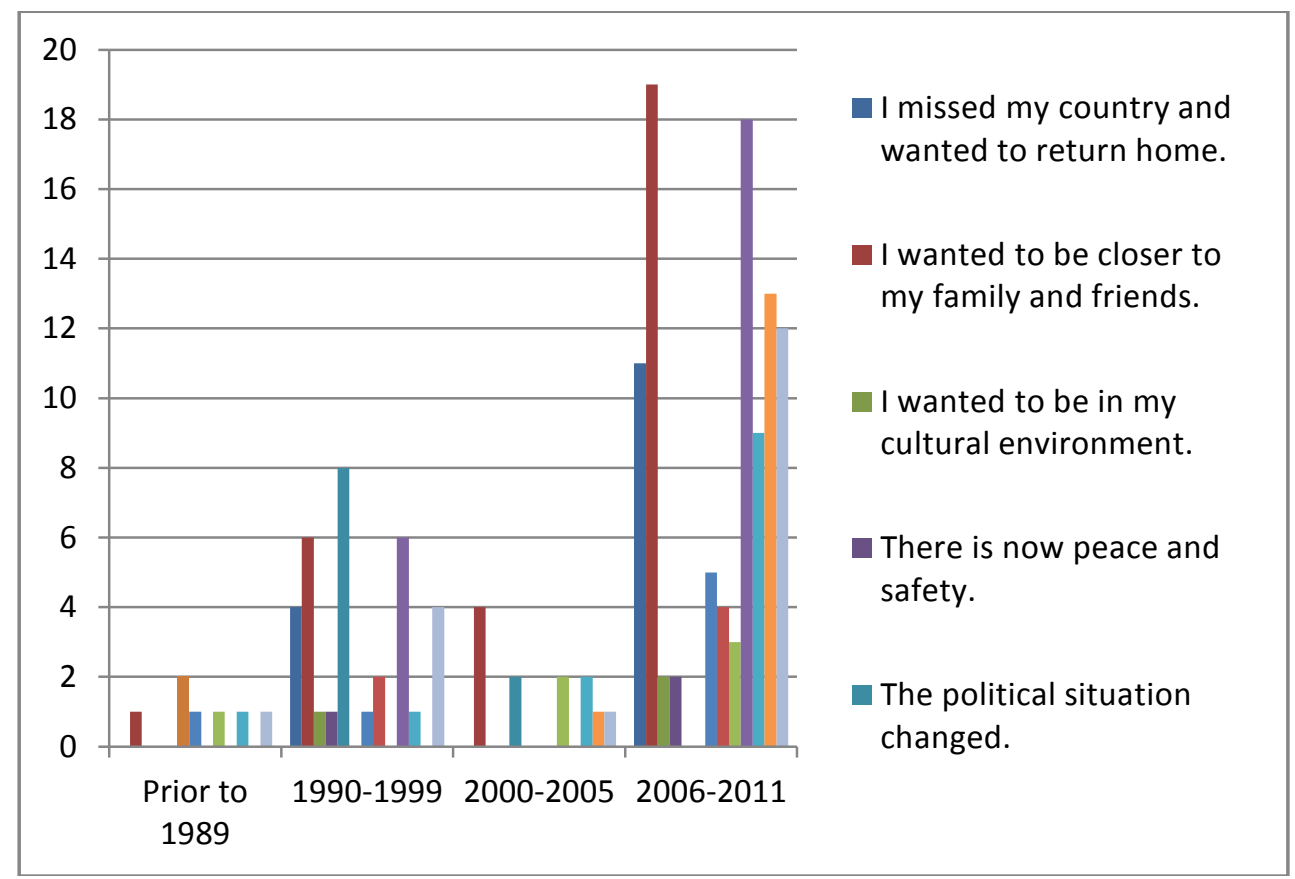

In the IS Academy survey, the majority of returnee's repatriated/deported were male $(88.0 \%)$ and according to the Guardian 63 per cent of current deportees from Saudi Arabia are male (Jobson, 2013). This suggests an interesting gender dichotomy in repatriations/deportations. This is most likely due to the fact that most Ethiopian female migrants to Saudi Arabia are live-in domestic workers, meaning that if they are irregal they are largely invisible to the wider society. Men, on the other hand, are more visible as irregal migrants as they do not live in their employers houses.

In the IS Academy survey, at the time of interview, the majority of returnees expressed that they now feel very much a part of a community in Ethiopia (87.50\%). The majority of respondents that expressed that they either do not feel a part of a community or feel somewhat apart of a community in Ethiopia were returnees from the Middle East (75.0\%).

The IS Academy survey results provide an overview of the different forms of return migration currently occurring to Ethiopia. This data portrays the following key themes: 1) the increasing volume of migration and return, 2) the feminization of migration and return migration to the Middle East, 3) the prevalence of deportations from the Middle East and 4) that return migrants from the Middle East may face more challenges in their return than return migrants from other countries. 
It is also important to highlight the low number of returnees from the North in the dataset, particularly as one third of the sample in this study is returnees from the North and there is a perception in Addis Ababa of large numbers of returnees to Addis Ababa. A possible reason for this is that returnees from the North are from a higher socio-economic status and primarily live in specific neighbourhoods in Addis Ababa, such as the upper class Bole neighbourhood. Surveys were completed in Bole, however, it was very difficult to get respondents, particularly from well-off households as guards would generally not allow surveyors access to the household members. It must therefore be assumed that returnees from the North are underrepresented in this survey.

\section{Number of Diaspora Investors (Ethiopian Investment Agency)}

One source that can provide insight into the scale of returnees from the North is the Ethiopian Investment Agency (EIA). The EIA is a one-stop shop for all investors in Ethiopia, including the diaspora and diaspora returnees. The EIA has maintained a list of all investors from the diaspora. Figure 5 provides an overview of the number of diaspora projects per year. The data used to generate this figure does not distinguish between Ethiopian diaspora investors living abroad and Ethiopian diaspora investors who live in Ethiopia. It is evident from Figure 5 that the number of diaspora investors steadily increased each year from 1994-2006, as the number of total projects increased. Since the peak in 2006, the number of diaspora investment projects has slightly decreased. It is hypothesized that this is because the government implemented new policies in 2005 to encourage the diaspora to invest in Ethiopia. Therefore, there is a large increase in 2006 immediately after the implementation of the new policies that tapers off with time.

\section{Figure 5: Number of Diaspora Investment Projects per Year}

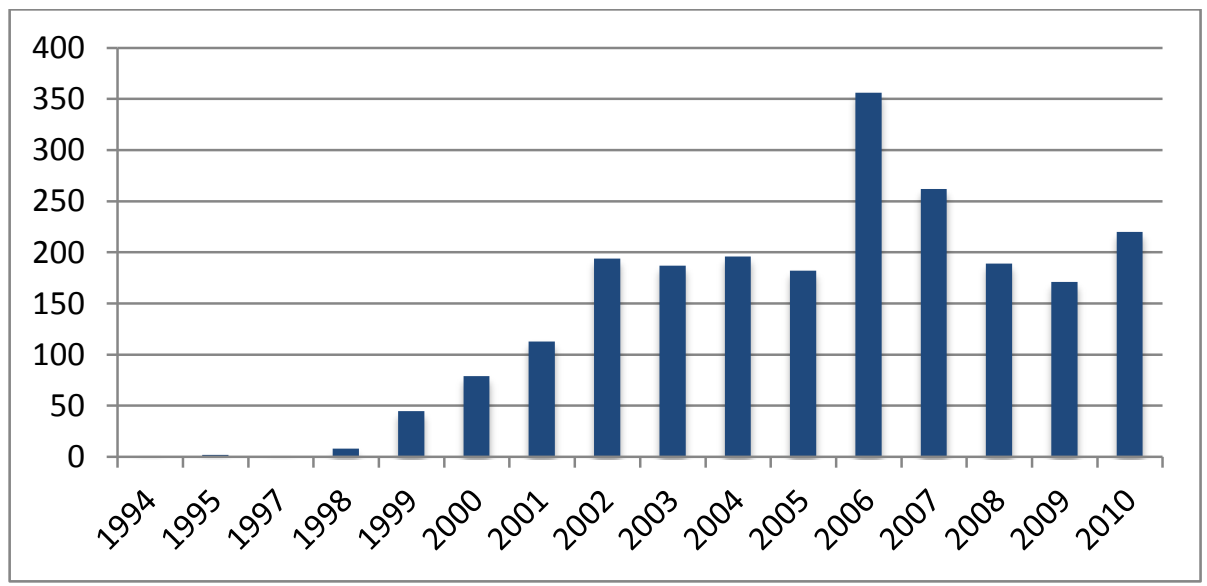

Source: EIA, 2011 
The majority of Diaspora investors in Ethiopia are male; however, exact figures on the percentage of female investors are not currently available.

\section{Addis Ababa Airport Administration}

The Addis Ababa Bole Airport Administration becomes involved with returnees when they are deported from the Middle East and are incapacitated to leave the airport on their own. Although the majority of returnees are able to walk and move, they suffer from mental challenges and may not know their name, where they were born, where their family can be found, or in extreme cases be able to speak to at all. The Airport Authority works to try to find information on their history and family, so that they can contact a family member to let them know the individual has returned. In general, the role of the Addis Ababa Airport Administration is facilitation and to solve any problems at the airport as a facilitator. However, the airport has seen increasing challenges with return migrants and is the only body willing and able to provide assistance. Without the assistance of the Airport Administration, these people would be placed on the street.

Generally, returnees who are assisted by the Airport authority have found themselves in jail in the Middle East and have been issued a laissez-Passer document from the Ethiopian embassy in the country of migration. This document has very little information on it, but is necessary for entering the country. The returnees are placed on an Ethiopian Airlines flight and brought to immigration. In some cases, returnees are drugged for the air-flight with a sleeping pill. When they arrive at the airport some have to be carried from the plane and will not regain consciousness until a few hours after arrival. They are left to wait on a few benches in the immigration waiting area of the airport.

According to the Airport Authority, the majority of people returning that require their assistance are female. In 2009, the Airport Authority began keeping records and in 2009, 83 returnees were assisted from the Middle East and in 2010, 108 returnees were assisted from the Middle East. The final resolutions for the returnees were one of the following options: returned to family; went to hospital; sent to Agar shelter (described in next section); or in some cases the staff will pool together money to assist the returnee. At this time statistics are not available on the breakdown of the situations of the returnees who are assisted by the Airport Authority.

Those assisted by the Airport Authority are extreme cases of vulnerable returnees from the Middle East. There are daily flights arriving at Addis Adaba Airport from the Middle East that are often filled with returnees. Generally, returnees are fine to leave the airport on their own. It is in rare cases that the Airport Authority becomes involved, however, for the Airport Authority the cases are difficult to deal with and is increasing in number. 


\section{Institutions Involved in Return Migration}

This section will discuss all relevant institutions dealing with return migration to Ethiopia. Institutions for return migration in Ethiopia include: Government Institutions, International Organisations, and non-governmental organisations (NGOs). Each of these categories will be discussed below.

\section{Government Institutions}

There is no specific government authority that is charged with providing services to returnees. The Administration for Refugee and Returnee Affairs (ARRA) was initially conceived as an organisation to assist returning refugees in the 1990s. However, as return migration flows to Ethiopia have changed, the organisation has moved to focus primarily on providing support to refugees in Ethiopia.

In 2012, ARRA became involved in AVRs through the signing of a Return agreement with Norway. In this bi-lateral agreement the role of Ethiopia is to administer travel agreements and to provide reintegration support through ARRA (Eide, 2013). Ethiopia does not have re-admission agreements with many other countries, and the bi-lateral agreement with Norway is not standard. It is unusual for a receiving country government to administer reintegration assistance to rejected asylum seekers, and the ethics of this have been questioned by academics and civil society. In the agreement, ARRA receives roughly US\$ 4, 760 per returnee, in addition to Norway paying for all the costs of return (Eide, 2013). At the time of writing, the agreement had only been in place for 18 months. Eide (2013) found that some Ethiopians in Norway had opted for AVR, however, ARRA was not yet prepared to offer the intended reintegration services of job seeking support and training. Therefore, AVRs were provided a cash-grant from the IOM.

The Ministry of Foreign Affairs Diaspora Directorate (MFA) is the largest institution in Ethiopia providing services to diaspora. This includes diaspora returnees. The MFA provides facilitation to diaspora returnees seeking to invest in Ethiopia. This is done by the MFA providing a letter of support to the diaspora returnee that is necessary for starting a business with the Ethiopian Investment Agency (EIA). The EIA does not actively provide services to returnees, but is a onestop shop for all investment in Ethiopia, meaning that diaspora returnee business owners are commonly in contact with the EIA.

Within the Ministry of Justice there is a team working on violence against women and children, which encompasses human trafficking. This team works to provide education and prevention on trafficking, and in 2011 began to provide support for returnee victims of trafficking. At the time of interview in April 2011, a vacancy announcement had just been circulated to hire two social workers to provide support to trafficking victims for rehabilitation in two sub-cities in Addis 
Ababa. The plan was to provide specific training to the social workers so that they would be equipped to handle the complex issues facing returnees.

There are several other government institutions working on issues of migration, diaspora, and human trafficking ${ }^{3}$ in Ethiopia and specific technical working groups to address these issues, however, none of these organisations have specific components for returnees. There is a growing momentum and recognition in Ethiopia that returnees from the Middle East are vulnerable and require support, which is prompting responses from the government, such as the hiring of social workers. However, a comprehensive strategy for return migration is not in place at this time.

\section{International Organisations}

The International Organisation for Migration (IOM) is the primary international organisation providing services to return migrants. IOM manages AVR, as discussed above and IOM manages temporary return programmes to Ethiopia of the highly skilled diaspora including Migration for Development in Ethiopia (MidEth) and Temporary Return of Qualified Nationals Programme (TRQN). In addition, IOM leads the Inter-governmental Authority on Development - Regional Consultative Process on Migration, for which Ethiopia is a member state, along with Djibouti, Kenya, Somalia, Sudan, and Uganda. This group works together to improve cooperation on migration, which includes return migration, however return is not the key priority.

It is important to note that the United Nations Office on Drugs and Crime (UNODC), United Nations Women (UN Women), and the International Labour Organization (ILO) have all become involved at a policy and promotion level to advocate on issues of human trafficking in Ethiopia. This includes the provision of support to primarily women returning from the Middle East. UN Women, although not a funding agency, provided a special grant to Agar (detailed below) of USD 23,000 in 2011 for them to continue their services for an additional year providing support to female returnees, while looking for a long-term funder. The UN agencies, however, are not generally involved in providing practical assistance to return migrants.

\section{Non-Governmental Organisations}

Several non-governmental organisations are working in Ethiopia to assist return migrants. These include: Agar, Ethiopian Orthodox Church (EOC), Association for Forced Migration and Stichting Dir Foundation. These four organisations work together in a consortium to provide assistance to female returnees from the Middle

\footnotetext{
${ }^{3}$ This includes government institutions such as the Ministry of Labour and Social Affairs, The Federal Policy, and the Ministry of Interior Diaspora Unit.
} 
East. Agar provides a shelter for the most vulnerable women wherein they can have a safe place to stay with food, clothing, and services provided. As of April 2011, Agar had provided support to 119 women. The majority of these women were not from Addis Ababa and had migrated illegally to the Middle East. Often, women are referred to Agar through the Addis Ababa Airport Authority. As the women recover, Agar assists them in returning to their families or finding a place to stay in Addis Ababa.

The EOC provides psychosocial support, medication, and counselling services to returnee women. They treat the women at Agar, of which approximately 85 per cent are mentally ill, and other female returnees that are identified as needing psychosocial care, which at the time of interview had included 300 women. When women return and have family in Addis Ababa, it is recommended that they stay with their family instead of at Agar, where space is limited. The EOC has a psychiatric doctor, nurse and medical attendant devoted to providing these services. In addition, the EOC assists the returnees in getting the necessary medical care they need for conditions such as tuberculosis, HIV, and treating physical injuries.

The objective of the Association for Forced Migrants was to provide skill training for reintegration to healthy, physically fit, and mentally well female returnees and to then assist them in receiving employment opportunities or providing them with capital and linking them with microfinance institutions. The Association for Forced Migrants provided training to 102 female returnees. Recruitment was conducted by providing flyers about the programme in several local communities (sub-cities of Addis Ababa). Female returnees living in the local communities could write a letter to the sub-city administration, which would register their name and provide the woman with a letter stating that she is a returnee. The woman would have to show the sub-city that they lived abroad via their passport of documents showing they lived in another country. The woman could then bring the letter to the Association for Forced Migrants and be registered for the training. The training was free of charge and the women were provided a stipend for living and transportation expenses while they were in training.

Training was offered in seven different areas and was based on the women's interest. Table 6 shows the fields and the number of participants per field. It is evident from Table 6 that catering and food preparation was the most popular field. The women joined courses that already existed in these areas. Most of the courses lasted for six months. 
Table 6: Returnees Training Areas from Association for Forced Migrants

\begin{tabular}{|l|c|}
\hline Training Area & No. of Participants \\
\hline Catering and Food Prep & 63 \\
\hline Hair Dressing & 20 \\
\hline Sewing & 4 \\
\hline Hotel Management & 1 \\
\hline Car Driving & 8 \\
\hline Videography & 5 \\
\hline IT Training & 1 \\
\hline Total & 102 \\
\hline
\end{tabular}

Due to the high number of participants in the catering and food preparation and the low demand for work in this area in Addis Ababa, the Association for Forced Migrants encouraged and assisted women to do internships at hotels and restaurants after their course completion for two months. That is, the women worked on a voluntary basis at restaurants providing assistances to waiters and food staff. At the end of the internship, 28 of the women were hired. A small number of women (less than 5) opened their own businesses after the completion of the course.

The final organisation in the consortium was Stichting Dir Foundation. Stichting Dir did not provide direct services to returnees, but undertook research on the situation of female migrants in the Middle East and their situation upon return.

It is evident that there is a need in Addis Ababa for the services provided by these organisations. Agar is regularly filled to capacity, and without their programme, people returning at the airport would not have any place to go. Furthermore, the women returning often need psychosocial care. Perhaps the new social workers being hired into the Addis Ababa sub-cities can fill this gap, but until that time the work of the EOC is the only service providing psychosocial care to women that are not in the hospital. Training appears to be a good idea in principle to assist this group of returnees; however the training has not led to high levels of employment. Without employment, many women think to re-migrate. In a city and country of high unemployment, this does raise questions as to how to best assist this population with economic reintegration. At this time there are no NGOs that seek to provide return assistance to other forms of return migrants.

\section{Government Policies on Return Migration}

This section will now turn to examine the Government of Ethiopia's policies on return migration. In June 2013, the government of Ethiopia launched its first official Diaspora Policy. Overall, the document provides a positive image of the Ethiopian diaspora and the contributions that the diaspora and returnees can make towards the 
country. This is expected, as the policies implemented since the inception of the MFA Diaspora Directorate have been to increase gains from the diaspora. Although, primarily directed at the diaspora, the policy also makes reference to returning migrants. The background in the policy states:

“However most people have agreed that citizen's contribution for their country, while they are outside of their home land, is limited compared to their contribution while living in their home country." (Ethiopian Ministry of Foreign Affairs, 2013: 4)

This suggests that the government gives preference to contributions made by individuals in Ethiopia, which should therefore include returnees. The policy makes the following specific references regarding returnees:

\section{“5.4 Encouraging foreign currency inflow and Diaspora participation:}

5.4.1. A mechanism that could build confidence on returnee Diasporas to come home with their entire capital and property would be crafted and implemented.

\subsection{Encouraging organized participation:}

6.3.1.5. Support would be given to returnees to strengthen their participation in an organized manner and to help new returnees in different sectors.

\subsection{Assisting members of the Diaspora:}

6.5.1. Providing services for returnees going back to their country to have the opportunity of bringing their personal effects in accordance with the law.

6.5.5. Mechanisms will be put in place for Diaspora returnees to help find jobs in the country."

\section{- $\quad$ Ethiopian Ministry of Foreign Affairs, 2013}

All of these policies reference future actions, as such none of the above have been implemented at this time. Reflecting on Alan Gamlen's (2006) typology of diaspora policies that includes: 1) capacity building, 2) extending rights; and 3) extracting obligations, it is evident that the intended policies towards returnees include all of 
these groups. Policy 5.4.1 is rooted in extracting obligations by assisting returnees to invest in the country. Policy 6.3.1.5 reflects capacity building by providing returnees support to establish networks. Finally, 6.5.1 and 6.5.5 extend rights to returnees in that they can bring personal effects and also receive assistance in finding jobs. This suggests a balanced approach to return wherein the government is expecting to 'give and receive', which contrasts existing policies that have primarily focused on receiving investments from the Diaspora.

There are questions regarding the practicalities of implementing such policies. Ethiopia has a high unemployment rate, and it is questionable as to if the government could provide specific job searching support to returnees. This is especially considering that low-skilled returnees are most in need of employment and the market in Ethiopia is overcrowded with low-skilled job seekers.

It must also be recognized that this policy was established in consultations with the diaspora. This reflects that the Ethiopia government is working to balance the desires of the diaspora with their policy realities. Time will tell if the proposed policies are implemented or if the document becomes a paper tiger.

\section{Existing Policies Relevant to Return}

Prior to the implementation of the diaspora policy, a number of individual policies have been implemented by the MFA over the last decade that impact returnees. As previously stated, returnees that have foreign citizenship are considered diaspora in Ethiopia. For this reason, some of the policies below have been targeted towards the diaspora, but also impact returnees as defined within this study.

\section{Citizenship and the Ethiopian Yellow Card}

Ethiopia does not allow for dual citizenship. Individuals that choose to return to Ethiopia that have acquired citizenship abroad do not have the right to Ethiopian citizenship unless they denounce their foreign citizenship. In order to make travel to Ethiopia more accessible for this group with foreign citizenship, the government instituted The Ethiopian Origin Identity Card, which is most commonly referred to as the 'Yellow Card'. The Yellow Card has been described as allowing for all the rights of citizenship, except the right to vote. The Card has two exceptions; the first is that the holder of the card does not have the right to vote or be elected into public office; and secondly, the holder of the card does not have the right to work for the National Defence, Security, Foreign Affairs, or other similar establishments on a regular basis (Kuschminder and Siegel, 2013). Rights afforded to the Yellow Card holders include: entry into Ethiopia without a visa and the ability to work in Ethiopia without a work permit. Initially the Yellow Card cost $\$ 500$ for the first five years and $\$ 200$ for a 2 year renewal, and was reduced in October 2011 to $\$ 100$ for a period of five years and $\$ 40$ for a two year renewal. 
The Yellow Card allows returnees with foreign citizenship to enter and leave Ethiopia freely, and to work in Ethiopia. The lack of allowance for dual-citizenship, however, prevents returnees with foreign citizenship from being able to vote or engage in politics in Ethiopia. This limits the political reintegration for this group of returnees.

As there are no official statistics on the number of return migrants to Ethiopia, it is not possible to know how many returnees have the Yellow Card. In 2010 the Government of Ethiopia estimated that approximately 21,000 Yellow Cards had been granted (Kuschminder and Siegel, 2013). This was below expectations and through consultations with the diaspora; the Government came to the conclusion that the fee was a large barrier for diaspora members in applying for the card, thus resulting in the fee reduction in 2011. The majority of Professional women interviewed in this study held the Yellow Card. They were very pleased with the card, reporting that it made working and living in Ethiopia much easier for them, while being able to maintain their foreign citizenship.

\section{Former Incentives for Diaspora Return - Land Policies and Duty Free Importation}

In 2003 the Council of Ministers passed the revised Regulation on the importation of goods on franco- Valuta basis Council of Ministers Regulation No. 88/2003. This Regulation permitted individuals returning to Ethiopia permanently to import their personal and household effects 100 per cent duty free. In July 2006, the provision was lifted as the government suspected that vehicles were being signed over to third parties without paying duty, which violated the law (Mekuria, 2006). The lifting was revised so that all vehicles that were stranded at ports could be brought to Ethiopia until October 2006 (Mekuria, 2006). This incentive is thus no longer in effect (Embassy of Ethiopia Washington, 2010).

Allowing the duty free importation of household effects of return migrants is a common policy in most developed states (such as: Canada and the Netherlands). It is a policy that practically makes sense, as returnees do not want to pay duty on shipping their personal goods. However, in countries with high duties on foreign goods to protect local markets, it also makes sense to take caution. India has managed this issue by allowing a maximum value on goods to be imported duty free, and specific conditions for the importation of one vehicle, and gold and silver (Welcome NRI, 2013). In 2013, according to an Emirates news site India placed a specific ban on the importation of flat screen televisions, as it was estimated that a million flat screen TVs were being important annually and harming domestic markets (Kapur, 2013).

In addition, in 2003, to encourage return migration the Government of Ethiopia granted returnees a piece of land upon their return. All land is governmentally owned in Ethiopia and people hold leases to land. Land in Addis Ababa is the most desirable and land close to the city is scarce. This policy become 
highly opposed by local Ethiopians as the majority of returnees come to Addis Ababa and were receiving scarce land. This provision was quickly lifted (Kuschminder and Siegel, 2013). This policy is not commonly practiced in other countries, as returnees (that is, non-refugee returnees) are often viewed as the privileged that can afford land upon return. Land is a controversial issue in Ethiopia and can act as a large incentive for return, however, clearly to the opposition of locals. At this time, there are no longer any specific incentives for return migrants.

\section{Businesses and Investments}

One of the first initiatives of the Ethiopian Expatriate Affairs Department at their inception in 2002 was to make investment in Ethiopia more attractive to the diaspora. In 2002, the Investment Proclamation No. 280/2002 defined a Domestic Investor to be inclusive of foreign nationals who are Ethiopian by birth. This allows the members of the diaspora to be treated as domestic investors, who have significantly different rights than foreign investors in Ethiopia. For instance, foreign investors must invest a minimum of US $\$ 100,000$ in a single project, or if a foreign investor has a domestic partner the foreign investor must invest US $\$ 60,000$ in a single project. For a domestic investor there is no minimum amount required for investing (Kuschminder and Siegel, 2013). This has a significant impact in allowing diaspora returnees to open businesses in Ethiopia.

\section{Promotion of Temporary Return of Highly Skilled}

The Government of Ethiopia has been active to encourage the skilled diaspora to participate in temporary return programmes that focus on knowledge transfer. Two key programmes have been run in Ethiopia: the first is the Migration for Development in Ethiopia (MidEth) Programme, and the second is the Temporary Return of Qualified Nationals Programme (TRQN). Both programmes are administered by IOM and work in cooperation with the Diaspora Coordinating Office of the Ministry of Interior. The Ethiopian Government and UNDP jointly fund MidEth and the Dutch Ministry of Foreign Affairs funds TRQN. Both programmes work to place skilled diaspora members from abroad in temporary assignments in Ethiopia to focus on transferring knowledge and skills. These programmes are not to encourage permanent return, but have been the only focus area of the Ethiopia government in terms of return programmes.

\section{Government's Position on Return Migration}

Although the government of Ethiopia does not have an official position on return migration, interpretations can be made regarding their behaviour towards returnees from the implemented policies. It is evident that there is a high interest from the Ethiopian government for investment from the diaspora. In March 2011, the 
Government published All Basic Information for Ethiopian Diaspora , which is a guide detailing the rules of investment, remittances, the diaspora bond and the role of the diaspora in contributing to Ethiopia (MFA, 2011). At the beginning of the guide the Prime Minister Meles Zenawi is quoted as saying "Ethiopians in the Diaspora need to further consolidate their efforts and do their part for the efficient implementation of the GTP [Growth and Transformation Plan], a plan which aims at extricating the country out of poverty." Based on this language, the contributions of the diaspora are expected in Ethiopia. This is further evidenced by the expectation that diaspora members will contribute to the building of the Great Renaissance Dam (formerly called the Millennium Dam), which will be the largest dam in Africa. The Dam is a source of great pride in Ethiopia, wherein it has been described that to be against the dam is to not be Ethiopian. Diaspora groups in different countries are being encouraged by the government to make pledges to generate funding targets for the construction of the dam (Walta Info, 2011). Some groups have been active in this regard and are working to raise the funds.

Diaspora returnees fall into this category of diaspora that has received great attention from the Ethiopian Government in recent years. There are thus high expectations of diaspora returnees from the Government, including that diaspora returnees are expected to invest in the country, generate business and contribute to the Renaissance Dam. In exchange, diaspora returnees do sometimes receive special treatment at the EIA and from the government for their initiatives, although there are no policies to support this. Other returnees do not receive any form of special treatment from the government, or any special attention. The focus of the government is on growth and investment, thus the focus has remained on diaspora and diaspora returnees.

The new policy does suggest the increasing of rights and protection of returnees and migrants abroad. As mentioned previously in this chapter, even if there is a will to provide these supports there are questions regarding capacity. The Ministry of Labour has identified in an interview with the researcher that there is a strong will from Ethiopia to provide further protection to workers in the Middle East, but that they lack the capacity to do. In regards to providing increased services to returnees, it must be questioned as to if this will be the same situation.

\section{Local Attitudes and Perceptions towards Returnees}

The perception of locals towards returnees has been assessed through the interviews, IS Academy survey data, examining local media, and observations made by the researcher while conducting the research. The IS Academy survey asked all participants for their perspectives on return migrants in a series of four questions.

\footnotetext{
${ }^{4}$ Availabe at: http://www.mfa.gov.et/Diaspora/Diaspora.htm
} 
Table 7: Perception Questions by Household Type

\begin{tabular}{|c|c|c|c|c|}
\hline & Migrant & Return & Non-Migrant & Total \\
\hline \multicolumn{5}{|c|}{ When people who have lived abroad come back they... } \\
\hline \multicolumn{5}{|l|}{ Help the country } \\
\hline Strongly disagree & $\begin{array}{c}7 \\
(1.69 \%)\end{array}$ & $\begin{array}{c}3 \\
(2.28 \%)\end{array}$ & $\begin{array}{c}19 \\
(2.73 \%)\end{array}$ & $\begin{array}{c}29 \\
(2.34 \%)\end{array}$ \\
\hline Disagree & $\begin{array}{c}29 \\
(7.00 \%)\end{array}$ & $\begin{array}{c}8 \\
(6.35 \%)\end{array}$ & $\begin{array}{c}87 \\
(12.48 \%)\end{array}$ & $\begin{array}{c}124 \\
(10.02 \%)\end{array}$ \\
\hline Neutral & $\begin{array}{c}63 \\
(15.22 \%) \\
\end{array}$ & $\begin{array}{c}22 \\
(17.46 \%) \\
\end{array}$ & $\begin{array}{c}116 \\
(16.64 \%) \\
\end{array}$ & $\begin{array}{c}201 \\
(16.25 \%) \\
\end{array}$ \\
\hline Agree & $\begin{array}{c}266 \\
(64.25 \%)\end{array}$ & $\begin{array}{c}76 \\
(60.32 \%) \\
\end{array}$ & $\begin{array}{c}421 \\
(60.40 \%)\end{array}$ & $\begin{array}{c}763 \\
(61.68 \%) \\
\end{array}$ \\
\hline Strongly agree & $\begin{array}{c}49 \\
(11.84 \%) \\
\end{array}$ & $\begin{array}{c}17 \\
(13.49 \%) \\
\end{array}$ & $\begin{array}{c}54 \\
(7.75 \%) \\
\end{array}$ & $\begin{array}{c}120 \\
(9.70 \%)\end{array}$ \\
\hline \multicolumn{5}{|l|}{ Do not fit in } \\
\hline Strongly disagree & $\begin{array}{c}66 \\
(16.71 \%)\end{array}$ & $\begin{array}{c}22 \\
(18.03 \%)\end{array}$ & $\begin{array}{c}89 \\
(13.88 \%)\end{array}$ & $\begin{array}{c}177 \\
(15.28 \%)\end{array}$ \\
\hline Disagree & $\begin{array}{c}162 \\
(41.01 \%)\end{array}$ & $\begin{array}{c}56 \\
(45.90 \%) \\
\end{array}$ & $\begin{array}{c}255 \\
(39.78 \%)\end{array}$ & $\begin{array}{c}473 \\
(40.85 \%)\end{array}$ \\
\hline Neutral & $\begin{array}{c}68 \\
(17.22 \%)\end{array}$ & $\begin{array}{c}11 \\
(9.02 \%)\end{array}$ & $\begin{array}{c}123 \\
(19.19 \%)\end{array}$ & $\begin{array}{c}202 \\
(17.44 \%)\end{array}$ \\
\hline Agree & $\begin{array}{c}81 \\
(20.51 \%) \\
\end{array}$ & $\begin{array}{c}21 \\
(17.21 \%) \\
\end{array}$ & $\begin{array}{c}144 \\
(22.46 \%) \\
\end{array}$ & $\begin{array}{c}246( \\
21.24 \%) \\
\end{array}$ \\
\hline Strongly agree & $\begin{array}{c}18 \\
(4.56 \%) \\
\end{array}$ & $\begin{array}{c}12 \\
(9.84 \%) \\
\end{array}$ & $\begin{array}{c}30 \\
(4.68 \%) \\
\end{array}$ & $\begin{array}{c}60 \\
(5.18 \%) \\
\end{array}$ \\
\hline \multicolumn{5}{|c|}{ Bring new ideas, knowledge and technology } \\
\hline Strongly disagree & $\begin{array}{c}7 \\
(1.69 \%) \\
\end{array}$ & $\begin{array}{c}2 \\
(1.59 \%) \\
\end{array}$ & $\begin{array}{c}12 \\
(1.71 \%) \\
\end{array}$ & $\begin{array}{c}21 \\
(1.69 \%) \\
\end{array}$ \\
\hline Disagree & $\begin{array}{c}30 \\
(7.26 \%)\end{array}$ & $\begin{array}{c}7 \\
(5.56 \%) \\
\end{array}$ & $\begin{array}{c}49 \\
(6.98 \%) \\
\end{array}$ & $\begin{array}{c}86 \\
(6.93 \%)\end{array}$ \\
\hline Neutral & $\begin{array}{c}63 \\
(15.25 \%)\end{array}$ & $\begin{array}{c}14 \\
(11.11 \%)\end{array}$ & $\begin{array}{c}94 \\
(13.39 \%)\end{array}$ & $\begin{array}{c}171 \\
(13.78 \%)\end{array}$ \\
\hline Agree & $\begin{array}{c}210 \\
(50.85 \%)\end{array}$ & $\begin{array}{c}65 \\
(51.59 \%) \\
\end{array}$ & $\begin{array}{c}402 \\
(57.26 \%)\end{array}$ & $\begin{array}{c}677 \\
(54.55 \%)\end{array}$ \\
\hline Strongly agree & $\begin{array}{c}103 \\
(24.94 \%)\end{array}$ & $\begin{array}{c}38 \\
(30.16 \%)\end{array}$ & $\begin{array}{c}145 \\
(20.66 \%)\end{array}$ & $\begin{array}{c}286 \\
(23.05 \%)\end{array}$ \\
\hline \multicolumn{5}{|c|}{ Receive preferential treatment } \\
\hline Strongly disagree & $\begin{array}{c}24 \\
(6.27 \%) \\
\end{array}$ & $\begin{array}{c}5 \\
(4.17 \%) \\
\end{array}$ & $\begin{array}{c}27 \\
(4.13 \%) \\
\end{array}$ & $\begin{array}{c}56 \\
(4.84 \%) \\
\end{array}$ \\
\hline Disagree & $\begin{array}{c}84 \\
(21.93 \%) \\
\end{array}$ & $\begin{array}{c}21 \\
(17.50 \%) \\
\end{array}$ & $\begin{array}{c}126 \\
(19.30 \%) \\
\end{array}$ & $\begin{array}{c}231 \\
(19.98 \%) \\
\end{array}$ \\
\hline Neutral & $\begin{array}{c}76 \\
(19.84 \%)\end{array}$ & $\begin{array}{c}22 \\
(18.33 \%)\end{array}$ & $\begin{array}{c}145 \\
(22.21 \%)\end{array}$ & $\begin{array}{c}243 \\
(21.02 \%)\end{array}$ \\
\hline Agree & $\begin{array}{c}152 \\
(39.69 \%) \\
\end{array}$ & $\begin{array}{c}56 \\
(46.67 \%) \\
\end{array}$ & $\begin{array}{c}267 \\
(40.89 \%)\end{array}$ & $\begin{array}{c}475 \\
(41.09 \%) \\
\end{array}$ \\
\hline Strongly agree & $\begin{array}{c}47 \\
(12.27 \%) \\
\end{array}$ & $\begin{array}{c}16 \\
(13.33 \%)\end{array}$ & $\begin{array}{c}88 \\
(13.48 \%)\end{array}$ & $\begin{array}{c}151 \\
(13.06 \%)\end{array}$ \\
\hline
\end{tabular}

Source: Authors own calculations.
The results are presented in Table 7, which illustrates the responses of migrant, return migrant, and nonmigrant households separately. 
Overall, these questions suggest that return migrants are positively viewed in Ethiopia. Table 8 shows the total responses for these same questions from the participants in Addis Ababa, as compared to the total population. It is interesting to note that on all questions, Addis Ababa respondents do not view returnees as positively as the rest of the total sample. One hypothesis for this would be that on the whole there are more returnees in Addis Ababa, and therefore respondents have more experience with returnees. In the survey, $28 \%$ of all returnees sampled were living in Addis Ababa, with only Oromiya region having a slightly higher number of sampled returnees at $29 \%$, whereas in all other regions it was less than $18 \%$ of the returnee sample. Furthermore, the returnees to Addis Ababa were the most likely to return from the North, at 25\%, with the majority returning from the Middle East. Perhaps the type of returnee also has an impact on responses as the other regions had virtually no returnees from the North. These responses suggest that return migrants are viewed slightly less favourably and more as equals in Addis Ababa. The interviews and observations were all made in Addis Ababa, thus it is important to note that the perceptions in Addis Ababa might differ from the rest of the country.

In the following tables all categories of return migrants are grouped together, however, the situation is quite different for different groups of return migrants. First, return migrants from the north are characterized as diaspora returnees in Ethiopia and are represented in different ways. The media often portrays a positive image of diaspora returnees and highlights the achievements they have brought to Ethiopia (BBC, 2006; Habtamu for Ezega News, 2009). The so-called 'poster-boy' for the successful Ethiopian diaspora returnee is Tadiwos Belete, a diaspora returnee from the US who has opened several successful businesses such as the Boston Day Spa and the high-end Kuriftu Resort. The portrayal of Belete is positive in the media, as someone who suffered as a refugee in Sudan, and was able to make it to the United States and be successful, but always had a desire to return to Ethiopia. Belete has described the achievement of Kuriftu in an interview with Ezega News (an Ethiopian Business, News and Information Website) as: "the $1^{\text {st }}$ standard benchmark for a lodge here. It proves that we Ethiopians can make and operate 5star resorts", which gives a sense of pride to the Ethiopian identity (Habtamu, 2009). This type of portrayal of the diaspora returnee is common in the media and seeks to bring pride to the Ethiopian identity and contribution of returnees to modernizing the country. 
Table 8: Addis Ababa Respondents Perception Questions compared to Total Respondents

\begin{tabular}{|c|c|c|}
\hline & Addis Ababa Respondents & All Respondents \\
\hline \multicolumn{3}{|c|}{ When people who have lived abroad come back they... } \\
\hline \multicolumn{3}{|l|}{ Help the country } \\
\hline Strongly disagree & $\begin{array}{c}2 \\
(0.86 \%)\end{array}$ & $\begin{array}{c}29 \\
(2.34 \%)\end{array}$ \\
\hline Disagree & $\begin{array}{c}12 \\
(5.17 \%)\end{array}$ & $\begin{array}{c}124 \\
(10.02 \%)\end{array}$ \\
\hline Neutral & $\begin{array}{c}44 \\
(18.97 \%)\end{array}$ & $\begin{array}{c}201 \\
(16.25 \%)\end{array}$ \\
\hline Agree & $\begin{array}{c}135 \\
(58.19 \%)\end{array}$ & $\begin{array}{c}763 \\
(61.68 \%)\end{array}$ \\
\hline Strongly agree & $\begin{array}{c}28 \\
(12.07 \%)\end{array}$ & $\begin{array}{c}120 \\
(9.70 \%)\end{array}$ \\
\hline \multicolumn{3}{|l|}{ Do not fit in } \\
\hline Strongly disagree & $\begin{array}{c}34 \\
(14.66 \%)\end{array}$ & $\begin{array}{c}177 \\
(15.28 \%)\end{array}$ \\
\hline Disagree & $\begin{array}{c}88 \\
(37.93 \%)\end{array}$ & $\begin{array}{c}473 \\
(40.85 \%)\end{array}$ \\
\hline Neutral & $\begin{array}{c}52 \\
(22.41 \%)\end{array}$ & $\begin{array}{c}202 \\
(17.44 \%)\end{array}$ \\
\hline Agree & $\begin{array}{c}32 \\
(13.79 \%)\end{array}$ & $\begin{array}{c}246( \\
21.24 \%)\end{array}$ \\
\hline Strongly agree & $\begin{array}{c}4 \\
(1.72 \%)\end{array}$ & $\begin{array}{c}60 \\
(5.18 \%)\end{array}$ \\
\hline \multicolumn{3}{|c|}{ Bring new ideas, knowledge and technology } \\
\hline Strongly disagree & $\begin{array}{c}4 \\
(1.72 \%)\end{array}$ & $\begin{array}{c}21 \\
(1.69 \%)\end{array}$ \\
\hline Disagree & $\begin{array}{c}9 \\
(3.88 \%)\end{array}$ & $\begin{array}{c}86 \\
(6.93 \%)\end{array}$ \\
\hline Neutral & $\begin{array}{c}52 \\
(22.41 \%)\end{array}$ & $\begin{array}{c}171 \\
(13.78 \%)\end{array}$ \\
\hline Agree & $\begin{array}{c}84 \\
(36.21 \%) \\
\end{array}$ & $\begin{array}{c}677 \\
(54.55 \%) \\
\end{array}$ \\
\hline Strongly agree & $\begin{array}{c}72 \\
(31.03 \%)\end{array}$ & $\begin{array}{c}286 \\
(23.05 \%)\end{array}$ \\
\hline \multicolumn{3}{|c|}{ Recieve preferential treatment } \\
\hline Strongly disagree & $\begin{array}{c}6 \\
(2.59 \%) \\
\end{array}$ & $\begin{array}{c}56 \\
(4.84 \%) \\
\end{array}$ \\
\hline Disagree & $\begin{array}{c}31 \\
(13.36 \%) \\
\end{array}$ & $\begin{array}{c}231 \\
(19.98 \%)\end{array}$ \\
\hline Neutral & $\begin{array}{c}59 \\
(25.43 \%) \\
\end{array}$ & $\begin{array}{c}243 \\
(21.02 \%)\end{array}$ \\
\hline Agree & $\begin{array}{c}77 \\
(33.19 \%) \\
\end{array}$ & $\begin{array}{c}475 \\
(41.09 \%) \\
\end{array}$ \\
\hline Strongly agree & $\begin{array}{c}29 \\
(12.50 \%)\end{array}$ & $\begin{array}{c}151 \\
(13.06 \%)\end{array}$ \\
\hline
\end{tabular}

Source: Authors own calculations. 
The local perspective on diaspora returnees, is however, not as positive as the portrayal in the media. There are high levels of scepticism towards diaspora returnees. A common perspective is that diaspora returnees worked in low-level jobs in the US, such as parking attendants, dollar store cashiers, or as dishwashers, and now return to Ethiopia flaunting money and behaving as though they are better than locals. This extends to the degree that there are low levels of trust for genuinely successful diaspora returnees, wherein locals question if they are telling the truth regarding their education and previous employment. At one point during the field research when explaining the purpose of my interviews with diaspora returnees to a local colleague, I was asked, "How do you know what they are telling you is true?" This exemplifies the mistrust between locals and diaspora returnees.

Diaspora returnees also experienced a lack of trust from locals, but in the opposite experience wherein locals were not honest with returnees. One returnee explained as follows:

"When you go to stores they could charge you more... For example I would ask somebody to facilitate some permit for me. I didn't know the going price was about, you know 10 to 20 thousands, he said 80 thousand and the guy next to him said yeah that is very reasonable and I signed it. And people were like I don't believe you paid 80 thousand! So you know you do get taken sometimes, that is frustrating."

\section{- Participant 41}

Overall diaspora returnees expressed that it is clear to locals and to themselves that they are different and initially there can be clashes.

Furthermore, even the use of the term 'diaspora' to describe the returnees suggests an othering process in Ethiopia. Locals do not consider diaspora returnees as 'really Ethiopian'. This is witnessed in other countries, such as India, where returnees are frequently called NRI's, officially meaning Non-Resident Indians, but given the local slang of Not-Really Indian. The diaspora returnees in Ethiopia recognize this, but often also accept it, and can even view it as an element to be used to their advantage. One diaspora returnee stated:

"People, well, categorize me as diasporas now, so somehow if I do some mistakes culturally, they would pass on them, they don't mind me being a bit crazy. They say "oh she's diaspora, so it's ok"."

Participant 54 
This acceptance of the label 'diaspora' assisted returnees to overcome clashes with locals. Diaspora returnees expressed that over time they were able to overcome these clashes, however, for locals stigmas of returnees appear to still exist, particularly of returnees from the United States. It is clear that this stigma is not resentment for people abandoning their country during the war, as is found in other post-conflict countries such as Bosnia (Stefansson, 2004). This stigma appears to stem from a reaction to changes occurring in Ethiopian culture as returnees bring new businesses and new ways of working. Addis Ababa has undergone massive changes in the last ten years and many of the changes are attributed to diaspora returnees. Furthermore, as expressed in the perception questions, nearly half of the respondents in Addis Ababa feel that returnees receive preferential treatment (45.69\%), which can fuel resentment towards returnees.

For the second group of return migrants from the Middle East the local perception and treatment is quite different. The media primarily portrays migrants to the Middle East as victims: both as victims of poverty and "backwardness" in Ethiopia, which instigates their migration, and as victims of abuse and trafficking in the Middle East (Tigabu, 2011; Berhane, 2012). The focus in the media, however, is on curbing the illegal migration and finding solutions for youth unemployment in Ethiopia. There is little information on the struggles of Middle Eastern returnees upon their return to Ethiopia, with the exception that they are happy to be home. As one Middle Eastern returnee stated: "We escaped from hell and went back home. It was too good to be true" (Tigabu, 2011). The return is thus portrayed as the safe haven after the horrors of the migration episode.

There are several other elements that occur for Middle Eastern returnees in their return experience. Previously, the common perspective amongst locals is that all returnees are rich. When a woman returned to her home after being in the Middle East, neighbours would come expecting some money or fancy clothes due to the migration. One participant stated:

"After you come from there they may think you have brought a lot with you. "She did not do this for me" that type of thing I heard, so I do not go anywhere."

\section{- Participant 82}

This quote shows how the assumptions of the locals that as a returnee the participant should have brought them gifts has negatively affected the reintegration of the woman into the local community.

The emerging NGOs and increased government and media attention is starting to create more knowledge regarding the circumstances of returnees from the Middle East and it is beginning to trickle-down to the local level that returnees may 
not have had a positive experience or brought back lots of wealth. For instance, other participants stated their families and neighbours were just happy that they had returned unharmed from the Middle East. This creates a mixture of treatment towards Middle Eastern returnees.

Finally, for the third category of return migrants, the students, the situation is also quite different. This is also largely due to the difference in social networks of each of these groups. Student returnee's networks are more educated than those of Middle Eastern returnees. Student returnees are not expected to be wealthy upon their return, but receive a mixed reception. Some people believe that they should have stayed in the country of migration, and question if they were not good enough to get a job in the country of migration. On the other hand, others treat students with high respect as they have received high quality education and now returned to help their country, versus staying abroad. Most students expressed that they have encountered both of the perspectives. Overall, however, student returnees do not face many stigmatizations by locals and there is little media attention towards student returnees.

\section{Characterizing the Structural Environment of Return Migration in Ethiopia}

Thus far this chapter has sought to provide an overview of the structural environment of return in Ethiopia for each group of returnees: professionals, students and domestics. The final section of this chapter will provide an assessment of the structural environment for each return group based on Table 3 of Chapter 2, also shown below.

Table 9: Overview of the Structural Environment of Return

\begin{tabular}{|l|l|l|l|}
\hline \multicolumn{1}{|c|}{ Government } & $\begin{array}{l}\text { Favourable } \\
\text { - encourage return } \\
\text { migration } \\
\text { - implement policies to } \\
\text { support returnees } \\
\text { reintegration/ } \\
\text { participation }\end{array}$ & $\begin{array}{l}\text { - discourage return } \\
\text { migration } \\
\text { - no policies to support } \\
\text { returnees }\end{array}$ & $\begin{array}{l}\text { - ambivalent towards } \\
\text { returnees }\end{array}$ \\
\hline Local Population & $\begin{array}{l}\text { - inclusive attitude } \\
\text { towards returnees } \\
\text { - open towards cultural } \\
\text { diversity }\end{array}$ & $\begin{array}{l}\text {-exclusive attitude } \\
\text { towards returnees } \\
\text { - closed towards } \\
\text { cultural diversity }\end{array}$ & $\begin{array}{l}\text {-ambivalent towards } \\
\text { returnees }\end{array}$ \\
\hline Private Sector & $\begin{array}{l}\text { - inclusive attitude } \\
\text { towards returnees }\end{array}$ & $\begin{array}{l}\text {-exclusive attitude } \\
\text { towards returnees }\end{array}$ & $\begin{array}{l}\text {-ambivalent towards } \\
\text { returnees }\end{array}$ \\
\hline Return Migrant Flows & $\begin{array}{l}\text { - medium flow of return } \\
\text { migrant }\end{array}$ & $\begin{array}{l}\text { - flow is too large and } \\
\text { overwhelms local } \\
\text { population } \\
\text { - flow is too small to be } \\
\text { noticed }\end{array}$ & $\begin{array}{l}\text { - small to medium flow } \\
\text { of returnees (does not } \\
\text { affect local populations } \\
\text { daily lives) }\end{array}$ \\
\hline
\end{tabular}




\title{
Professionals
}

The government can be classified as between favourable and neutral to professional returnees. On the one hand, the government has implemented policies to make investing in Ethiopia more accessible for those who are Ethiopian born and now have foreign citizenship. This has had a large impact on the ability of professionals in invest in the country. The government had also implemented policies to encourage return migration, which highlights a favourable structural environment, but these were discontinued. Therefore, at present there are no policies specifically aimed at encouraging return migration, however, the government does continue to encourage professionals to invest in Ethiopia. This suggests a slightly favourable government approach towards returnees.

Professionals have for the most part had positive experiences in working with the government to open businesses and acknowledge that diaspora returnees do receive some special treatment from the government in the opening of their businesses.

\begin{abstract}
"Actually they [the government of Ethiopia] came to Boston and everywhere they are going and asking people. They promised to give us a loan and other opportunities. It was very interesting what they can do for you. We came and bought land from the government. It was very smooth, nice place. They are very helpful. Right now we are doing the design and I am about to get the building permit. I will see how it works but so far things are good."
\end{abstract}

\section{- Participant 55}

Frustrations with the government are experienced in other ways, such as the effective use of professional's knowledge contributions. One returnee described their frustration as follows:

"So I see something being done as an engineer and I wish I could help out, I wish they would ask me without payment for support. For example the traffic and there is so much about the air quality...I wish they would involve people in their field and say 'ok' you came in and we are working on environmental issues and training issues, can you help us with these? I would love to get involved here...it is frustrating knowing that you could be part of the solution." 
Overall, the situation with government can thus be viewed as a slightly favourable structural environment for diaspora returnees.

The treatment from the local population can be characterized as slightly adverse for the professional returnees. There is a high level of stigmatization towards diaspora returnees from the general population, but this of course does not include all locals. It is arguable that professionals are able to breakthrough these stigmatizations within a few months, however, these stigmas do still exist at a general level. In addition, there is a mixed environment for accepting other cultures in Ethiopia. The youth in Addis Ababa are open to the changes and the western influence, whereas the older generations are often resisting the changes and the influence of the west on local culture. This creates a mixed environment.

The positive portrayal of professional returnees in the media, may lead to future changes in the treatment of locals. Chan and Tran (2011) found in Vietnam that a positive media portrayal of skilled returnees has influenced a positive social attitude from locals towards returnees. The locals accept the skilled Vietnamese returnees as part of the Vietnamese nation. This, however, may not be the case in Ethiopia. Similarly to the slang in India that Persons of Indian Origin (PIOs) and Non-Resident Indians (NRI's) are 'not really Indian' there is a perception in Ethiopia that diaspora returnees are not necessarily Ethiopia. India initially had a contested relationship with PIOs and NRI's wherein prior to 2000 they were viewed as deserters, however, this changed to a more positive light in the last decade as they are now viewed as agents of development and a source of pride for the country (Hercog and Siegel, 2013). These examples highlight that the current mixed environment towards returnees in Ethiopia may change in the future as the role of returnees in developed potentially grows.

Finally, the flow of professionals to Ethiopia can be characterized as small to medium. As there are no exact figures it is difficult to quantify the flows. However, the number of professional returnees does appear large enough to be having an impact on Addis Ababa, but is not too large to overwhelm the city. Therefore the size of the flow has a neutral impact on the structural environment.

Overall the structural environment for professionals and diaspora returnees in Ethiopia is slightly favourable. The professionals that participated in this project represent those that have managed to resist the negative aspects of the structural environment and establish successful businesses. However, many interviewees stated, "for every one who stays, at least two go back". This suggests that the difficult aspects of the structural environment led to unsustainable returns for many individuals that were excluded from this study. 


\section{Students}

For student returnees the structural environment of return is neutral. There are no government policies aimed towards student returnees that are either positive or negative. The local population has a mixed attitude towards student returnees, that overall appears slightly more positive than negative. The number of student returnees is small, although arguably increasing, but not large enough to be having a noticeable impact on Ethiopia. Therefore, the overall structural environment of return for students is neutral.

Ethiopia is currently undergoing a transition- as the country and economy grows there is a critical recognition of a need for higher skills. The country is currently investing in higher education institutes, however, often lacks the required level of instructors. There is a strong recognition of the prestige of foreign education in Ethiopia. This acceptance of the prestige of foreign education is common in other countries, such as China, India, and Ghana and further across Africa, and is easily identified by the tradition of elites sending their children to study abroad. At the same time as there is acknowledgement of the prestige of foreign education, there is not necessarily an automatic acceptance of student returnees. For the most part, students in this study felt accepted upon return in Ethiopia and had high levels of labour market reintegration.

A large gap exists in the literature on student migration, with a particular dearth of literature on students return and reintegration. The majority of literature focuses on the decision making of international students to return or stay in the host country (Hazen and Alberts, 2006; Harvey, 2009) and human capital transfers of students (Balaz and Williams, 2004). Ragurham (2013) argues that current theories of migration do not take into account the unique perspective of student migration and that further research is required in this area. This gap makes it difficult to compare the experiences of the students in this study to other cases.

\section{Domestics}

The structural environment of return for domestics in Ethiopia can be characterized as slightly adverse. The government of Ethiopia does not necessarily promote return from the Middle East, but does acknowledge the challenges of returnees and has begun to implement policies to support returnees, such as the social workers in the local Kebeles in Addis Ababa. This shows that there is an interest in providing protection and support to returnees who have experienced challenges in the Middle East.

The attitudes of the local population towards domestic returnees are mixed. As described above, in some situations locals are accommodating towards domestic returnees, and in other situations locals have high expectations for domestic returnees. These different attitudes can have different impacts on the returnee. 
The situation in Ethiopia presents a contrast to the treatment of returning domestic workers in other countries, such as the Philippines. In the Philippines, the Overseas Workers Welfare Administration (OWWA) is a government body that provides reintegration assistance (OWWA, 2013). This includes: job referrals (local and overseas employment), business counseling, community organizing, financial literacy seminar, networking with support institutions, social preparation programs, and loan facilitation. Additional services are provided to distressed returnees. It is widely acknowledged and promoted by the government that female migrants for domestic work are 'heroes' by providing remittances and making sacrifices in their migration and that support needs to be provided upon return. This perception is not held in Ethiopia where more there is commonly a negative view of domestic worker migration.

The flow of domestic returnees to Ethiopia is increasing, and increasing to levels where it is gathering attention in Ethiopia. The size of the flow has generated a response from international organisations, NGOs, and the government. Efforts are increasing to prevent Middle Eastern migration and to provide support to returnees. This can be viewed as a positive step in providing domestic returnees access to care and services that they need. At the same time, however, the number and availability of services is only accessible by a small segment of the domestic returnee population. The services and supports need to be vastly expanded in order to truly impact the domestic returnees. Therefore, the structural environment of return for domestic returnees can be viewed as slightly adverse.

\section{Summary}

The structural environment of return plays a critical part in the reintegration process. It is evident that the structural environment of return is different for different groups of return migrant. Table 10 shows a summary of the differences of the structural environment of return for the different analytical groups.

Table 10: The Structural Environment of Return in Ethiopia per Analytical Group

\begin{tabular}{|c|c|c|c|}
\hline & Professionals & Students & Domestics \\
\hline Government & Favorable & Neutral & Neutral \\
\hline Local Population & Adverse & Neutral & Adverse \\
\hline Private Sector & Favorable & Favorable & Adverse \\
\hline $\begin{array}{l}\text { Return Migrant } \\
\text { Flows }\end{array}$ & Neutral & Neutral & Neutral \\
\hline Overall & Neutral & Neutral & Adverse \\
\hline
\end{tabular}


Although there are variations, on the whole, the structural environment of return can be classified as neutral for all of the return migrant groups. For the professionals there is more variation is the favourable conditions experienced from the government and the adverse conditions experienced by the local population, creating a more challenging environment of return. Student returnees have received very little attention on the whole, thus return to a neutral environment. For domestics, there is some indication of the government moving towards a more favourable environment by providing services to returnees, but this is not yet strong enough to be labelled as favourable. Domestics face challenges in the private sector in finding employment and with reception and treatment from locals. This will be discussed further in the coming chapters with an examination of their reintegration.

This chapter has sought to characterize the structural environment of return migration for the professional, student, and domestic returnees in Ethiopia. It is evident that there is room for improvement in assisting returnees to successfully reintegrate in Ethiopia. The structural environment discussed in this chapter will be referred to in later chapters in discussing the impact of the structural environment on the reintegration strategies of return migrants in Ethiopia. 


\section{Chapter 5: Overview of Female Return Migration to Ethiopia: Professionals, Students, and Domestics}

\section{Introduction}

A key element in assessing return migrants reintegration strategies is understanding the role of their life cycle in their return migration. The life cycle includes experiences prior to migration, during migration, and upon return. Critical to the reintegration strategies approach is the class of the individual, their opportunities for integration abroad, and their preparedness and process of return.

As stated by Cassarino (2004), "the returnee's preparedness is shaped by circumstances in host and home countries, i.e. by pre- and post-return conditions" (272). Migration must be envisioned as a cycle, wherein return and reintegration are stages, which are highly affected by the experiences of the preceding stages. Figure 6 illustrates the migration cycle.

\section{Figure 6: The Migration Life Cycle}

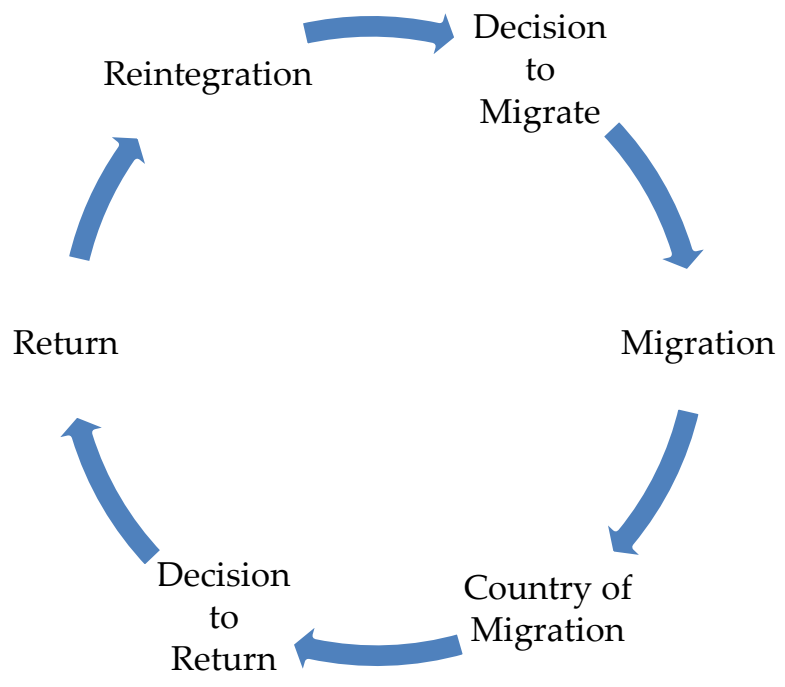

At any point the cycle can be discontinued or interrupted. That is, in the event that a returnee has a successful reintegration they may not choose to re-migrate and the cycle has been discontinued. On the other hand, the migrant's cycle may be interrupted, such as in the case of unexpected family events, ostracism, or 
deportation, meaning that migrants return unexpectedly and have no preparedness for their return (Cassarino, forthcoming). This chapter will provide an overview of the migration life cycle of each analytical group so as to inform their reintegration strategies.

It is also important to note that the process of return and reintegration is not necessarily as linear as Figure 6 suggests. As demonstrated by Cassarino (2004, forthcoming), returnees often prepare for their return, effectively pre-empting their reintegration. That is, returnees with higher levels of preparedness for their return, including established networks, willingness and readiness to return, have arguably in part already started the reintegration process while in the country of migration.

For the purposes of this study, the interviews have been divided into three analytical categories:

- Professionals- Women who migrated in the 1980s and 1990s primarily and returned to Ethiopia after an extended duration abroad having worked in the country of migration, acquired skills, and returning to Ethiopia with professional expertise.

- Students- Recent migrants that migrate primarily to European countries for the purposes of Bachelors or more commonly a Master's degree.

- Domestics- Women from primarily lower class families that migrate to the Middle East for domestic work.

The stark differences between these groups will be highlighted in this chapter. The following chapters will elicit how these different migration experiences lead to differences in reintegration strategies (as illustrated in Chapter 2) upon return. It will be illustrated in the forthcoming chapters how the analytical categories reflect different iterations in the reintegration strategies.

\section{The Migration Cycle and Return to Ethiopia}

Table 11 provides an overview of the background characteristics of the professionals, students, and domestics. From Table 11 it is evident that domestic workers are the youngest interviewees, and professionals are significantly older at an average of 43 years of age. However, at the time of migration, on average professionals were the youngest at 20 years of age, compared to domestics at 21 and students at 24 years of age. Unsurprisingly, domestics have the lowest levels of education, with none of the domestics having completed graduate school, as compared to all of the students having a minimum of a graduate degree and the majority of professionals having a graduate degree. The majority of domestics are single and do not have children, which is different than the case of domestic workers from countries such as the Philippines, where women are frequently migrating to support their children (Parrenas, 2005). The majority of students are also single with professionals being the most likely to be married and have children. 
The professionals were abroad for significantly longer than the other two groups at an average of 19 years, and at the time of interview had also returned for longer at an average of four years. Duration abroad can be significant in impacting reintegration as Amassari (2009) suggests that an optimal duration abroad is five years, with longer durations making reintegration more difficult. This will be discussed further in the following chapters.

The countries of migration show that the majority of professionals migrated to the United States, and the majority of students migrated to Europe. The culture in the country of migration has a strong influence on the experiences of migration and return. Most skilled Ethiopians speak English, so the language factor alone allows for better integration of Ethiopians in the United States than in most countries of continental Europe where English is not the main language. Professionals were well integrated in the United States, whereas the majority of students were not integrated in Europe and did not learn the local language.

Domestic workers migrated to several different countries in the Middle East, with Lebanon and the United Arab Emirates being the most frequent. Significant variations among experiences in the Middle East based on country of migration were not found, with the exception that Syria and Yemen provided worse conditions (in terms of abuse, pay, and human rights) for the female migrants than the other countries.

At the time of interview, on average, professionals had been in Ethiopia the longest at 4.2 years, compared to 2 years for students and 1.3 years for domestics. This is an important variable for the analysis as the professionals on average have had a longer time to reintegrate into Ethiopia than the other two groups. At the time of interview the professionals primarily owned their businesses $(80 \%)$, the students were most likely to be in paid employment (82\%), whereas the domestics were most likely to be unemployed (61\%). These figures are to be expected based on the return migration literature and skills of each group upon return. The rest of this chapter will discuss the migration and return experiences of each analytical group in further depth.

\section{The Professionals: Refuge and Decided Return}

The majority of professionals were members of Ethiopia's elite prior to the Revolution in 1974. Due to different familial occupations, some of the professionals' families became immediate targets of the Dergue regime. As all of the participants are female and were relatively young at the time of the Revolution, the participants themselves were not direct targets by the Revolutionaries, however some were still in danger due to their families positions and regularly scrutinized by the regime. The 
Table 11: Participants Overview: Professionals, Students, and Domestics

\begin{tabular}{|c|c|c|c|}
\hline Variable & Professionals & Students & Domestics \\
\hline $\mathrm{n}$ & 20 & 17 & 44 \\
\hline Average Age (at the time of interview) & 43 & 29 & 26 \\
\hline Average Age at Initial Migration & 20 & 24 & 21 \\
\hline \multicolumn{4}{|l|}{ Education Level } \\
\hline Incomplete Primary & - & - & $7(16 \%)$ \\
\hline Primary & - & - & $6(14 \%)$ \\
\hline Incomplete Secondary & $1(5 \%)$ & - & $10(23 \%)$ \\
\hline Secondary & $5(25 \%)$ & - & $16(36 \%)$ \\
\hline Incomplete Graduate & $1(5 \%)$ & - & $2(5 \%)$ \\
\hline Graduate (Bachelors) & $6(30 \%)$ & $5(29 \%)$ & - \\
\hline Masters or Higher & $6(30 \%)$ & $12(71 \%)$ & - \\
\hline \multicolumn{4}{|l|}{ Country of Migration } \\
\hline \multicolumn{4}{|l|}{ Middle East } \\
\hline Bahrain & - & - & $3(7 \%)$ \\
\hline Lebanon & - & - & $15(34 \%)$ \\
\hline Kuwait & - & - & $6(14 \%)$ \\
\hline Qatar & - & - & $1(2 \%)$ \\
\hline Saudi Arabia & - & - & $4(9 \%)$ \\
\hline Syria & - & - & $3(7 \%)$ \\
\hline United Arab Emirates & - & - & $12(27 \%)$ \\
\hline Yemen & - & - & $2(5 \%)$ \\
\hline \multicolumn{4}{|l|}{ North } \\
\hline Belgium & - & $1(6 \%)$ & - \\
\hline Canada & $1(5 \%)$ & - & - \\
\hline Denmark & - & $1(6 \%)$ & - \\
\hline France & $2(10 \%)$ & $1(6 \%)$ & - \\
\hline Germany & $1(5 \%)$ & $1(6 \%)$ & - \\
\hline Italy & $1(5 \%)$ & - & - \\
\hline Netherlands & - & $4(24 \%)$ & - \\
\hline Norway & $1(5 \%)$ & $2(12 \%)$ & - \\
\hline Singapore & - & $1(6 \%)$ & - \\
\hline Sweden & - & $3(18 \%)$ & - \\
\hline United Kingdom & $1(5 \%)$ & $1(6 \%)$ & - \\
\hline United States & $13(65 \%)$ & $2(12 \%)$ & - \\
\hline Average Duration Abroad (Months) & $\begin{array}{c}229 \\
\text { (19 years) } \\
\end{array}$ & $\begin{array}{c}41 \\
\text { (3.4 years) } \\
\end{array}$ & $\begin{array}{c}44 \\
\text { (3.6 years) } \\
\end{array}$ \\
\hline \multicolumn{4}{|l|}{ Marital Status (at the time of interview) } \\
\hline Single & $5(25 \%)$ & $12(71 \%)$ & $33(75 \%)$ \\
\hline Married & $12(60 \%)$ & $5(29 \%)$ & $8(18 \%)$ \\
\hline Divorced & $2(10 \%)$ & - & $3(7 \%)$ \\
\hline Widowed & $1(5 \%)$ & - & - \\
\hline Children (at the time of interview) & $10(50 \%)$ & $4(24 \%)$ & $9(20 \%)$ \\
\hline \multicolumn{4}{|l|}{ Employment upon Return } \\
\hline Unemployed & $2(10 \%)$ & $1(6 \%)$ & $27(61 \%)$ \\
\hline Employed & $2(10 \%)$ & $14(82 \%)$ & $11(25 \%)$ \\
\hline Self-employed & $16(80 \%)$ & $2(12 \%)$ & $6(14 \%)$ \\
\hline Average Time Since Return (Months) & $\begin{array}{c}50 \\
(4.2 \text { years }) \\
\end{array}$ & $\begin{array}{c}24 \\
\text { (2 years) } \\
\end{array}$ & $\begin{array}{c}15 \\
\text { (1.3 years) } \\
\end{array}$ \\
\hline Average Income Upon Return (Birr/ Month) & 95166 & 8155 & 229 \\
\hline Average Income Upon Return (USD/ Month) ${ }^{1}$ & 5598 & 479 & 13.5 \\
\hline
\end{tabular}

Source: Authors own calculations.

${ }^{1}$ Based on USD 1= 17 Birr. In the spring of 2011 this was the average exchange rate. 
conditions in Ethiopia under communist rule (including job placement, lack of freedom, and regular terror) led the professionals to migrate. For the majority of professionals, their family members were also migrating, so some went with family, while others sought to join family already abroad.

For this group, routes out of the country were often complicated. Some migrated on foot to Sudan or Kenya to claim refuge in a camp and waited for family members to sponsor them to the United States or an opportunity to get to Europe. For others, they sought to get exit visas through creative means, to countries such as India for education, and after arrival in India migrated to the United States. Essentially all members of this group did have family in the country of migration that was able to assist them in their arrival.

For the younger professionals, they grew up during the communist era, but many migrated after 1991 . Their reasons for migration were primarily to have a better education and life abroad. In the early 1990s the University system in Ethiopia was not very developed as it had been neglected under communist rule. It was common for students attending the top private schools to seek to migrate for further education. After 1991, it was feasible to obtain a passport and exit visa and the younger professionals were able to go abroad, initially for education purposes, but these migrations were extended beyond education as they developed careers abroad. This group was less likely to have immediate family in the country of migration, but commonly had a host family or connection that was established by their families prior to their migration.

Prior to arrival in the host country the majority of professionals had limited information on what life would be like. At this time, the focus of families was getting out of Ethiopia and little discussions were had regarding the actual way of life abroad. Many of the professionals spoke English or French, and were able to converse upon arrival in the United States or France. Some however, did not have language capacity or the right language capacity (ie: spoke French and not English and migrated to the United States), thus having a more difficult time in adjusting to the language. As shown in Table 1, the majority of professionals were young at the time of migration (average age of 20 years old) and for the majority this was their first experience outside of Ethiopia.

The majority of participants experienced high levels of culture shock in their initial migration. As the majority was well off in Ethiopia, their family had lost their finances and resources in the Revolution and as migrants they were struggling. In addition, many participants still had family in Ethiopia that they were trying to support. Participants in this situation sought to work immediately in low-income jobs to make money to support their families. One participant stated: 
"My brothers, they didn't want me to work. They wanted me to go to high school for one year and then join college. I said no, I have to work. I knew at that time my mother was not working [in Ethiopia] and things were not the same as before [when my brothers left]. I knew all these problems my mom had before I left. I had to help my family and my brother that I also left in Kenya. I preferred to go to work and assist my brother left in Kenya. After a few days I got a job at McDonalds and started working."

-Participant 55

This quote illustrates the ambition of the participants upon arrival and the need to support their families. The majority of participants did not work in low-end jobs (such as McDonalds or restaurants) for long. They were able to get better jobs and attend school part-time, or were able to get family to the United States so that they did not have to support family abroad. With time, they were able to move into professional occupations.

Other participants were more fortunate and were able to study from the beginning. Some participants had gone abroad for education purposes prior to 1974, thus, upon graduation they were not able to return home. Other participants were in their early teens at the time of their migration and their family abroad ensured that they went directly into high school and were not working. The initial experiences in the country of migration were often tumultuous for the participants, but as time passed, they adapted to life in the country of migration and became highly integrated.

The average duration abroad for the professionals was 19 years, thus there was ample opportunities to integrate in the country of migration. All had a residence permit, and the majority acquired citizenship while abroad. The majority of professionals held high-level jobs as managers, government employees, or entrepreneurs in the country of migration. Professionals felt a high level of integration abroad and felt at home in the countries of migration. One participant stated:

"I can truly say I am an American. I mean in every sense of the word. Because I really feel first of all it's a place where you are really able to find yourself. I really feel grateful for having been given the opportunity to be sheltered. I mean, there are so many countries where you go you are not wanted, they don't care. Close the door on your face and throw you out." 
Very few of the participants spoke about being treated as 'second class citizens' abroad. The majority of professionals felt well integrated and respected in the country of migration. Participants developed a strong sense of belonging and the country of migration became home.

The majority of professionals maintained ties with Ethiopia while in the country of migration, but engagement with Ethiopia during the Dergue regime was difficult. The fall of the Dergue and increases in communications technology allowed professionals to strengthen their ties to Ethiopia. For many, in their initial migrations in the 1980s, phone calls were very expensive and communications to Ethiopia were less frequent. After the fall of the Dergue, family (mostly parents) were able to leave Ethiopia and visit in the country of migration. Phone communication became easier and more frequent, as did the sending of remittances. Professionals had always sought to send money to family in Ethiopia; however this was more difficult during the Dergue. With the fall of the Dergue regime money could easily be sent and was sent to support family, friends, and previous employees of the families.

The fall of the Dergue regime also created an opportunity in which people could temporarily return to Ethiopia for the first time. These visits typically occurred after eight or more years outside of the country and were a profound experience for the individuals. Many of the professionals interviewed did not initially migrate with the plan to be permanently abroad, but as they were or became refugees and the situation in Ethiopia did not improve they were not able to return. In 1991, the change in regime and the progress that ensued in Ethiopia in the following decade meant that people could come and visit the country for the first time.

The majority of professional returnees came first to visit family and friends, however some came for purposes of managing family property or to provide assistance to a friend in their temporary return. Temporary return for this group was a return from exile and many changes had taken place in Ethiopia during their time abroad. For many the experience was the confrontation between the imagined and the reality (Stefansson, 2004). One participant described their experience as follows:

"It was very shocking and mind you I was the last one from the family friends to come back, because of what happened to my family: about 50 per cent of them were dead. And I was the last one. I was forewarned. I was told just about everything and I thought I knew everything and I was going to be okay. And when I got here, what I saw was really shocking. The country went back 50 years. It was a lot of poverty and a lot of people and it was a shock. It was very depressing."

- Participant 41 
These initial experiences were often difficult for the participants. After this statement the woman above continued:

"But what I said was no matter what I will have to help this country. I am an educator, so I just said I would start some kind of education program and then I will see what I would like to do. And then I went back home."

\section{- Participant 41}

After the experience of temporary return, this participant was motivated to contribute to Ethiopia and went home to start a new project that focused on children's education. The majority of women that decided to return to Ethiopia were motived by altruistic means to contribute to their country of origin. One woman described her experience as follows:

"That is when I said I can't do this. I need to go back because here my
work, whether there is one less businesswoman in the US doesn't really
matter, but I thought there [in Ethiopia] I will make a difference. I said
if I go, my work will have meaning and I have wanted to do that for a
long time." - Participant 51

The desire to contribute to Ethiopia and to make a difference was a key motivating factor in the decision to return for over half of the professionals.

For a smaller number of the professionals, the key motivating factor in the decision to return was economics:

"I told you what I do, I do real estate, and the market was not good. So we wanted to try something else. We definitely wanted to move from [city], somewhere warm weather but we didn't know where to go. We tried, we travelled here there, but I cannot take the cold anymore. I said why don't we try to go to Ethiopia? Ethiopia is coming up now and Real estate is good here. Then we tried to develop some houses and we found a good school for our son. We came and looked at that. He joined the School and he liked it. And we said that is it, we left and then we try it."

\section{- $\quad$ Participant 55}

For this participant there were push factors in leaving the United States, but the primary motivating factor in moving to Ethiopia was the strong real estate market. Ethiopia's business opportunities is thus a motivating factor for return. 
Some of the married participants were heavily influenced by their husbands in their decisions to return. One participant stated:

"The first time I came is after 17 years. And I came for three weeks and believe it or not I cried for almost the whole three weeks. When I came back I said 'I will never step on this land again'. Then my husband came a month after me...And he fell in love with it. When he came back he said 'we are moving to Ethiopia' and I said 'did we go to the same place? You think we are going to function better there?' He said 'yes'...It was amazing, but you know, he convinced me."

- Participant 50

Women who made the decision to return had high levels of preparedness for return. Virtually all had participated in a previous temporary return, had acquired the resources necessary for their return, including information and securing accommodation in Ethiopia, and had the mental preparedness for return. Some of the married participants recognized that they were not ready to return, but had to relocate as their husbands were already in Ethiopia and waiting for them. This lower level of preparedness for return led to further challenges in the initial reintegration process and participants recognized this through the culture shock they experienced upon their initial return. However, after one to two years these participants felt highly reintegrated and had overcome the initial challenges faced in their return.

Professionals were highly integrated into the countries of migration and engaged transnationally with Ethiopia while in the country of migration. Although initially challenging, the migration experience overall provided many opportunities to the professionals for education, work experience, acquiring resources, and gaining citizenship. The professionals were active in maintaining ties to Ethiopia through conversations, remittances, and temporary return visits. Temporary return visits were significant to professionals making the decision to return more permanently. This is a contrast to other cases, such as Afghans wherein Oeppen found that during temporary return visits of Afghan-Americans to Afghanistan the participants felt like "strangers in what they might otherwise consider their "home'", and as a result the temporary visits led to further integration in the United States (2013: 261). It is highly possible, that this has also been the case for many members of the Ethiopian Diaspora in the United States, as the respondents regularly discussed that most diaspora do not want to return. This was also the case for some of the participants in this study, but their spouses desire to return had a strong influence on their final decision to return.

All professionals made the decision to return free from any form of coercion. For the majority this decision was primarily motivated by altruism and a desire to 
contribute to their country of origin. For others, it was motivated by business decisions. Professionals had high levels of preparedness for return as the majority returned in stages. These stages included temporary return trips to gather information, re-establish networks, and find housing and other necessary resources for return. Temporary return trips were significant in the women preparing for their return. These initial trips allowed the women to see the changes in Ethiopia prior to return and to overcome the initial shock and emotion that tended to accompany these visits. At the time of the actual return movement, the women were thus prepared for the current situation in Ethiopia and able to effectively manage their affairs. This also allowed them an open attitude towards Ethiopia that is vital for reintegration.

\section{Students: The Optimal Migration Episode}

The majority of students were from middle income families, wherein the returnees family was self-sustaining. A few of the students were from low-income families in rural areas where they were the first in their families to go to University, and a few were also from upper class families that were able to pay for their education abroad. Those from upper class families were more likely to go abroad for their bachelor's degree, whereas the other students were only able to migrate by receiving scholarships, most commonly for master's degrees. In Ethiopia, the best students from each course are often offered a position at the University after they completed their undergraduate degree. Once working for the University they are exposed to opportunities for master's degrees abroad and are encouraged to go abroad. In addition, several European funding streams particularly focus on funding those in higher education, such as Nuffic in the Netherlands.

The majority of students made the decision to migrate on their own. One participant compared receiving a scholarship to winning the lottery:

"I might be exaggerating a little bit, [but] if you win the lottery you don't consult with anyone you just go and get the money. So it's the same thing here. It is considered as a good thing, so I am not going to consult with anybody."

\section{- Participant 40}

Receiving the scholarships abroad was considered by all students as an excellent opportunity not to be turned down. Scholarships generally covered all tuition, living, and transport costs for students. Some students were able to remit some of their money to their families at home, but the majority stated they did not remit money back home, as their families did not need it. Thus, they were able to take the opportunity to travel in Europe and visit other countries. 
The integration process for students was primarily one of integration into the university environment. One participant described this feeling as follows:

"When I am with my international friends, because we all miss our homes, we have lot of common things to discuss, so I feel like I belong with them."

\section{- Participant 32}

Upon arrival, the university had generally arranged for people to assist the international students in getting around the university and the city to find groceries and other necessary amenities. Often other Ethiopian students volunteered to assist the new students, which many appreciated as they could speak in their own language. The majority of students reported becoming very comfortable in the university and feeling it was a second home. The environments at the universities were international with students coming from many different countries. None of the students learned to speak the language of the country of migration (with the exception of English speaking countries wherein students spoke English prior to migration) whilst abroad. The majority did not feel a part of the country of migration, however did feel strongly connected to the university and a sense of belonging within their course and international friend network.

It is important to note that the majority of students did not have an opportunity to stay in the country of migration beyond the duration of their course. A few countries allow for a one-year extension to be able to look for a job in the country of migration. Only one participant in the sample opted to stay for this year and was not successful in finding a position. All of the remaining students returned at the end of their course.

Return for the students was a part of their intended migration cycle and thus all of the students engaged in decided return. For the students, return was a part of the initial migration strategy and returning home was the final stage of executing their migration experience. As one participant stated:

"That had been my plan the whole time. Like my plan was to go there and go to school and come back. It is just what I did, and everything went according to plan."

\section{- Participant 28}

During their time abroad, approximately sixty per cent of students engaged in temporary return visits. These visits occurred in one of two contexts: first, to visit family and friends in between semesters or on holidays, or secondly, to complete fieldwork for a master's research project. In general, students with means and that were in longer programmes (two year programme as opposed to a one year 
programme) were more likely to return to visit family and friends and maintain contacts. A few students utilized these visits to explore future work opportunities by making visits to Addis Ababa University and networking with people in their field. These return visits and regular email, skype, and phone conversations with people in Ethiopia allowed students to have a high level of preparedness for their return.

Overall, the migration experience of the students was the shortest on average and the least challenging of the three groups. Migration was a positive opportunity that was accepted without question, wherein return was part of the intended migration cycle. Virtually all students greatly appreciated their experiences abroad and enjoyed their course and learning opportunities.

\section{The Domestics: Shattered Dreams, Interrupted Cycles, and Stories of Success}

Virtually all of the domestic workers were from low-income families and decided to migrate to support their families or to 'improve themselves and their situations'. The vast majority of women made the decision to migrate alone. Often, women did not consult their families, knowing that they would not be supportive, and only told their families one or two days before they left Ethiopia. This situation contrasts other research in Ethiopia in rural areas, wherein the decision to migrate is made by the family and is not necessarily the choice of the woman (ILO, 2011). The majority of the participants interviewed were from Addis, and there is increasing information available in Addis regarding the hardships women face in the Middle East. Many families do not want the women to migrate for fear that they will be harmed or not return at all. Thus, many women did not tell their families of their migration intentions as they knew that they would not be supported in their decisions to migrate.

One third of the domestics were in vulnerable situations prior to migration. This included different situations, with a first example being the death of a parent, wherein the household lost a key income generator. In this situation, it sometimes fell to the children to provide for the household and as one of the elder children the woman struggled to support her family, or similarly the income of the one parent was not enough to support the entire family. A second situation leading to migration was poor education results. In Ethiopia, students must receive high enough grades in secondary school (finishing in Grade 10) to attend Preparatory school (Grade 11 and 12). From Preparatory school students write exams and if they achieve a high enough grade they can go to University, which is now free across Ethiopia. Many of the domestic workers did not achieve high enough grades in Grade 10 to continue to preparatory school, or once in preparatory school knew they would not be able to go to University and left school to migrate. Finally, of those participants that had a job prior to migration, the key challenge was the low salary they were receiving for their work. Pre-migration salaries ranged from 80-300 birr per month (US\$ 4.70-17.64). This was, and is still, not enough to live off of and for those that had to take 
transportation to work their wage barely covered the cost of their transport leaving them with very little at the end of the month.

The women migrating to the Middle East were heavily influenced by the current myth of migration occurring in Ethiopia. One woman summarized this as follows:

"What is being said about [the Middle East] here and the reality in Dubai is quite different. We do not trust people when they tell us the facts about migration, we only look at the artificial clothes returnees wear here and consider as if life is good. But in reality, life is difficult."

\section{- Participant 71}

Information has increased in Addis Ababa regarding the challenges of migration to the Middle East and many women have heard about and were aware of these challenges. However, as highlighted above, some women do not believe the negative information, thinking that the migrants/ returnees only want to keep the wealth for themselves and do not want others to migrate. This lack of trust leads to missleading perceptions regarding migration to the Middle East. Many women expect that they will go and work hard, and be able to change their situations in a short period of time:

"I knew that I will work, but I didn't expect the work to be so exhaustive. I only expected that I will be rich within a short period of time and I will change my family's life to make it easier. But the reality is not smooth like that."

\section{- Participant 83}

Women received information both from trusted friends and family that had migrated and from other returnees. This information was often a combination of positive and negative pieces. Depending on the experiences of the family member abroad and the degree of closeness they did or did not support the women in migrating. For instance, in some cases, sisters who were abroad did not want their sisters to migrate, however at their continued insistence supported the sister in migration.

The women that received the positive and negative information regarding the country of origin were more realistic in their expectations of going abroad:

"I expected both good and bad things. I was prepared to face any challenges for the sake of my children. I didn't expect only good things."

- Participant 08 
Women tended to hope for the best in this situation, in that they would receive a good house and would not be harmed by their employers.

Further information is also provided to women that attended pre-departure training. Pre-departure training is officially provided by the Ministry of Labour and Social Affairs (MOLSA), but brokers also offer unofficial training. MOLSA training is three hours in duration and provides information to women on the conditions in the Middle East. A key stakeholder that attended the training said that information is provided on many topics, including the issue of rape. Women are advised in this training to avoid being alone in the house with the husband and that if they find themselves in a situation of rape not to fight, but to be quiet and move on from the situation. As this is government led training, questions must be posed as to the appropriateness of such advice. However, most rape cases in Ethiopia, particularly in rural areas, are not prosecuted, and rape of young women is a common offense in rural areas where if the woman married her abductor the case is then absolved (Wax, 2004). Furthermore, rape of a non-virgin is often not considered an offense in Ethiopian court (Wax, 2004). In this context, the advice seems less appalling; however, the lack of support from the government for migrant women who are abused in the Middle East is clear. It is also evident that despite this knowledge, women still migrate, stressing the desperation of these women to put themselves in situations of such known risk.

Private employment agencies and brokers sometimes offer their own trainings. These trainings last from one day to a full week and are more comprehensive with a focus on teaching women the appropriate behaviours for working in the Middle East. This includes information on not talking back to employers or being difficult, smiling and speaking kindly, and some brief language training prior to departure. Women who were involved in this form of training said they found it very useful; however, the majority of women received no form of training prior to departure.

The domestics' migration to the Middle East is regulated by the Kafala sponsorship system. The Kafala system "makes an individual national citizen or a company sponsor (known as a Kafeel) legally and economically responsible for the foreign worker for the duration of the contract period" (Lori, 2012: 4). Thus, the sponsor is the only person allowed to employ the worker. Domestic workers are also excluded from the labour legislation in most Arab States (Chammartin, 2004). Their work is not considered as an 'employee' and therefore they are not protected in national law. This further empowers the employer/ sponsor under the Kafala system as they are entirely responsible for domestic workers. As there is no legal system to protect domestic workers rights in the Middle East, the working conditions are primarily dependent on the character of the employer. The result of the Kafala system is that the migrant is not only dependent upon the sponsor for recruitment 
and entry, but also for their daily sustenance and staying legal in the country (Pande, 2013). For domestic workers as soon as they leave their employers/sponsors house they have violated their contract and are now illegal (Pande, 2013). For this reason, domestic workers that flee their employers' house and go to the police for help are placed in prison as they are now an illegal migrant. In other cases domestics are able to 'run-away' from their employers and become 'freelancers' living irregularly and doing live-out domestic work or other jobs.

It is therefore not surprising that the working conditions in the Middle East vary primarily depending on the employment household. No consistent difference was found between country conditions in the Middle East. Based on the employer, a good situation can be described as one in which women work 8-10 hours per day, are responsible for a specific task (such as cleaning, child or elderly care), and are given one day off per week. A bad situation, on the other hand, can be described as one in which women work in excess of 18 hours per day, are responsible for all domestic tasks in the household (cleaning, cooking, child care, etc.), are not given time off and are not permitted to leave the house. From here, bad situations escalate to different forms of abuse experienced by the domestic workers. The majority of women interviewed were in bad situations in the Middle East. The few women that had a good situation were generally working for an upper class family, such as a sheikh. In this situation there were multiple domestic workers in the household and each worker had a specific task. This allowed for a manageable workload. Furthermore, perhaps due to the education and status of the upper class households, the women felt that they were treated with respect.

It is important to note that domestic workers in the Middle East are placed in a hierarchy by the country of origin. At the top of the hierarchy is Filipinos, followed by Indonesians, then Ethiopians, and Somalis are at the very bottom (de Regt, 2008). Asian women tend to be employed by the upper class and are more expensive than African women (de Regt, 2008). Having a domestic is a symbol of status in the Middle East, so lower and middle-class households work to ensure that they can afford a domestic. These conditions place the majority of Ethiopian women into middle class households that can afford one domestic, which they rely on to complete all domestic duties. This differs greatly from working in an upper class house with other domestics where tasks are allocated.

Several accounts of human rights abuses of domestic workers have been made in the Middle East (HRW, 2008; ILO, 2011; Mahdavi, 2011). One key challenge is that there is no record or official method to capture the statistics of the number of domestic workers experiencing challenges. One report found that in 2000, over 19,000 domestic workers fled their employers in Saudi Arabia (Chammartin, 2004). Vlieger notes that all embassies included in her study in the UAE and Saudi Arabia 
stated receiving multiple requests for help on a daily basis and safe houses were consistently overly full (2011).

Just over half of the women interviewed experienced at least one of the following forms of abuse: beatings, indentured labour, not receiving food, not receiving payment, sexual harassment, or verbal abuse. The most common forms of abuse were withholding food and withholding payment. One woman explained the food situation as follows:

“Our employer didn't give us food and because of that we were begging food from our Ethiopian friends and from Filipinos...Everything with our neighbours had to be done secretly. One day we were hungry and asked our woman employer to give us food and she told us to eat the wall. We then asked her to show us how to eat a wall..."

\section{- Participant 33}

In this situation two Ethiopian women worked in the household wherein the employer only gave them one cup of rice per day. The house had a backyard and the women were able to go into the backyard and speak over the fence to other domestic workers in neighbouring houses. The domestic workers in neighbouring houses put food in a bag and threw it to them over the fence. This was the only way the women could get food as the fridge was always kept locked in the household and they were forbidden to leave the house.

In five cases, the women worked for their employers for two years or more and never received a single payment from their employer. In this situation, the women were either eventually sent back by their employer, or they fled the household to the police and were placed in prison. In other cases, women had disputes with their employers regarding their payment and did not receive their full payment for all their work, however, did at least receive some funds.

Nine of the participants were in prison during their time abroad. As in the above situation, some of the women fled the houses they were in due to the abuse they were experiencing. Upon turning themselves into the police, they were arrested for violating their work permits. Their duration of stay in the prison in this case is usually short, recognizing that the woman has not done anything wrong. In another case a woman was taken by her employer to the airport and left there. Not having anywhere to go, she was picked up by the police and placed in prison. Eventually all women were deported to Ethiopia from the prisons.

The experiences of prison depended on the country of migration. For instance, one woman who was in prison in the UAE stated: 
"I was happier for the one month I was in jail, than the eight months I passed working. I passed good time in prison, I slept well in the prison and in general I have a good memory of the prison. The government is very nice to take care of all the prisoners, whether they are citizens or migrants."

\section{- Participant 44}

Other women that were in prison in countries such as: Bahrain, Qatar, and Saudi Arabia, also stated that they were happy to be in prison. They were given regular food and were not abused, thus the situation was better than their employment situation. For women imprisoned in countries such as Syria, however, the situation was very different. One participant described the prison in Syria as follows:

"There are many Ethiopian women there in Damascus in prison...They live in three rooms. The prison is very dirty and there are more than 200 women there in prison. There were instances where a woman was gang raped by five men. But they don't have any representatives/visitors [embassy support]...There are many problems. I wish there were things we could do to help."

- Participant 07

The prisons are one area where the difference in wealth between the Middle Eastern countries is highlighted. However, justice was not differentially achieved for women in the different countries. That is, there was no punishment to employers who did not pay the women or abused the women in any of the countries. Deportation from prison was one form of forced return experienced by the women, however, in many cases, they were relieved to be deported and return to Ethiopia. The case of the domestics in the Middle East is unique as they are unable to engage in decided return because their employers will not agree to return them, thus keeping them in a system of indentured labour. Their only option to return is therefore through deportation, which is thus preferable for them to the alternative of continuing work. This highlights another unique aspect of this migration flow.

Seeking recourse to abuse and human rights for domestic workers in the Middle East is highly unlikely within the Kafala system. Kafala ties a migrant to an employer and gives them no options for support or assistance in the event that the employer is abusive. Furthermore, the system empowers the employer who can recognize that there is no recourse for maltreatment of domestic workers. The situation is perhaps best articulated by Vlieger: "Under the best of circumstances a domestic worker in the United Arab Emirates or Saudi Arabia may be treated right, but she has no rights" (2011: 11). 
For domestics, return was thus a mixture of compelled and forced return; wherein the majority of domestics were engaged in compelled return. Forced return most commonly occurred as described above, when women found themselves in prison. Another form of forced return that did occur was when employers unilaterally made the decision for the woman to return to Ethiopia. One participant described their experience as follows:

"She [the employer] bought a ticket with my money and sent me back. I did not think of coming. I was planning to work if not for her, in another house after I finished my two years."

- Participant 12

This highlights that the woman wanted to stay and work, but was compelled into returning. Furthermore, the employer had her passport marked so that she could not return to the country of migration for a minimum of six months.

Approximately one quarter of the sample of domestic workers was engaged in a form of forced return. These women had no preparedness for return and minimal to no resources for return. Often, their families were not informed in advance of their return and they arrived at the airport with no resources. The migration episode was viewed as a failure. Furthermore, these women tended to return with a greater emotional burden due to the abuse they had experienced that negatively hindered their reintegration. This will be evidenced in their reintegration strategies in Chapter 7.

As stated previously, the majority of domestics were engaged in decided return that generally occurred at the end of the contract. There are two groups of domestic workers engaged in decided return, first being women that return due to their unhappiness in their situation in the Middle East. These women had some form of resources upon return, which would typically include some money and gifts for family. The amount of money taken upon return was generally small as these women were regularly remitting money to their families. This group had been able to maintain communications with their families at home while abroad, but had not engaged in temporary return as they had a shorter migration cycle. Their preparedness for return was thus low, and their migration experience was not necessarily a success or failure. In general, the initial expectations of the migration experience had not been achieved as these women were not able to 'change their lives' from their short episodes abroad. In addition, some of these women also returned with mental trauma due to the conditions of their work. The migration experience can thus not be classified as a success and the reintegration experience was generally found to be challenging. 
This situation juxtaposes that of the second group of domestic workers engaged in decided return that have been able to engage in temporary return visits, have acquired more substantial resources in the country of migration, and generally have a plan for reintegration. Of the six domestic workers that returned for a temporary return visit all were engaged in a longer-term contract (more than three years) with an employer abroad. The return visits thus occurred once every two to three years wherein the domestic returned for a period of two weeks to three months (generally one month) to visit with family and friends. During this visit the domestic was able to see the living conditions of their family, how the remittances they were sending were being used, and the changes occurring in Ethiopia. This trip proved very informative for the domestic workers to make decisions regarding their continued migration and/ or return. One interviewee stated as follows:

\begin{abstract}
“When I came here I saw that if you don't have money it would be difficult. If I didn't have money I realized I would be in the same position as before. I thought I would be better off there than here, so I went back."
\end{abstract}

\title{
- Participant 02
}

On the other hand, some domestic workers came back for a visit and due to familial pressure to stay decided not to return to work abroad. Overall, temporary return visits were informative for domestic workers in making decisions regarding their migration and return, maintaining contacts with family and friends in Ethiopia, and in understanding the current situation in Ethiopia and how they would live within such a context upon return. This significantly increased their preparedness for return for when they decided to permanently return.

Domestics have varying migration and return experiences, which lead to different reintegration experiences. On the whole, the majority of domestics are not able to achieve their migration goals and face more difficulties in the Middle East than they were expecting. Their return experiences are also more challenging than those of the students or professionals as they return with less preparedness and resources.

\section{The Importance of the Migration Cycle in Return and Reintegration}

The focus of this chapter has been on the returnees' experience in the country of migration and how this experience has impacted on their preparation for return, which affects their reintegration (as discussed in the next chapter). The two key elements of preparedness are the ability of returnees to mobilize resources for return and their willingness and readiness to return at that particular time. The ability of returnees to mobilize resources is dependent on their experiences in the country of 
migration, including the opportunities they have had for integration, acquiring skills, networks, and resources.

\section{Resource Mobilization}

It is evident that the professionals were the only group that integrated into the country of migration and simultaneously had the greatest opportunity to acquire resources including: networks, skills, and finances in the country of migration. This is due to their longer duration abroad, ability to work in the country of migration, and acquisition of citizenship. The acquisition of these resources allowed professionals to mobilize significant resources for their return. Although students were also able to gain valuable skills abroad, they were not permitted to work in the country of migration and were not permitted to stay in the country of migration legally beyond their student visa. Thus, although students could acquire skills, finances, and networks in the country of migration, this was to a lesser degree than the acquisition of professionals.

Domestics as a whole were able to acquire the least level of resources for return. 'Successful domestics' meaning those that stayed for a longer duration and engaged in a form of decided return were able to acquire financial resources for their return. The acquisition of financial resources allowed the returnee to build a home or start a business. For these women, this was the goal of migration and does represent a change to their quality of life by being able to have their own home or start their own business. At the time of interview, those that had started their own business were still in the initial start-up phase and had not been in operation long enough to know if the business would be successful. In addition to financial resources, successful domestics also acquire independence and fortitude during their migration. This is often cited by the domestics as important in their return as they are better equipped to deal with challenges and look after themselves then they were prior to their migration.

Unsuccessful domestics return to Ethiopia in situations of vulnerability. This includes having an interrupted migration cycle, experiencing high levels of trauma in the country of migration, and returning without resources. Some of these women return in debt, as they have not been able to pay their initial loans taken out for migration. This situation is very different than all of the other analytical groups in that upon return these women are often worse off than prior to migration either financially, mentally, or both.

\section{Readiness to Return}

In terms of preparedness for return, the majority of professionals, students, and successful domestics are ready for their return. Return is decided by the individual, they are willing to return, and have prepared for their return. 
For some of the professionals, this was not the case. In particular, for a handful of the married professionals they returned earlier than they were ready due to their husbands waiting for them in Ethiopia. For these women, it was stated that the initial months after return were very difficult, however over time they were able to adjust.

Virtually all of the students had a strong willingness to return. Their defined student visas meant that the students had been planning for their return at that particular time since the beginning of their migration and were willing and ready to return when that time came.

Successful domestics were also prepared for their return. They had chosen to return at that time on their own accord and were ready for the move. Domestics that were involved in a forced return were not ready for their return, although many wanted to return to Ethiopia to escape the bad situations they were in. For the remaining domestics, they were willing to return to Ethiopia, but had a low preparedness as they had not accomplished their migration goals.

\section{Summary}

This chapter has underscored that there are vast differences between the analytical groups in this study, which emphasizes the importance of the life cycle in migration and return and highlights the diversity of return migration to Ethiopia. This further emphasizes that as discussed in Chapter 2, return migrants are a heterogeneous group and discussing return migrants homogenously is miss-leading. Within the three analytical groups in this study this chapter has demonstrated that key differences exist amongst the returnees in terms of class, experiences abroad, opportunities for integration abroad, and resource mobilization and readiness to return, reflecting various levels of return preparedness. All of the factors are important in the reintegration process, which will be illustrated in the next chapter through an examination of how the analytical categories reintegrate in Ethiopia. 


\section{Chapter 6: Reintegration Dimensions of the Analytical Groups}

\section{Introduction}

Following from the previous chapter, which explored the life cycle of the analytical groups, this chapter will examine how the different analytical groups vary across the four dimensions of the reintegration strategies. The reintegration strategies define how an individual reintegrates based on the choices the individual makes across the dimensions. In establishing the reintegration strategies of return migrants, Chapter 2 discussed the four dimensions that characterize the reintegration strategies: cultural orientation, social networks, self-identification, and access to rights and institutions, as illustrated in Table 12. Each of the dimensions, viewed horizontally in Table 12, is important in assessing the reintegration strategy of the returnee.

Table 12: Typology of Reintegration Strategies

\begin{tabular}{|c|c|c|c|c|}
\hline & Reintegrated & Enclaves & Traditionalists & Vulnerable \\
\hline $\begin{array}{l}\text { Cultural } \\
\text { Orientation }\end{array}$ & $\begin{array}{l}\text { - value both the } \\
\text { culture of the } \\
\text { country of } \\
\text { migration and } \\
\text { country of origin/ } \\
\text { return }\end{array}$ & $\begin{array}{l}\text { - value the culture } \\
\text { of the country of } \\
\text { migration }\end{array}$ & $\begin{array}{l}\text { - value the culture } \\
\text { of the country of } \\
\text { origin/ return }\end{array}$ & $\begin{array}{l}\text { - rejection of } \\
\text { culture of country } \\
\text { of migration } \\
\text { - rejection from } \\
\text { dominant society } \\
\text { in country of } \\
\text { origin/return }\end{array}$ \\
\hline Social Network & $\begin{array}{l}\text { - locals, returnees } \\
\text { and cross-border } \\
\text { ties }\end{array}$ & $\begin{array}{l}\text { - returnees and } \\
\text { cross-border ties }\end{array}$ & - locals & $\begin{array}{l}\text { - ties to kin and } \\
\text { other vulnerable } \\
\text { groups }\end{array}$ \\
\hline Self-Identification & - transnational & - transnational & - unidirectional & - unidirectional \\
\hline $\begin{array}{l}\text { Access to Rights } \\
\text { and Institutions }\end{array}$ & $\begin{array}{l}\text { - limited or full } \\
\text { access to rights in } \\
\text { country of return } \\
\text { (depends on } \\
\text { citizenship choices) } \\
\text { - limited access to } \\
\text { key institutions in } \\
\text { country of return }\end{array}$ & $\begin{array}{l}\text { - limited access to } \\
\text { rights in country of } \\
\text { return } \\
\text { - limited access to } \\
\text { key institutions in } \\
\text { country of return }\end{array}$ & $\begin{array}{l}\text { - full access to } \\
\text { rights in country of } \\
\text { return } \\
\text { - full access to key } \\
\text { institutions in } \\
\text { country of return }\end{array}$ & $\begin{array}{l}\text { - full access to } \\
\text { rights in country of } \\
\text { return } \\
\text { - limited access to } \\
\text { institutions in } \\
\text { country of return }\end{array}$ \\
\hline
\end{tabular}

Following from the previous chapter, it is evident that the analytical groups have varying migration and return experiences and therefore it is assumed that the analytical groups' experiences will vary across these dimensions. The objective of this chapter is to show how/in what dimensions the analytical groups are differently reintegrated and how this impacts their lives upon return. This chapter then leads 
into the next chapter which discusses the reintegration strategies of the participants. The varying migration and return experiences led to large differences between the analytical groups on these elements, which thus determine their reintegration strategy.

\section{Cultural Orientation and Maintenance}

In returning to Chapter 2, cultural maintenance was defined as "the value systems of the return migrant and their orientation towards the values of the country of migration or the values of the country of origin/return". Cultural orientation is thus assessed within a range of the returnees decisions to adapt to the culture of the country of return, or to maintain the culture of the country of migration, as depicted in Figure 7. The top right corner represents the category of the reintegrated, the bottom right the enclaves, the top left the traditionalists, and the bottom left the vulnerable.

\section{Figure 7: Cultural Orientation Upon Return}

\section{Highly Values Culture of \\ Country of Return}

Culture of Country of

Migration

\section{Traditionalist:}

Values the culture

of the country of

return/ Rejects the

culture of the

country of

migration
Reintegrated:

Values both the

culture of the

country of

migration and

country of return
Rejects
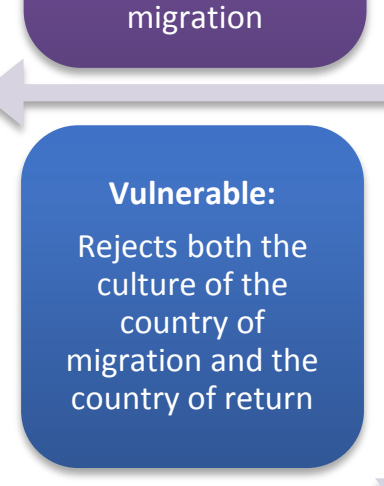

Highly Values Culture of Country of Migration

Rejects Culture of Country of Return 
The significance of cultural orientation in the individuals reintegration strategy is rooted in the argument that culture is an important determinant of behaviour (Berry, 1997). When an individual from one culture lives in another cultural context, and then returns to the original cultural context, do they bring new behaviours or not? What factors determine these behavioural changes or lack thereof? This section will assess these questions, highlighting that opportunities for integration in the country of migration, duration abroad, and individuals choices all impact their cultural orientation upon return.

\section{Professionals: Negotiation and Adaptation}

As described in Chapter 5, the professionals had lived in the country of migration for the longest duration of time and were well integrated into the culture of the country of migration. Expectedly, upon return, the professionals experience the greatest cultural gap between the country of migration and Ethiopia. In the case of Ethiopia this gap is also more acute than in comparison countries as it is a post-conflict country wherein the majority of professionals were cut-off from the country for over a decade. Upon return, professionals were thus generally more adapted to the culture of the country of migration, than the culture of Ethiopia.

Despite this gap, the majority of professionals valued both the culture of the country of migration and the culture of the country of return. Although, many of these women experienced some challenges with both cultures, they were able to view both cultures positively and highlighted some of the positive and negative elements of each. Key elements appreciated in Ethiopian culture were being able to have more time due to the assistance provided by having domestic staff, the generous nature of Ethiopian culture, and being close to family and friends. This is similar to findings in other studies of highly skilled return migrants to African countries (Ammassari, 2009). Key elements of the culture of the countries of migration that were maintained were professionalism and hard work, women's rights and position in society, and valuing equality of treatment, customer service and honesty.

One participant described her initial challenges in Ethiopia as follows:

“People in position hate to say 'I don't know' if they don't know something. Instead of telling me: 'I don't know this, I am sorry or I will ask, or I will do something' they will shove you aside. They make you think like you are mean. If you really want to know and if you sincerely want to know why they are doing that, it's because they want to make sure they know it all. Not knowing is like a sin in this society. I think that is what I was experiencing. And that part really damaged a lot of things for me. I had a couple of big investment projects that I was not able to do just because somebody 
in a position felt like he had, he didn't want to say 'I don't know' ... I am trying to forget, I guess, most of it."

- Participant 50

This was a common challenge that the professionals experienced in returning to Ethiopia that the way people communicate is different than what they were accustomed to in the country of migration. Other women described this as: "I don't know how to communicate even though I speak the language" (Participant 09). Returnees highlighted that they needed family or friends to assist them in learning how to interact with the government and bureaucracy in Ethiopia.

This challenge was also reflected in staffing. One woman described how she would interview people who told her they were fluent in English for front desk work at hotels, but it was quickly evident that they were not. Professional returnees found it frustrating that people would state they had competencies they did not possess in order to receive jobs.

At the same time as experiencing these challenges, the same woman as above highlighted some of the challenges experienced in the US and her appreciation for life in Ethiopia. One participant stated:

“The western life, it doesn't allow you to get out of yourself. The demand is too big. I mean, just to take care of your house, to cook, to take care of your kids, that takes the whole you. There is no way you can think about your neighbors; you can think about a nation, you can think about a city. You know, I work in Amhara Region with some fistula program ${ }^{5}$ and I travel and I do it voluntarily. There is no way I could have done that in America because life doesn't allow for someone to get out of themselves to do that. For that I am glad I am back."

- Participant 50

This quote highlights the appreciation for the culture of Ethiopia. The majority of professional women were able to value elements of the culture of Ethiopia that did not exist in the country of migration. This primarily included the ability to slow down, the valuing of social networks, friendships and family time, and the generosity and kindness within the culture. At the same time as these elements were strongly valued, it must be noted that at other times they were viewed as a burden.

\footnotetext{
${ }^{5}$ An obstetric fistula impacts women leading to permanent incontinence. According to The Fistula Foundation (2013) there are an estimated 100,000 women suffering from untreated fistulas in Ethiopia. They are commonly ostracized by their communities. Surgery can often repair the damage and allow women to return to a normal life.
} 
For instance, the social obligations of weddings and funerals for extended networks (not close relations) was at times viewed as cumbersome due to their frequency and the amount of time this takes from working life.

A minority of professional women only valued the culture of the country of migration and rejected the culture of Ethiopia. These women continued to struggle with the culture of Ethiopia, and although they appreciated elements of it, more commonly they reacted to it instead of embracing it. One participant stated her experience as follows:

\begin{abstract}
"So that was very difficult for me, people always blame. I think it is universal but I think in my culture in the States quite a lot of people take responsibility for their own actions. In this country people blame the government, they blame the weather, they blame God, they blame their upbringing, but at the same time they are very resilient people. With what little they have they manage to survive. They are very strong people but over time instead of frustration I came to a conclusion people do what they do because they don't really get help. So I am sympathizing and that happens, it gives you space to not be judgmental and really to understand why people do what they are doing and how to help them."
\end{abstract}

\title{
- Participant 41
}

This quote highlights how the participant views herself as relating to American culture and 'this country' as being foreign. It is evident that she has maintained the culture of the country of migration and has not reintegrated into the culture of Ethiopia. Simultaneously, she has developed coping mechanisms for being in Ethiopia to allow understanding for the people and not to bear judgment. This does not mean, however, that she herself adopts the culture, but has learned how to work proactively within it.

The professionals are thus placed in different sections on the cultural orientation spectrum. The majority fall into the category of valuing both the culture of migration and return, however, a minority fall into the category of valuing the culture of migration and rejecting the culture of return.

\section{Students}

The experiences abroad were formative to the majority of students reflecting that they highly valued the learning experiences of the culture in the country of migration. Upon return, elements of the culture of the country of migration were continued to be highly valued, as were elements of the culture of Ethiopia. Students valued both cultures upon return. One student described a key learning from the culture of migration that she brought with her in her return to Ethiopia: 


\begin{abstract}
"Actually the other thing that I learnt there is here in Ethiopia women are assigned in very low positions; maybe as a janitor cleaning or something like that. But when I go there [Europe] everybody is involved in this kind of activities [professional activities]. So women are involved in these kinds of activities and what came to my mind is if women can participate in the higher position development will come because these countries are very developed countries and women and men are participating equally, there is not any work totally given to women or to men. So this is the most important thing that I learned from there."
\end{abstract}

\title{
- Participant 25
}

The values of the culture of the country of migration, such as equality of women and men are brought back with the students in their return. In Addis Ababa women's rights are more advanced than in the rest of the country, however overall the society is still primarily patriarchal. Ethiopia is ranked as 173 of 186 countries in the UNDP gender inequality index, which reflects inequality between women and men reproductive health, empowerment and the labour market (UNDP, 2013).

In many cases, like the professionals, students underwent a negotiation process between the two cultures upon return wherein elements of the culture of return were rejected and renegotiated. One participant stated her experience of returning as follow:

"There were changes in the way you think, in the way you expect to arrive in your appointment place, in the way you put yourself that some things, for example in the way you know after being used to the way of life in Europe, you don't automatically accept the way of life in Ethiopia sometimes. For the first few months things were a bit strange"

\section{- Participant 46}

The above quote highlights that expectations of the culture of the country of return have changed due to the experiences of the culture of the country of migration.

Although the migration experience was much shorter in duration and did not allow for permanent integration opportunities, the migration experience has demonstrated to be highly formative in influencing the values of the students. The majority of students have chosen to maintain elements of the culture of migration which have included: gender equality, hard work, professionalism, and assertion. A key element that combines with the adoption of gender equality values is the behavioural difference this led to in many female students learning to assert their opinions. This will further be discussed in the next chapter. At the same time 
however, students maintained many of the values of the country of origin and were able to reintegrate fairly easily.

\section{Domestics: Freedom at Last}

Due to the lack of an opportunity for integration, there was a limited ability for domestics to first adapt to cultural elements of the country of migration and secondly to maintain elements of the culture of migration upon return. In addition, as domestics were in a subordinate position in the country of migration, the elements of the culture that they were able to see were often viewed negatively by the domestics. The experiences within the culture of the country of migration for domestics are limited to their employer and their employer's families. One participant stated:

"Arab countries change your thinking, in most cases you will never see good things there...You will understand that doing bad doesn't add value to your life and you will learn to be good in your life. You know, if my employer was good to me I would not have come back home. I didn't want to leave her kids, but she was not that kind. This gave me a lesson for being good."

\section{- Participant 45}

This quote highlights that for this participant behavourial changes occurring from her migration are in reaction to the employer in the country of migration. From her negative experience with the employer, she understandably extrapolates these experiences to reflect the culture of Arab countries. In this case, the reaction led to a further desire to be a good person in Ethiopia, however, for many domestics the resulting negative experience from the migration led to stress, unease, and overall negative reactions.

Considering the experiences of the domestics as servants in the Middle East, it is not surprising that upon return they value the culture of Ethiopia and reject the culture of the country of migration. As stated in Chapter 5, most commonly domestics were relieved to return to Ethiopia and embraced the Ethiopian way of life upon return. For the domestics return to their culture meant that they were able to express themselves freely, have freedom of movement, and engage in regular behaviours.

Within the sample there were some anomalies of participants that did feel they partially integrated into the life of the culture of migration and adopted behaviours they would not express in Ethiopia. One participant stated:

"When we adapted to the lifestyle of Dubai, we began to behave like Dubai people and at that time we used to make huge expenses for 
different items. It was difficult at that time to imagine that we are migrants, because the expenditures we were making were so crazy. This of course was not good for us, but if you have to live abroad, you have to behave like the native people and you think yourself as a native; not as migrants."

\section{- Participant 71}

However, upon return, the cultural orientation of this participant did not change. Upon return, the participant valued the culture of Ethiopia, and as is reflected in the quote, recognized that the adaptation to the consumer culture in Dubai was not positive, thus rejecting the culture of the country of migration upon return.

\section{Overview}

Patterns of cultural maintenance differ not only between the three analytical groups but also within the groups. The primary factor that influences cultural maintenance is the opportunities for integration in the country of migration. Both professionals and students were able to integrate in the country of migration, and therefore returned valuing elements of that culture, whereas domestics had no opportunities for integration and returned as traditionalists. The duration of time abroad and individual's choices also affects the cultural maintenance. The students, who were abroad for a shorter period of time, did not have lasting challenges with reintegration. Some of the professionals, on the other hand, that were abroad for much longer rejected the culture of the country of origin upon return. This is significant because opportunities and the ability for integration impact upon a returnees' ability to influence social change, as will be discussed in Chapter 8 .

\section{Social Networks}

Social networks reflect the type of network of the return migrant: if it is comprised of returnees, locals, cross-border networks or a combination of the three groups. The network of the return migrant will determine the access to resources and social capital that the network can provide. As described in Chapter 2, not only is the type of network important, but also the strength of the network ties. Reintegration is therefore impacted by the type and strength of the returnees' network.

\section{Professionals}

Upon return, professionals had diverse networks that generally consisted of family members in Ethiopia, other returnees in Ethiopia, and family members and friends in the country of migration. For the most part, professionals were in a position of power upon return due to their education and/ or status. Due to their high status within the hierarchy of Ethiopian society and their international connections, professionals had wider access to both bonding and bridging social capital that 
included: Ethiopian elite, returnees, expatriates, and other professionals. This is a large contrast to the students and domestics who do not have social capital to access resources from positions of power.

Professionals had the resources to increase their bonding social capital through memberships in homogenous groups. This included organisations such as the Chamber of Commerce, Ethiopian Women in Business, Women Entrepreneurs Group, and other international groups such as the American Chamber of Commerce. Professionals that were business owners were invited by the Chamber of Commerce to attend events targeted towards business owners. Access to these types of organisations allowed professionals to develop further networks with individuals of a similar status and to further their bonding social capital. This could lead to important information such as for exporting goods and other business development opportunities.

Membership in these forms of groups was exclusive. Several of the professionals that were involved stated that they did not need anything from these groups, but thought it was important to help others. Underlying this participation was also most likely a piece of recognition of the social returns involved in participation in these networks. That is, the recognition of status and power associated with membership in these elite organisations.

Others were more open about the returns that they received from their network membership. For instance, one participant below states her expected benefits from participation in a women's entrepreneur group:

"I expect a lot from it, but at the moment what I am getting is networking. You know, I am part of a group that is like an interim board trying to get it going. Partly because I believe it's good to do some kind of service, it is good. I don't have much time, I don't give that much but I believe in the principle of it. Second, I expect to network with other women entrepreneurs. Things that I would never know, information that I would never get I might get through that, because if I am sitting here in a closed gate I won't get the information. But if you are networking then you know if there are buyers coming from outside, who is doing what you know; you can network and help each other out. And the USAID also, in some ways, because the US ambassador started it there, so they are sort of like right along beside us, so I think it's good to be connected.

- Participant 36

Through this quote it is evident that the woman recognizes the importance of access to information for the success of her business. She therefore participates not only because she believes it is the right thing to do, but because she recognizes the 
economic and social instrumental returns that can be achieved through participation in the network and the social returns that can be provided through connections with USAID. Membership in this form of network provides access to important resources for the acquisition of economic, social, and positional power.

Although all professionals had access to the above networks, not all professionals opted to join these forms of networks. Some were highly involved in organisations and others did not feel that they had the time for these forms of organisations. Those that were involved also tended to be professionals with wider networks that spanned locals, returnees, and transnational ties, thus being in the reintegrated analytical group. Individuals, who were not involved, tended to have more closed networks comprising primarily of other returnees and transnational ties.

Several of the professionals' networks were primarily comprised of other returnees with limited interactions with locals. One returnee explained the situation as "I mean we have fun with the returnees more because the value systems are clearer" (Participant 48). This was furthered by another participant stating:

"Most of them [in the network] are people who have returned. Even if they did not live there, at least they travel for business, they have the exposure, but I can't have an acquaintance with someone who didn't travel internationally."

\section{- Participant 54}

This quote highlights that it is not important if the individual is a returnee or not, but as stated in the previous quote the values system of the individual is essential for creating network connections. Returnees value an international understanding within their networks. This finding is similar to other cases of returnees, such as Stefansson (2004) found with returnees to Bosnia and Herzegovina wherein returnees preferred to network together as they could discuss common identity aspects of life in exile and reintegration challenges. A key difference however, is that returnees to Bosnia and Herzegovina faced high levels of animosity from the local population. This is somewhat true for professionals in Ethiopia as there is some animosity towards diaspora; however, it is not necessarily to the same degree as Stefansson indicates existed in Bosnia and Herzegovina.

Professionals operating within returnee networks are members of exclusive networks that bar access to others that do not possess the characteristics of this group. The networks are therefore more inwards looking and lack the access to bridging social capital that other professionals gain through their wider networks. At the same time, however, professionals operating within return networks run successful businesses and do not need further resources. They openly state that they limit their social interactions as they do not have time for social activities due to their 
busy work schedule from their business. Therefore, perhaps their inward looking networks are due to the fact that they do not have a need for further resource acquisition.

A final element that distinguishes between the types of a professional's returnee network is the amount of effort put into expanding the network. As one returnee explained:

\begin{abstract}
"at the beginning you know you end up sticking with the Diaspora because you know somebody in [the country of migration] when you go out with them the next person they know is also somebody who has been overseas so you end up going out with them.... but now I am starting to have [local] friends, but at the beginning I didn't. So, now I like it...I have now more Diaspora friends than those who never left, but it's on the rise so I like it."
\end{abstract}

\title{
- Participant 51
}

This quote highlights that it is easier for the returnees to network within their own group and that they are not necessarily against creating relationships with locals. Thus, in this case the returnee's network was a network of convenience and not necessarily intended to be exclusive to other groups. It also stresses that establishing relationships beyond the central network requires a concerted effort.

Finally, all of the professionals had access to a transnational network that provided them with support for the challenges that they faced in Ethiopia. This transnational network was a vital element of everyday life and provided information and access to the globalized world.

Professionals networks varied along the continuum of reintegrated and enclavist. Reintegrated professionals valued their diverse networks and connections with locals as being enriching in their lives, providing access to economic and social returns, and providing expressive returns in terms of life satisfaction. For instance, for professionals that were highly engaged in charitable networks this provided them with feelings of life enrichment. For the professionals that were engaged in enclavist networks they tended to prefer to congregate with individuals of similar values reflecting the 'like-me' hypothesis. Professionals in enclavist networks did operate successful businesses and did not feel a need for gaining further economic and social resources through network membership. They had life satisfaction and this was furthered by participation in homophily based networks.

The variation in network membership amongst the professionals reflects the different needs and choices of the professionals in their reintegration strategies. Many of the enclavists choose for the closed network as this is what is comfortable and rewarding for them. The reintegrated, on the other hand, choose for wider 
networks that provide them with satisfaction. Network membership and reintegration for the professionals is therefore highly influenced by choice as all professionals had access to multiple networks but through their agency their membership is determined.

\section{Students}

The majority of students networks were primarily based in Ethiopia. A few of the students had strong transnational connections, however, these were generally not from their study abroad, but from strong connections in Ethiopia going abroad, such as friends and family. These transnational ties were thus strong connections with regular maintenance. From the migration experience all of the students cited maintaining ties with friends that they made abroad, but the majority maintained a weak connection with transnational tie maintenance primarily occurring over facebook and an occasional email. Students had also made professional contacts abroad, such as with professors, however these were often not maintained unless the student was still engaged in joint work with the professor. The majority of students stated that their networks from their migration could provide access to resources such as information. In addition, these networks could be substantial in the case of professional references. In terms of being able to rely on these networks in a situation of need, there was more uncertainty from the students as to if this would be possible.

Students' networks in Ethiopia tended to be diverse including connections to other returnees and locals. None of the students were engaged in enclavist networks, reflecting their shorter duration abroad and maintenance of ties with connections in Ethiopia while abroad. Returnee connections in Ethiopia were primarily with other students that had studied abroad. This included both individuals met while in the country of migration that had returned and previous connections that had also went abroad and returned. Students had strong bonding social capital within these networks in that the ties were strong enough that they could provide access to emotional and financial resources in times of need.

Through the acquisition of education, the students have gained an important resource for their return. Their educational status allows them to advance in the social hierarchy in Ethiopia, which can provide membership to new groups such as professional organisations, alumni organisations and clubs such as the Rotary club. These organisations can be quite useful to the students in terms of bridging social capital that can assist in gaining access to further resources. One student described the benefits of being involved in a professional organisation as follows:

"It gives me a lot, I mean because when you are there you will be attending [a lot of] research work. So that will give you a better understanding of the situation that the research was done, and it will 
even help you to identify the gap that some of the researchers have not even dealt with regarding Ethiopia. So you will be motivated to fill that gap in your research activity and you will be sharing a lot of information about what is really going on in rural Ethiopia, specifically in different regions. The other one is you will have some networks with some professors and doctors who are working there, which are better ones than us [laughs]."

\section{- Participant 27}

This student recognizes the importance of network membership in furthering her work and providing access to esteemed colleagues within her field. This form of membership thus provides primarily social returns in terms of reputation and status, but could lead to instrumental returns if the network provides access to information for economic or social gains.

One student's participation in the Rotary Club provides an example of how the resources gained through education provide for returns. One must be invited, or apply, to become a Rotarian. Membership is therefore exclusive to certain individuals. The objective of Rotary is to "develop and foster the ideal of service as a basis of worthy enterprise" (Rotary, 2013). Through having a Master's degree and a professional job, the students have resources to contribute to organisations such as Rotary. Individual identity attributes are also of course significant in this selection, however, the acquisition of education and professional employment is an instrumental precursor to membership. One participant described the impact of their membership in rotary on themselves as:

"I see very ambitious people and the way people are thinking is changing. So I am really happy and I am really optimistic about making the change and making this country very, you know, a very comfortable place to live. So, I am very optimistic. I am happy I see so many changes, so many developments, so many things that are being done."

\section{- Participant 34}

For this participant rotary provided an opportunity to network and engage with other like-minded people. It is also a status symbol to be involved in such an organisation.

Several students were also involved in religious based organisations such as church groups. These groups provided important connections for life satisfaction and could also provide instrumental returns if necessary. One participant described her membership as follows: 
"It's more like having a second family. It's not like an association or a group I am involved in; it's something that is like a relative that is really deep down inside of me...But the thing is the value that it has in all the members' hearts is not as an association. So if someone is broke and need money whoever is there will help out."

\section{- Participant 22}

This quote illustrates the strength of the network membership and the resources that could be provided from the network if needed. Finally, many students were also involved in charitable organisations. Membership in these organisations primarily provided for life satisfaction returns.

Students that did not have membership in organisations cited reasons such as not having an interest or a need for membership. There were no striking differences observed between students having active membership in organisations and those that did not.

Overall, within the reintegration strategies framework, the students in general had networks that were primarily based in Ethiopia and included both returnees (primarily other students) and locals. The networks of the students illustrated a traditionalist/ reintegrated orientation. The strategy includes reintegration because of the returnee and weak transnational networks; however, is primarily traditionalist as the strength of the student's networks is predominantly oriented towards local connections. These local networks were strong and for students involved in associations offered more opportunities for bridging social capital.

\section{Domestics}

Upon return domestics' networks were mainly based in Ethiopia and comprised predominately locals and some other returnees. Similarly to the students, other returnees primarily included friends or family that had also migrated as domestics and returned. There were a few instances of domestics maintaining connections upon return with women they had met in the country of migration; but this was less common. In two cases, however, the connections made in the country of migration provided formative relationships that were essential modes of support in return.

The majority of domestics cut all ties with the country of migration upon return. Few domestic workers maintained contact with other domestic workers they had met in the country of migration (that were still abroad), or with their employer or employer's children. The most significant form of contact is phone calls made to other Ethiopian domestic workers that are either family or friends working in the country of migration. These are made on a less regular basis due primarily to cost, and are made in anticipation of an eventual return of the individual. Thus, these are not long-term transnational networks. 
Particularly in the case that a domestic worker had been with an employer a long time (over three years) and had a positive relationship with the employer, the employer would call them to see how they were doing or asking them to return. For instance, one participant stated: "They [the employers] are calling me for two years. They called me last week from abroad to go back, but I am not willing to migrate again" (Participant 02). This communication, however, appears to be a one-sided communication at the maintenance of the employer and not the returnee. The women do not feel that they could rely on the employer in a time of need and thus the transnational network ties are too weak to provide resources to the returnees.

Upon return, domestics did engage in networks with other returnees. This was not a formal type of network membership, but was significant in providing support to returnees. A non-governmental organisation in Addis Ababa offered a training programme for domestic returnees. The participants that were involved in the training found that it was useful to connect with other returnees that had experienced similar situations to them while abroad. Other individuals that did not have such an opportunity to meet returnees often had friends that had been abroad, which they engaged with upon return. Within these return networks participants expressed that they would sometimes speak in Arabic so as to not lose the language and provided support to each other regarding the situations they have been through. In Ethiopia it was not culturally acceptable for domestics to discuss the abuse they had experienced abroad. Return networks allowed them an acceptable space to discuss these issues.

Approximately one quarter of domestics had active membership in an organisation, which is far less than the professionals or students. These were primarily church based organisations, the local edir-informal savings organisationkebele organisations or other forms of micro-finance groups. Domestics stated that participation in the church based organisations gave them fulfillment, illustrating expressive returns of life satisfaction. Participants stated that these networks could also be relied on in times of need, suggesting instrumental social and economic returns as well. Participation in edir provides a small piece of financial security as if one is in need they can ask the savings association to receive the money that month to address their needs. It also provides for social connections to other members in the community and illustrates a form of engagement. This is similar to participation in kebele associations and other micro-finance groups. These networks are not socially based in that they provide emotional support, but they can provide access to information sources.

Overall, domestics were the least networked of the three groups. This reflects, in part, a class based difference as domestics had the least opportunity to join associations. Many of the participants were not involved in organisations such as edir as other women in their households (such as their mother or sisters) were 
participating for their household. It is obvious, of course, that the domestics also did not have the opportunity to join professional and business organisations which comprise the primary membership for the professionals and students.

Upon return, domestics primarily returned to their networks prior to migration. These networks had commonly decreased in membership due to the migration episode. Primarily they comprised close family and in some cases neighbors and friends. Domestics also had the weakest networks upon return in terms of bridging social capital with limited connections beyond their peers. This lack of access to information and opportunities is reflected in part in elements such as the high unemployment rate of domestics.

\section{Overview}

Networks are essential in providing support and access to resources for returnees, which can assist in their reintegration. Many of the professionals recognize the importance of networks and are highly involved in professional organisations that provide access to information for their businesses. The professionals also have the most extensive transnational networks, reflecting their longer duration abroad, that could be relied upon in times of need. Students are also well networked upon return, having access to diverse networks of other returnees and locals. Students transnational networks are weaker than professionals, but still do exist and can provide access to information or other resources. Domestics networks are the weakest of the three groups, providing limited access to bridging social capital and resources.

It is noteworthy that the networks vary along class divisions with the professionals being the highest class and having the widest networks and the domestics being the lowest class and having the weakest networks. This reflects homophily in social network theory. The distinctions between the three groups can be characterized as status homophily, in which differences between age, education, and occupation (among other demographic characteristics) separate the three groups (Lazarsfeld and Merton, 1954). This is reflective of the social stratification that is prevalent in Ethiopia. On the other hand, this is different from variations within the analytical groups, such as for the professionals wherein value homophily differentiates the professional's networks as being focused on other returnees or including locals as well (Lazarsfeld and Merton, 1954).

Overall, access to social networks and strength of network connections vary greatly between the three groups. The impact of this on the reintegration strategies will be discussed in the next chapter.

\section{Self- Identification}

Self-identification is the returnees' subjective view and self-definition of their own identity. Return migrants can identify themselves as one of the following: 
unidirectional orientation towards the country of origin/ return, unidirectional orientation towards the country of migration, or a transnational bidirectional orientation towards both the country of migration and origin/ return. Senses of belonging can overlap and individuals can have multiple affiliations at any one point in time. Transnational ways of belonging refer to social relations and practices that individuals engage in across national borders and that individuals simultaneously highlight as a key part of who they are and their identity (Levitt and Glick Schiller, 2004).

Social networks form a central part of an individuals' identity, sense of self and notions of belonging. Lin (1999) states:

\begin{abstract}
"Social relations are expected to reinforce identity and recognition. Being assured and recognized of one's worthiness as an individual and a member of a social group sharing similar interests and resources not only provides emotional support but also public acknowledgment of one's claim to certain resources. These reinforcements are essential for the maintenance of mental health and the entitlement to resources." (31)
\end{abstract}

The maintenance of networks in the country of migration is a key component in maintaining the individuals transnational or bidirectional self-orientation. Furthermore, being recognized and feeling a part of a group in the country of return is central to developing a sense of belonging and further identification with the country of return.

It is essential to note that identities are not fixed, they are static entities constantly being re-and de- constructed (Madsen and van Naerssen, 2003). Feelings of belonging and if the return migrant feels a part of the society in the country of return has a fundamental impact on their reintegration strategy. As illustrated in transnationalism, senses of belonging can overlap and the notion of 'home' can have multiple meanings to an individual. This section will discuss how the analytical groups perceived their self-identification.

\title{
Professionals
}

Feelings of identity and belonging were most complex for the professionals as they had integrated abroad and developed new notions of belonging whilst in the country of migration. As also discussed in the section on cultural orientation, the professionals experience the greatest culture clashes in return, thus, it is arguably more difficult for the professionals to establish feelings of belonging upon return. In light of this situation, it is not surprising that the majority of professionals had a transnational bidirectional orientation towards both the country of migration and the country of origin/return. The primary allegiance was not always universal, with 
some women considering themselves Ethiopian first and American (as an example) second, or vice versa. In essence, however, the majority of professionals recognized a dual belonging and adaptability to two homes, which both contributed to their identity and notions of self.

Beyond a transnational way of being, professionals exhibited a transnational way of belonging by explicitly recognizing that their everyday social networks and practices span borders as a regular feature of everyday life (Levitt and Glick Schiller, 2004). Glick Schiller, Calgar, and Karagiannis (2003) propose that dual-identification is furthered if dual connections are grounded in the nation-state institutions, thus going beyond social acquaintances. The majority of professionals had foreign citizenship and a Yellow Card identity card in Ethiopia, thus demonstrating regular engagement between two nation state systems. The dual identity can be described as a pendulum for the professionals, swinging between the different identities depending on their daily interactions and experiences. One participant stated this by responding to the question if she has a notion of belonging in Ethiopia as: "Some days I do, some days I don't, depending on the day" (Participant 36). This was furthered by her pondering notions of home, identity and belonging and making a conscious choice to choose:

"I think more Ethiopia, we have settled in here. We have built a home since you know initially we were renting but now we built a home and we are saying okay. But we were meant to be back here and we are back here. [Country of migration] is always ours, but we were meant to be here. Let's make it work, let's make it last, let's make it real."

\section{- Participant 36}

This quote reflects the conscious effort that goes into decisions of home, identity, and belonging. This participant identifies herself as firstly Ethiopian and secondly the country of migration, but both countries remain to be important in her identity.

A few of the professionals suffered from a feeling of loss of identity, commonly highlighted in the migration literature as a loss of feelings of belonging and home. One participant stated:

"I think maybe I don't have any....I think I am lost I am not completely part of that culture [country of migration]... and here after several years I came back and my generation is somewhere, but I don't know where they are, and people changed and I don't' feel like I belong here either so...."

- Participant 37 
This quote highlights how the migration and return experience has led to a loss of identity, more so than a dual identity. This participant experiences a very different notion of identity than the following participant that feels well integrated to both cultures:

"For me, home is Ethiopia, but you would be surprised...I'm as American as you can make me. I go wherever it is, pick up my car, and I'll be on the highway, just as I did, you know, last year or the year before. I travel at least once a year, as I told you. I'm very independent and I fit in perfectly when I go there [country of migration]. And then all the hardship that I had when I was here, fitting in, I fit in beautifully now. I think I carry both cultures very well."

\section{- Participant 60}

Overall, the majority of professionals feel a bidirectional sense of belonging, as identified by the participant above. Within this bidirectional self-identification however several iterations are discussed as noted above with notions of belonging being stronger in one direction or the other for different participants. This impact of these different iterations will be clarified in the next chapter on reintegration strategies, wherein it will be demonstrated that women with stronger attachments to the country of migration are often enclavists. Women that have a more balanced bidirectional self-identification are more likely to be reintegrated. Self-identification is thus a key element in determining the reintegration strategies.

\section{Students}

The short duration abroad and the lack of formal integration into the country of migration meant that students did not undergo an adaptation of identity and belonging to a new country during their migration. Therefore, it is anticipated that for the most part, the students had a unidirectional self-identification to Ethiopia. For many, the country of migration was seen as a significant influence in their lives and as a piece of a second home, but this connection was much weaker than for the professionals. The student's networks and institutional connection to the country of migration was not as enduring as it was for the professionals, influencing their notions of self-identification. Simultaneously, several students noted that they did not feel as strong of a connection to Ethiopia and in a small number of cases; students felt that they belonged more in the country of migration. Despite this dual belonging, the students still identified with being Ethiopian.

The weakening of the Ethiopian identity for the students highlights the impact of migration upon their notions of self. Primarily the students still see 
themselves as Ethiopia, but recognize that they themselves have been changed by the migration experience and this influences their interactions and sense of belonging with Ethiopian culture. One participant described this shift as:

“(I) Do you feel a part of Ethiopian society now?

(P) 70 per cent yes. 30 per cent no. not really

(I) What are the things that make it 'not really'?

(P) Because as we talked before, their way of thinking and their culture. Sometimes it's' a bit much. I don't agree with them. Sometimes I feel very distant but at the same time, I feel very connected to them as well."

\section{- Participant 21}

These shifting notions of identity are fluid and are not easily made concrete. It is important to highlight that many students felt these notions as they sought to (re)express their changed identity upon their return.

\section{Domestics}

Finally, the domestics had a unidirectional self-identification to Ethiopia. As discussed previously, the lack of integration opportunities and negative experiences in the countries of migration led to an inability to relate to the country of migration, and thus a dual identity was never poised to develop. Identity in terms of ethnicity and belonging was never contested within this group. The majority of domestics therefore felt a strong sense of belonging in their return to Ethiopia; "I feel as if I am a member of the Ethiopian society. If I don't isolate myself I feel good love from them" (Participant 02).

The challenges of identity experienced by the domestics were not related to notions of cultural belonging in Ethiopia, but questions of self-esteem for those that had suffered in their migration. For this group, self-identification was less about cultural notions and more about not feeling that they belonged anywhere at that time. This will be further discussed in the next chapter in identifying the vulnerable reintegration strategy.

\section{Overview}

Self-identification is an important dimension in the reintegration strategy as it reflects the degree to which to returnees feel that they belong in Ethiopian society. In this study, the majority of professionals, students, and domestics identified that they felt a sense of belonging in Ethiopia. For many of the professionals this included a bidirectional sense of belonging as they also felt belonging in the country of migration. Some of the professionals and some of the domestics identified that they did not feel a sense of belonging, which was cultural for the professionals and a sign 
of vulnerability for the domestics. This lack of feeling of belonging hinders reintegration and is fundamental in assessing reintegration strategies of the returnees, as shown in Chapter 7.

\section{Access to Rights, Institutions, and the Labour Market}

The final dimension is the access to rights and institutions in the country of return that are available to the return migrant. This includes the position and statuses that the return migrant can achieve in institutions such as the labour market, citizenship rights, political institutions, housing rights, and within the education system (Heckmann, 2001). It is understandable that these structural components are essential in the reintegration process as returnees require employment, housing, and citizenship rights to live productively in society.

\section{Professionals}

The professionals return as highly skilled migrants and diaspora, which grants them a high level of status and access to rights and institutions. The Ethiopian government has been active to encourage the diaspora to establish businesses in Ethiopia, thus they are welcomed to the entrepreneurial labour market. As shown in the previous chapter nearly all of the professionals were entrepreneurs and a few participants had been attracted back to Ethiopia by specific initiatives of the government that offered incentives for diaspora investors.

The majority of professionals had acquired foreign citizenship. This meant that the majority possessed the Ethiopian "Yellow Card" allowing them several rights in Ethiopia, but not citizenship rights as Ethiopia does not recognize dual citizenship. As per the Yellow Card, professionals were thus not allowed to vote in Ethiopia nor run for political office. Political participation of the professionals was therefore limited.

Although the formal rights of professionals are slightly limited by their lack of citizenship, due to their position and status upon return they have the widest access to institutions of the three analytical groups. The professionals engage with a wide variety of actors including the senior level government officials, international organisations (such as the World Bank and UN Organisations), professional associations and other business professionals in Ethiopia. Their position as returning elite enables them to have the greatest access to resources upon return.

\section{Students}

Upon return the students have acquired resources (their education) to gain status in Ethiopia, which can lead to positions of greater prestige than they were able to access before. Overall, the majority of students were employed at the time of interview $(89 \%)$ with the majority in employment positions $(72 \%)$. Most of the students were satisfied with their current occupations and for several students they felt that their 
master's degree enabled them to be in their current positions. At the same time however, some of the students do return to their previous positions. This is either because this institution funded their masters and they now are in servitude to the organisation or they were able to take a leave from their previous positions. Students who returned to their previous position stated that they were given greater respect from colleagues for having studies abroad; however, fundamentally their job roles remained the same as prior to migration.

The students have Ethiopian citizenship and remain to have all rights of citizens in the country. Virtually all of the students were not involved in politics in Ethiopia. Although they had the right to vote, many do not vote in the country and do not engage in the political sphere. More important than politics is the ability to access institutions within the country. The gaining of a Masters degree enabled them more prestige within professional associations, however, they were still considered junior as these associations are primarily dominated by older professionals.

\section{Domestics}

Although the domestics had full rights of citizenship they had limited access to rights, institutions, and the labour market upon their return to Ethiopia due to their lower social class. This is evidenced by the fact that only 39 per cent of domestics were employed at the time of interview, and several of the employed domestics were underemployed. The primary occupations of employed domestics were either as a waitress or sales person. Those with a job were fortunate to find employment in Addis Ababa; however, their employment was generally barely enough to meet their daily needs. The average salary of the employed domestics was 602 Ethiopian Birr (USD 35) per month. Due to the lack of labour market integration, many domestics were dependent on family for meeting their needs:

"I did not get anything good now in fact it is worse because I do not work I came here and still am dependent on my family. I am not good on thing."

- $\quad$ Participant 14

Family support networks primarily provide housing to returning domestic workers.

As also illustrated in Chapter 5 the majority of the domestics did not have secondary education. Many of the domestics dream to be able to study upon their return, however, this is clearly not realistic. A few of the participants in this study were able to receive training through an NGO, but this was for cooking or sewing. The domestics thus are not able to access further educational opportunities due to lack of funds, grades, and social status. 
As a group the domestics were not engaged in politics in Ethiopia. This is not surprising, however, as political apathy is common in Ethiopia due to a lack of tolerance for political opposition.

\section{Overview}

Despite being the only group to not have full citizenship, professionals have the greatest access to rights and institutions in Ethiopia due to their social status. The professionals and students have significantly higher labour market integration than the domestics, which also reflects migration motivations as the domestics are the only labour migration group of the three (emigrating because of a lack of employment opportunities). Of the three groups professionals are the most likely to be able to access rights and institutions within the government, due to their social status.

\section{Summary}

This chapter has illustrated that not only are the three analytical groups reintegrated differently across the dimensions, but that there is also sizeable variance within the analytical groups across the dimensions. On the whole, professionals have a dual cultural orientation, wide and strong social networks, bidirectional self-identification and a high level of access to rights and institutions. The majority of professionals are economically and socially reintegrated, with a segment of professionals choosing to reject the culture of Ethiopia and focusing on enclavist networks of returnees.

The students also value both cultures; have diverse social networks with primarily weak transnational ties, a unidirectional self-identification and access to rights and institutions in Ethiopia. For the most part they are effectively reintegrated; however lack the social status of the professionals.

Finally, the domestics have unidirectional cultural orientation towards Ethiopia, local social networks, unidirectional self-identification and limited access to rights and institutions in Ethiopia. The majority of domestics are not economically reintegrated and a minority struggle with social exclusion. Of the three groups, the domestics are the most at risk upon return, and one manifestation of this is that many seek to re-migrate.

The analysis of the reintegration dimensions highlights the importance of the following three characteristics: 1) class and one's position prior to migration, 2) opportunities for integration in the country of migration 3) the migrants' agency and choices upon return. In regards to class, migration from Ethiopia has not demonstrated upwards mobility for student or domestic returnees. The position from which they migrate is the position from which they return. In certain cases migration can lead to upwards mobility, but this has not been demonstrated in this study. 
In regards to the second point, opportunities for integration have an impact on the reintegration dimensions. The ability to integrate abroad is fundamental to adapting to the values of the country of migration and bringing these in return for a bidirectional cultural orientation. As domestics did not have the opportunity to integrate abroad, they had limited abilities to bring back elements of the culture of migration.

Thirdly, the dimensions have illustrated that returnees, especially the professionals and students, make choices regarding their reintegration, particularly in regards to their cultural orientation, social networks and self-identification. Returnees can choose to interact with locals or only other return migrantss, which impacts upon the ways in which they are reintegrated.

From these dimensions, the next chapter will assess the reintegration strategies of each individual participant. It will be evident that the analytical groups are divided across the different reintegration strategies. 


\section{Chapter 7: Reintegration Strategies of Female Return Migrants to Ethiopia}

\section{Introduction}

Having developed an understanding of how the analytical groups are reintegrated across the dimensions of the reintegration strategies in the previous chapter, this chapter moves to discuss the reintegration strategies themselves. The analysis highlights how different forms of reintegration across the dimensions affect the returnees overall reintegration strategy. In following up from the previous chapter, the reintegration strategies also illustrate how the choices the return migrants make affect their overall reintegration. The objective of this chapter is to examine different reintegration strategies. That is, this chapter assesses how the return migrants reintegrate within the typology of the reintegration strategies. Furthermore, this section considers how the analytical groups fit within the model of the reintegration strategies and assesses if there is a difference between the theoretical categories and the analysis of the participants. This section emphasizes variations within the reintegration strategies and inferences that can be made regarding each reintegration strategy as a whole. This chapter will discuss each of the four reintegration strategies, followed by a discussion of how returnees can move between the reintegration strategies and finally an overall analysis.

\section{Reintegration Strategies}

From the previous chapter, it is evident that the dimensions of the reintegration strategies of professionals, students, and domestics highly differ. Table 13, from Chapter 2, provides an overview of the reintegration strategies and the dimensions. Table 13 shows the anticipated return migrant background in each dimension and how the return migrant in each strategy is expected to be reintegrated on each dimension.

Following from Table 12 and stated in the introduction, the following three hypotheses were put forth regarding the reintegration strategies application to the analytical groups:

1) Professionals would fit within the reintegrated or enclavist strategies

2) Students would fit within the traditionalist category

3) Domestics would fit within the traditionalist or vulnerable category 
Table 13: Typology of Reintegration Strategies

\begin{tabular}{|c|c|c|c|c|}
\hline & Reintegrated & Enclaves & Traditionalists & Vulnerable \\
\hline $\begin{array}{l}\text { Return } \\
\text { Migrant }\end{array}$ & $\begin{array}{l}\text {-abroad for longer } \\
\text { duration } \\
\text { - decided return } \\
\text { - high return } \\
\text { preparedness } \\
\text { - economic } \\
\text { success }\end{array}$ & $\begin{array}{l}\text {-abroad for } \\
\text { longer } \\
\text { duration } \\
\text { - decided } \\
\text { return } \\
\text { - high return } \\
\text { preparedness } \\
\text { - economic } \\
\text { success }\end{array}$ & $\begin{array}{l}\text { - abroad for } \\
\text { shorter } \\
\text { duration } \\
\text { - decided } \\
\text { return } \\
\text { - medium } \\
\text { preparedness } \\
\text { - economic } \\
\text { stability }\end{array}$ & $\begin{array}{l}\text {-abroad for shorter } \\
\text { duration } \\
\text { - forced return } \\
\text { (deportees) } \\
\text { - no return } \\
\text { preparedness } \\
\text { - economically } \\
\text { vulnerable }\end{array}$ \\
\hline $\begin{array}{l}\text { Cultural } \\
\text { Orientation }\end{array}$ & $\begin{array}{l}\text { - value both the } \\
\text { culture of the } \\
\text { country of } \\
\text { migration and } \\
\text { country of origin/ } \\
\text { return }\end{array}$ & $\begin{array}{l}\text { - value the } \\
\text { culture of the } \\
\text { country of } \\
\text { migration }\end{array}$ & $\begin{array}{l}\text { - value the } \\
\text { culture of the } \\
\text { country of } \\
\text { origin/ return }\end{array}$ & $\begin{array}{l}\text { - rejection of } \\
\text { culture of country } \\
\text { of migration } \\
\text { - rejection from } \\
\text { dominant society } \\
\text { in country of } \\
\text { origin/return } \\
\end{array}$ \\
\hline $\begin{array}{l}\text { Social } \\
\text { Network }\end{array}$ & $\begin{array}{l}\text { - locals, returnees } \\
\text { and cross-border } \\
\text { ties }\end{array}$ & $\begin{array}{l}\text { - returnees and } \\
\text { cross-border } \\
\text { ties }\end{array}$ & - locals & $\begin{array}{l}\text { - ties to kin and } \\
\text { other vulnerable } \\
\text { groups }\end{array}$ \\
\hline $\begin{array}{l}\text { Self- } \\
\text { Identification }\end{array}$ & - transnational & - transnational & - unidirectional & - unidirectional \\
\hline $\begin{array}{l}\text { Access to } \\
\text { Rights and } \\
\text { Institutions }\end{array}$ & $\begin{array}{l}\text { - limited or full } \\
\text { access to rights in } \\
\text { country of return } \\
\text { (depends on } \\
\text { citizenship } \\
\text { choices) } \\
\text { - limited access to } \\
\text { key institutions in } \\
\text { country of return }\end{array}$ & $\begin{array}{l}\text { - limited access } \\
\text { to rights in } \\
\text { country of } \\
\text { return } \\
\text { - limited access } \\
\text { to key } \\
\text { institutions in } \\
\text { country of } \\
\text { return }\end{array}$ & $\begin{array}{l}\text { - full access to } \\
\text { rights in } \\
\text { country of } \\
\text { return } \\
\text { - full access to } \\
\text { key institutions } \\
\text { in country of } \\
\text { return }\end{array}$ & $\begin{array}{l}\text { - full access to } \\
\text { rights in country } \\
\text { of return } \\
\text { - limited access to } \\
\text { institutions in } \\
\text { country of return }\end{array}$ \\
\hline
\end{tabular}

From the analysis the resulting categorization of the analytical groups shows that professionals primarily fall within the categories of reintegrated or enclavists, students reintegrated or traditionalists, and domestics traditionalists or vulnerable. Figure 8 provides an overview of the analytical groups' reintegration strategies. 


\section{Figure 8: Analytical Groups Reintegration Strategies}

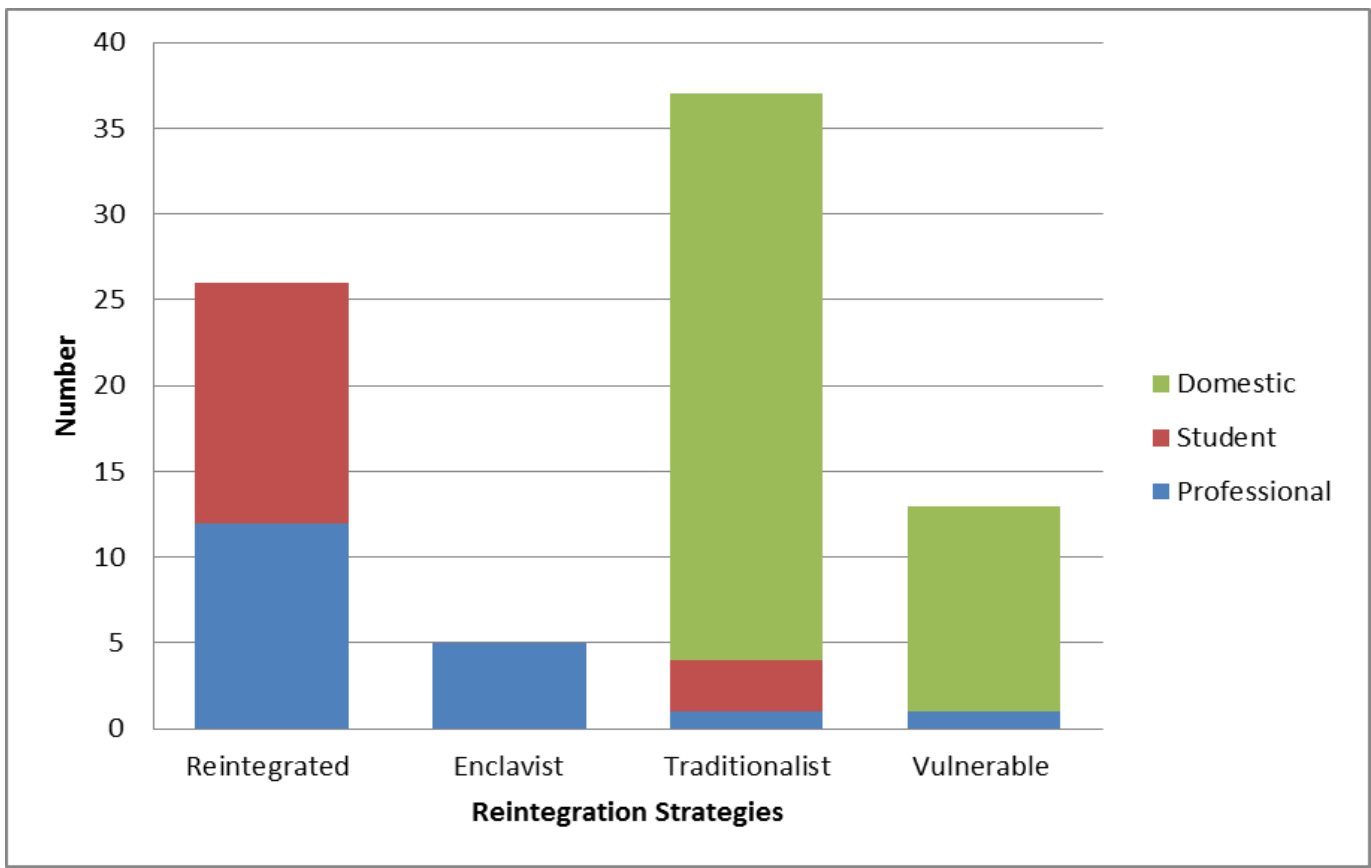

Source: Author's own calculations.

Figure 8 highlights that the first and third hypothesis regarding the professionals and domestics are correct, but that the hypothesis regarding the students is incorrect. It is surprising to see that the majority of students fit within the reintegrated strategy. This will be discussed further within this chapter. Two anomalies are also noted within the professional category that fit within the traditionalist and the vulnerable group. This also highlights the variations that can occur within the analytical groups. Each of the reintegration strategies will be discussed in detail.

\section{Reintegrated}

The reintegrateds' reintegration strategy reflects return migrants that are optimally reintegrated across the dimensions. In this study, both the professional and student analytical groups are represented in the reintegrated strategy. The analytical groups will be discussed separately.

The reintegrated professionals all epitomized the theoretically defined reintegrated returnee. Their average duration abroad was 16 years meaning they had successfully integrated into the country of migration, had acquired skills, resources, and new cultural values in their migration, were highly prepared for their return through temporary return trips and establishing a plan, and they had an active 
reintegration strategy. Their reintegration strategies were actualized through the establishment of businesses, joining associations and organisations for primarily professional purposes, developing active social networks across groups, and establishing a sense of belonging and purpose in Ethiopia. According to the definition of reintegration being used in this study, the reintegrated professionals embodied a successfully reintegrated returnee.

At the same time, however, the reintegrated professionals commonly experienced challenges in their initial return, the most frequent challenge being cultural clashes. However, the reintegrated professionals choose to value the culture of the country of return and are able to overcome challenges and integrate with locals and local culture. For this group return is a choice and an investment in a future. Hence, the women work hard to overcome the challenges of their initial return and reintegration. One woman described how she chose to adapt to Ethiopian culture as follows:

"But there are times that, if he [her husband] is with his friends and in a certain kind of circle, he would expect me to play or he would expect the role of an Ethiopian wife. Not serve, bowing down or something. But if we have guests, a very good example, if we have guests in our house, I would, even if he tries to serve the guests, know I'm the wife, I take care of that, you know. If it was in the States we both work, come home, we cook together....We clean, you know, wash the dishes together. Here, he's expected to sit with the guests and I'm expected to deal with the house help. And you know, serve and whatever it is. The thing is at first the challenge was: Why the hell are you sitting there? You know, I'm working, come with me and work. So I would go in and I would just stare. So ok, he'll come. And then the thing would be: Why? I'm with my friends. What's wrong? You know, you have help. Why don't you do this? And then I'd say: Why don't you do this? I'm helping, so help. And then, after a while I think that makes him happy. And then, for me being that hostess makes me fill with joy. You should see me; you should come to my house now when we have guests. I'm working with the maids. And I love setting the table. I love decorations. I love making sure everybody has everything. I just love it. It was, a very simple thing, you would think, but we would butt heads on that."

- Participant 60

Although the overall issue may seem small, this woman has chosen to negotiate between the culture of the country of migration and the culture of the country of 
origin. If she would reject the culture of the household in Ethiopia it would create continued conflict. She has chosen to adapt and embrace the new cultural environment. For women who are reintegrated, this frequent negotiation is a common aspect of everyday life, wherein they must choose which elements of the culture of the country of return they will embrace and adapt to, which elements they will not, and the same for the country of migration.

Reintegrated professionals express a transnational way of belonging (Levitt and Glick Schiller, 2004). They specifically identify that they live between two cultures and actively make choices regarding these cultures, thus expressing the transnational elements of who they are. The reintegrated professionals had vast social networks that spanned locals, returnees, and transnational connections. They were more likely to be engaged in associations and active in network activities. Through their connections they had access to both bridging and bonding social capital that could provide instrumental and expressive returns. For instance, they had access to elite business networks that provided information on new opportunities for development, which could further their economic reintegration. Reintegrated professionals large networks provide them with support for their reintegration in multiple dimensions. This includes support from transnational networks and other returnees regarding the challenges of reintegration and support from locals on how to live and conduct business in Ethiopia.

The result of the reintegrated professionals' choices made regarding their reintegration led to the reintegrated professionals being reintegrated across all of the dimensions. The reintegrated professionals maintain identity attributes of the culture of the country of migration, thus having a bidirectional cultural orientation. This allows them to have the potential to vernacularize, which will be discussed later in this chapter.

Students within the reintegrated strategy, on the other hand, contest the theoretically defined reintegrated strategy. On average, reintegrated students had been abroad for just over two years, which is less than the five years anticipated for the reintegrated category. Students did return with resources in terms of skills acquired abroad, and some had saved finances that they brought in their return, however, they do not embody an economic success that has high preparedness for return. Why then are the students classified as reintegrated?

The classification of the students into the reintegrated strategy reflects an unforeseen finding of the magnitude of the impact that migration can have on an individual. The students had shorter durations abroad, lacked the opportunity for long-term integration, and a minimal ability to gain resources. Despite these shortcomings, the opportunity to engage in the different values systems of the culture of the country of migration and the opportunity to develop transnational networks left a lasting impact on the students that resulted in behavioural changes 
upon return. All of the students that were categorized as reintegrated stated that their migration resulted in a change in themselves. After their time abroad, they thought differently about their positions within Ethiopian society, their rights, abilities and potential accomplishments. This finding is important, as it highlights that even a short migration experience can be formative in changing perspectives and values. This contrasts arguments in the return migration literature that with a short stay abroad a migrant will have gained too little experience to be able to impact modernization at home (King, 1986). For the students, duration abroad was less important than the experiences abroad.

The ability of the students to go between the two cultures with ease needs to be explored further. The students stated feeling very comfortable in the country of migration and many now considered it to be their second home. However, many of the students were not fully integrated into the countries of migration, as for instance, many did not speak the native languages. It was stated, however, that they did feel comfortable in the culture of the country of migration, suggesting an ability to adapt between both cultures. The reintegrated students do not express a transnational way of belonging, in particular as the transnational networks of the students were weak compared to the transnational networks of the reintegrated professionals.

Overall, the reintegrated students are successfully reintegrated in Ethiopia. In contrast to the theoretically established reintegration strategy, the students have a uni-directional self-identification, but this is caveated by their stressing the personal changes that occurred through migration. They have new values and behaviours from their migration that they bring back into their lives in Ethiopia. These behaviours are maintained as they re-adapt to the local culture and acquire rights for their successful return and reintegration.

As a whole, the reintegrated returnees can be viewed as effectively reintegrated and successfully negotiating between two cultures. The reintegrated returnees form a bridge between the culture of the country of migration and the culture of the country of origin. They are successful in acquiring their rights in return, including employment, social relations, and human rights. Their networks are comprised of locals, returnees, and cross-border ties, which underscores that they have an ability to access resources across borders and societies. For these reasons, the reintegrated have the greatest potential to vernacularize in Ethiopia. This will be further explored in the next chapter.

\section{Enclavists}

From the theoretical framework, the enclavists are similar to the reintegrated, with the key differentiating factor being that they unilaterally value the culture of the country of migration. The enclavists networks are primarily other returnees and they 
do not go between the two cultures with ease. Hence, enclavists are not culturally reintegrated.

Five women have been categorized within the enclavists reintegration strategy. All of these women are professionals that returned from the US to Ethiopia. In comparison to the professionals categorized within the reintegrated category, the enclavists had been abroad for a longer duration, 29 years as opposed to 16 years, and at the time of interview had been in Ethiopia for a shorter duration, 3 years as opposed to 5 years. The reasons and motivations for the initial migration and transnational tie maintenance did not differ significantly from the reintegrated. Three of the enclavists returned specifically for business reasons, and two for altruistic reasons. Overall, the reasons for return are also not substantially different than those in the reintegrated group.

The differences between the reintegrated and enclavist are in their attitudes and networks upon return. Within the enclavists reintegration strategy there is a division between the enclavists that choose to operate within returnee networks and those that are open to engaging with locals but do not seem to be able to bridge the cultural divide. For the first group, a choice is made in a preference for the culture of the country of migration. This group is critical of the culture of the country of return. If they wanted to reintegrate, and to adapt and value the culture of the country of return they could, but they choose not to. An example of this is provided as to how one of these participants characterize the local culture and her choice to not fit within it:

\footnotetext{
"A lot of the educated faculty members, the educated lot they want be something that they are not... Literally sometimes they want to be people that they can't be. So that makes it difficult to communicate. Because you don't know who you are talking to...Everybody wants to be westernized much more than anybody else- The very thing they hate they want to be, so I am confused. I don't know? So I don't really like it socially."
}

\section{- $\quad$ Participant 48}

This quote elicits the adverse attitude that locals often express towards the diaspora. The enclavists acknowledge this attitude and find support in each other to manage the challenges of negotiating with these differences.

The desire to engage in enclavist networks is not uncommon amongst returnees. As stated by Stefansson (2004), returnees, particularly those that have been abroad for a longer duration return with identity attributes that distinguish them from locals. The treatment from locals thus has a large impact on the returnees' reintegration strategy. In Ethiopia, the diaspora returnees frequently note that they are treated differently. It is thus unsurprising, that returnees choose to engage in 
enclavist networks. As stated above, these networks allow for mutual understandings of a shared experience.

For two of the enclavists it appeared that their participation in enclavist networks was less of a direct choice, but more of a reflection that they were unable to bridge the divide to develop meaningful relationships with locals. One of the women in this group stated that she did not really have any friends in Ethiopia and just engaged with her family. She experienced several challenges in working with institutions in Ethiopia in an attempt to set-up a business and relied on her family for assistance in mitigating these challenges.

The second woman had a romanticized vision of return; in that she always wanted to eventually return to Ethiopia, however, upon return she faced several challenges. This included being cheated in her business endeavors. She felt that she did experience hostility at being a 'diaspora' and gender biases as being an unmarried woman. On the whole, her friendships with people that had never left were increasing, but her network was primarily diaspora. Overall, her values were predominantly American and she expressed several pieces of dissatisfaction with Ethiopian culture. She enjoyed being in her homeland and had an altruistic desire to contribute to Ethiopia, however, she was not able to engage and maneuver within the culture in the way that the reintegrated did.

Returning to the definition of reintegration, enclavists cannot be viewed as successfully reintegrated across all dimensions as they self-identify themselves as not fully accepted into society. It is important to note that this can be chosen by the returnee and is not only dependent on the external environment. In addition, despite the challenges they faced and their choice for enclave networks, the three enclavists that chose to operate within enclavist networks were all successful in their businessestherefore having a high level of economic reintegration. Furthermore, this group was able to access the rights and institutions necessary for their success.

\section{Traditionalists}

The traditionalists' category is comprised primarily of domestics, with some representation from the students and one professional falling within this category. The domestics fit either within the category of the traditionalists or the vulnerable. Those within the category of the traditionalists are domestics that either had a positive migration experience, or a high level of resilience to overcome the challenges that they faced in their migration upon their return.

As a whole, the domestics slightly deviate from the theoretically defined traditionalist reintegration category. The majority of domestics in the traditionalist's category were engaged in decided return; however, five of the traditionalist domestics were engaged in forced return. As discussed in Chapter 5, the majority of domestic returnees had low preparedness for return. Only six of the domestic 
traditionalists had medium or high preparedness for return. The majority of domestics therefore returned with some economic resources, however, these generally were not enough to make a sizeable impact on their quality of life. Some of the domestic traditionalists returned with no resources and were fortunate to receive familial support. Overall, the domestic traditionalists hovered on economic stability with many living on the edge of poverty.

Domestics did not have any opportunities for integration in the Middle East. They were servants, not equals in the country of migration and with limited rights there were limited opportunities for them to adapt or gain elements of the culture of the country of migration. Therefore, it is not that they adopted a segregated integration approach themselves; they were forced into a segregated integration position. When asked if they felt like they were part of a community in the country of migration, one participant responded: "You don't feel like that because I knew who I was and that I was an Ethiopian, so you don't feel like you belong" (Participant 64). Other participants further echoed this: "You don't feel like that. There is a big difference. I think they look at us like inferiors" (Participant 63). The cultures in the countries of the Middle East actively work to keep a separation between domestic workers and citizens. This is reflected in aspects such as the domestic worker uniforms in Saudi Arabia, which is the only clothing domestic workers are permitted to wear. This separation meant that there were very limited opportunities for domestics to adopt new cultural capital or to expand their social networks in the country of migration.

Finally, the traditionalist domestics do not return to positions of medium power upon return. Only three of the domestic returnees were able to start their own businesses. A few others were able to build or repair their homes, thus making changes in their families' quality of life. However, on the whole, domestics do not return to a position of medium power; on the contrary, they return powerless. As illustrated in Chapter 5 the majority of domestics are unemployed upon return and lack status or position within Ethiopian society. Upon return, traditionalist domestics networks were primarily comprised of locals. Some domestics had networks with other returnees that they maintained in their return. Overall, however, domestic traditionalists had weak access to bridging social capital that could provide them access to resources.

A large gap exists between the theoretically defined traditionalist and the domestic traditionalist. The domestics in this category lacked the anticipated status, preparedness, and resources of the theoretically defined traditionalist. However, the domestics in this category were not in situations of vulnerability.

Three students were categorized in the traditionalist category. The key difference between these students categorization as traditionalists and the students in the reintegration category is that the traditionalist students did not feel that their 
migration had changed their views or behaviour. Therefore, their cultural orientation was only towards the culture of Ethiopia.

It is noteworthy that these three students were specific cases within the sample. Two of the student traditionalists had been abroad for only eight months, a shorter duration than the average duration abroad of the students. For one of these women the migration experience was a failure and they returned to Ethiopia unable to complete their degree. The third traditionalist student was from an upper class family in Addis Ababa and went abroad for her undergraduate degree. She returned at all of the school breaks (2-3 times per year) to Ethiopia, thus maintaining a highly transnational lifestyle during her degree, which is in contrast to the majority of the students. The traditionalist students therefore do not embody the same characteristics as the majority of the student's analytical group.

The traditional students also do not embody the theoretically defined traditionalist reintegration category. As mentioned above two of the three students were only abroad for 8 months, not the minimum of three years, and one was engaged in a failed migration experience. On the other hand, all of these students had medium to high levels of preparedness for return. One of the traditionalist students did also return to establish their own business.

In returning to the definition of reintegration, the traditionalists are not reintegrated because they maintain their cultural and social identities during their migration, thus assimilating back into Ethiopian culture upon their return. The traditionalists had shorter migration experiences, were strongly oriented towards the culture of Ethiopia, defined themselves as Ethiopian, and had primarily local networks. In this case, the traditionalists also struggle with economic reintegration upon return as several traditionalists are unemployed. Moreover, they lack the networks to make connections and access resources that would assist them in improving their situations. Thus, the traditionalists are hypothesized to have no potential to vernacularize.

\section{Vulnerable}

For the purposes of this study, an individual who is vulnerable is defined as someone that is in need of special care due to the lasting impacts of their migration experience. Based on the reintegration categories the vulnerable have been identified as having at least one of the following criteria: poverty to a degree that one does not have the ability to access rights and institutions, experiencing some level of social exclusion, and self-identify themselves as not being okay. A total of thirteen participants are identified as being vulnerable, twelve are domestics, and one was a professional. The professional case is an anomaly from the sample and will not be discussed further.

All of the vulnerable domestics had low preparedness for return. Seven of the women were forcibly returned, and five engaged in decided return; however those 
that engaged in decided return generally did so out of a necessity to leave a bad situation. This means that they were not prepared for their return and had not achieved their migration goals. Of the seven that were forcibly returned, three of these women were deported, however they did want to return. This presents an interesting intersection of decided and forced return, wherein women in the Middle East want to return to Ethiopia, but cannot afford to pay their airfare and their employers refuse to pay their airfare and let them return. By fleeing their employer they are placed in prison for violating their work permits. The state in the Middle East (country of migration) then either forces the employer to pay the return ticket or they are returned by Ethiopian Airlines. In either case, this form of forced return is desirable to the women, as they are able to escape a bad situation with their employer.

The majority of the women in vulnerable situations after return had experienced abuse in the country of migration. This included the forms of abuse described in Chapter 5 such as: not being paid their salary, physical abuse, not being given food, emotional abuse, and social exclusion. Their vulnerability upon return is in part a lasting impact of this abuse.

Upon return, the majority of the women were welcomed by their families, which provide essential support for their recovery. Two of the women, however, experienced animosity from their families for not being successful in their migration episode and making money. One woman's family was angry with her as the family had gone into debt to finance her migration and she returned without having paid back the debt. This form of a situation has been found in other cases of deportees, such as in Afghanistan. Schuster and Majidi (2013) highlight the power of shame in an unsuccessful return and the lack of understanding of families when other migrants are able to send remittances and the family member has returned empty handed. It is evident that this leads to further isolation and vulnerability as the returnee lacks essential support structures needed after an enduring migration experience.

The majority of the vulnerable experience social isolation from wider society upon return. Many of the vulnerable women do not want to go outside and engage in society. This can be for different reasons, including that people think they should have money or treat them differently than before, they are embarrassed about their appearance, or they simply prefer not to interact with people. One woman described her chosen isolation as follows:

"When people see me they say, "What happened to your hair? Your teeth? Your face? Why have you become like this?" They say things like this. It hurts me. They are afraid of how I became like this. They are confused and they make me confused too."

Participant 05 
For this reason, this participant did not like to leave her house. She preferred to stay at home and minimized the amount of time that she would have to leave her house.

Due to the preference for limited social interactions, networks of the vulnerable are limited to primarily close family and relations. Vulnerable domestics have a small dense network that lacks bridging social capital. Cattell's (2001) work in East London identifies vulnerable people as having socially excluded networks "limited to a small number of membership groups, and a small number of people within those groups" (1507). Although Cattell identifies these people as single mothers, elderly, or refugees, this same principle and categorization of the social network can be applied to the vulnerable domestic returnees. In their return, the vulnerable domestics experience social exclusion from Ethiopian society. For the most part, they are not able to access the services they need to improve their well-being. For instance, access to mental health workers could provide needed services to this group. Furthermore, the withdrawal of this group from society also means that they are not accessing institutions for assistance, such as employment opportunities.

As a whole, there is less variability within the vulnerable reintegration category as compared to the other categories. The vulnerable as a group are unhappy about their current situation. They identify that they either do not feel mentally well or do not feel like themselves. They are unhappy that they are dependent upon their families, were not able to achieve their migration goals, and have not improved their situations at all or have returned worse off than prior to their migration. One woman who was not fortunate to have a family to rely on was highly stressed at her unsuccessful migration and although she did not want to re-migrate, she felt there was no other option as she needed to provide for herself. This vulnerability places women in a situation of continued vulnerability as they consider re-migrating. It is evident that the vulnerable have not successfully reintegrated.

\section{The Potential to Vernacularize}

Within the reintegration strategies several assumptions were made regarding the potential of returnees to act as vernacularizers: first, the reintegrated have the greatest potential to vernacularize of the four groups; second, enclavists have less of a potential to vernacularize than the reintegrated; and third, traditionalists and vulnerable have no potential to vernacularize.

\section{Table 14: Reintegration Strategies and Potential to Vernacularize}

\begin{tabular}{|l|c|c|c|c|}
\hline & Reintegrated & Enclaves & Traditionalists & Vulnerable \\
\hline $\begin{array}{l}\text { Potential to Act as } \\
\text { Vernacularizer }\end{array}$ & High & Medium & Low & None \\
\hline
\end{tabular}


The results demonstrate that for the most part these assumptions have held. Eleven of the participants were identified as vernacularizers, of which, nine were reintegration and two were enclavists. This confirms all of the above assumptions. For both of the enclavists that were identified as vernacularizers their status as enclavists was a choice. That is, they chose to participate in ethnic enclaves and they had the ability to vernacularize with locals. This highlights the importance of agency and choice in the reintegration categories and the potential to act as vernacularizers. Both of these enclavists chose a preference for the culture of the country of migration. Simultaneously, they had a strong love of Ethiopia and a commitment to improve conditions in the country. They do this by acting as vernaularizers and assisting people in ways that they can to improve their situation by offering them mentoring, skills training, and employment. Through this they expose these people to western ways of working in terms of professionalism, respect, and presenting themselves. Therefore, enclavists that choose to be enclavists (are not enclavists because they are unable to reintegrate) are able to be vernacularizers and have the same potential as reintegrated vernacularizers to affect social change.

In order for return migrants to act as vernacularizers they must meet certain conditions. The first condition is that return migrants must have the ability to integrate while abroad and have regular, and meaningful outside interactions to their own culture. Secondly, returnees must have engaged in decided return and have had a high level of preparedness for return. Third, upon return, returnees must maintain their networks from abroad and continue to have regular outside connections to their local environment, which allows for the continual flow of new ideas. Fourth, returnees must be willing to work with locals and have the ability to frame discussions and topics in a way that key messages can be meaningfully communicated to locals. Fifth, returnees must occupy positions with high status in return, demonstrating prestige and according mutual respect for others. Each of these conditions will be discussed in further detail.

\section{Integration Abroad}

In order to bring new ideas and values upon return, individuals must have an opportunity for integration while abroad. This includes that first, the individuals must have the freedom to engage openly and meaningfully with locals or other foreigners, and secondly, that the individual chooses to value the culture of the country of migration. In order to integrate migrants must have freedom of mobility and expression. The majority of domestic workers interviewed in this study did not have this. Without the ability to openly interact with locals, migrants cannot meaningfully gain new values, social and cultural capital. Secondly, when migrants do have the freedom to engage in the culture of the country of migration, they must choose to do so. As illustrated in Berry's model of integration, migrants must choose 
to value the culture of the country of migration. If migrants do not make this choice they remain in ethnic enclaves and do not have the opportunity to acquire social and cultural capital. Hence, if a migrant lives in an ethnic enclave abroad, even if they return after fifteen years abroad they will have a low potential to vernacularize as they have not acquired new values, social and cultural capital.

\section{Decidedness and preparedness for return}

The preparedness model by Cassarino stresses the importance of decided return, voluntariness, resource mobilization and preparedness for return:

“The returnee's preparedness refers to a voluntary act that must be supported by the gathering of sufficient resources and information about post-return conditions at home"

- Cassarino, 2004: 271

In this study it is illustrated that the professional returnees, who have engaged in decided return with high preparedness have the greatest potential to impact social change. The students return can be depicted as partially decided and partially coerced as they do not have visas to permit them to continue to stay in Europe for the long-term. Simultaneously, however, the students wanted to return and decided to do so. This contrasts the situation of the many domestics that were engaged in enforced return, fighting to flee, or for some decided return.

The differences in these groups not only reflect voluntariness and preparedness for return, but an essential skills dimension. It is possible that low skilled returnees can also meet all of the conditions for having the potential to verncaularize and the case of domestic returnees in this study is very specific. One of the domestic returnees that returned voluntarily with high preparedness did establish her own business upon return illustrating the ability of low skilled returnees to also be successful.

Return migrants that do not engage in decided return and have low preparedness are the most likely to be vulnerable upon return. It is understandable that vulnerable returnees have a low potential to impact social change.

\section{Sustained transnational networks upon return}

Ideas are always circulating, evolving, and growing. Through transnational network ties individuals are able to maintain their connections to new ideas and ways of thinking evolving outside of their daily environment. These vital connections and ties promote the continued circulation of new ideas, culture and connections for return migrants. They also enable return migrants to maintain a connection to the 
culture of the country of migration for the continual flow and circulation of culture and ideas that they bring to the country of return.

Professionals stated that they were regularly in contact with their transnational networks. The majority of professionals also engaged in regular visits (from every few months to once every two years) to the country of migration. Several of the professionals stated these trips were important for them in 'getting out' meaning that these trips allowed a difference in the daily environment and perspective.

Sustained transnational networks through mobile communications, regular visits and travel allow the returnees to remain engaged in the globalized world. They have the opportunity to learn new ideas and apply new approaches and techniques from outside of Ethiopia. This ability for continual learning and global engagement increases the ability of returnees to be recurrent agents of social change.

\section{Willingness to work with locals and ability to frame discussions and topics}

In order to be able to impact social change, return migrants must choose to do so and must put the effort into creating and sustaining networks and relationships with locals. Return migrants act as vernacularizers by creating trust with locals and framing issues in a way that is accepted by local culture. Establishing this trust is a process that takes time and framing includes how one presents information, but also how one presents themselves.

Granovetter states "Much information is subtle, nuanced and difficult to verify, so actors do not believe impersonal sources and instead rely on people they know" (Granovetter, 2005: 33). This quote reflects both of the above points that information is difficult and must be framed appropriately, and that people rely on people they know - and trust. In order to be able to transmit information to locals, return migrants must be able to establish trust and effective social networks with locals.

Part of establishing trust is how vernacularizers frame issues. Levitt and Merry described frames as:

"Frames are not themselves ideas, but ways of packaging and presenting ideas that generate shared beliefs, motivate collective action, and define appropriate strategies of action (Snow et al. 1986; Tarrow 1998). Frames affect how problems are defined and understood, how causes of problems and their solutions are theorized and which perspectives are rejected completely."

- Levitt and Merry, 2009: 452. 
Framing is essential to the success of vernacularizers. How an idea, topic or issue is framed makes it appealing or threatening. In order to successfully communicate new ideas, vernacularizers must frame issues in a way that they are acceptable to the local population. One of participants illustrated the efforts required to create connections and frame issues as follows:

\begin{abstract}
"The locals, to get accepted, you have to act like a local... Most of the time they will not accept you. If you are diaspora they always think like- different kinds of directions. They have to believe you. You have to really change yourself, like oh I am one of you. You have to convince them, you have to be really strong...It takes time, but after that like, you will become ok. Most of the diaspora, they do not have local friends."
\end{abstract}

\title{
- Participant 58
}

Returnees must be able to first establish trust and then to be able to frame issues appropriately. Vernacularizers must invest the time in relationships to build bridges and trust with locals. The ability to vernacularize thus requires sustained relationships with locals and the ability to frame issues in a way that local populations can embrace the messages as their own.

\section{Status, Prestige, and Mutual Respect}

Power and authority place people in positions of status and prestige, which lead to respect and influence. Being in positions of power enables returnees to make decisions regarding their staff, to act as leaders, and to challenge the status quo in the society of return. The professional returnees demonstrated respect for the dignity of labour (Sennett, 2003). Sociologist Richard Sennett stresses the importance of mutual respect in the labour force, particularly in situations of inequality. There is a large gap between the returnees and their staff. The returnees are in positions of high status and prestige, but garner respect due to their mutual respect for their staff.

One example of this is from a woman who owned her own business and had a staff of approximately 40 people. Hierarchy is very established in Ethiopia within working culture. Some of the returnees have sought to break this down in their work practices:

"I called them [the employees] in here. I asked them to sit down and let us have a meeting and they said "no we are not going to sit next to you". Because this is the respect [you stand for the boss]. I said "no, if you don't sit, you do not have a job." And they all sat down."

- Participant 48 
This participant insisted that her staff have more equality and felt that they were not inferior to her. She wanted to encourage freedom of communication and expression amongst her staff, which is common in North American and western professional workplaces. These types of values are uncommon in Ethiopia and present an example of how this woman is bringing new values and ideas to the workplace of her business.

Due to their education, class, and networks, the majority of professional returnees occupied positions of status upon their return. Students were also able to acquire good positions upon return due to their education, but with lower levels of experience they were not yet in comparable positions to the professionals in terms of hierarchy. These positions have a role in the returnees being granted respect. For the professionals, this was important when working with the government authorities to establish their own businesses. For students retuning to universities their migration resulted in immediate higher levels of respect from their colleagues and students. Their superior position was also recognized by the students:

"They are respectful of the quality of education. The moment you tell people that you studied abroad then chances are greater that you would get a good job. So in that sense, I could say that I was treated somehow better."

\section{- Participant 39}

Through migration the professionals and students have acquired human, social, and often financial capital that result in increased social status upon their return. By demonstrating mutual respect for those that are unequal to them, the returnees further act as leaders, demonstrating the potential to vernacularize in Ethiopia.

\section{Moving between Reintegration Strategies}

As stated in the assumptions of the model in Chapter 2, Return migrants reintegration strategies can change over time, that is, over the short and long term, depending, among others, on the type of networks in which return migrants are involved and on the resources they mobilise. An individuals reintegration strategy is a dynamic process. It can remain consistent over several years, or it can change dramatically between the reintegration strategies. Each of the dimensions plays a critical part in the reintegration strategies; as such a change in any of the dimensions may lead to a change in the overall strategy.

The most common movements would be between the reintegrated and enclavist reintegration strategies or between the traditionalist and vulnerable reintegration strategies. This is due to the fact that the enclavist and reintegration strategies are aligned on the right side of the cultural orientation spectrum with high valuing of the culture of the country of migration. The traditionalists and vulnerable, 
on the other hand, are aligned on the left side of the cultural orientation spectrum with highly valueing the culture of the country of return. Cultural orientation is a significant dimension within the strategies. It is also possible, however, that an individual could move from the reintegrated or enclavist category to the traditionalist strategy. This could perhaps best be envisioned as someone who is reintegrated and over time their connection to the country of migration fades. They lose contact with their transnational networks and other returnees, stop making visits abroad, and focus themselves towards the culture of the country of return, redefining their self-identification as unidirectional and resulting in a change in reintegration strategy. It is more difficult to envision this change in reintegration strategy in the other direction, that is from traditionalist to reintegrated. Perhaps this could occur if the traditionalist increases their network ties to other returnees and rekindles network connections to the country of migration, resulting in an eventual change in their overall reintegration strategy. Possibly, one of the most dramatic changes in strategy would be from the vulnerable to the reintegrated strategy. This would require moving from a dual rejection to a dual acceptance. It is questionable as to if this could be realistic or not.

In essence, changes in the dimensions: cultural orientation, social networks, self-assessment and access to rights, institutions and the labour market can lead to an overall change in reintegration strategy. Networks and employment are essential components to the process of changing strategies. Networks provide the connections required to engage with culture. Through network connections individuals may change their cultural orientation, leading to a change in reintegration strategy. Employment is also a vital component, particularly for people moving out of the vulnerable strategy. Having access to the labour market, and having rights within the country of return is essential to moving beyond a position of vulnerability.

The fluidity of the strategies and the ability to move between strategies highlights the importance of taking a long-term approach to reintegration. A return migrants reintegration strategy may change with time and at different stages of their reintegration. For instance, upon a returnees immediate arrival they may be in the enclavist strategy, but by one year after return they are in the reintegrated category. Reintegration is a process that takes time and assessing reintegration too early after return may lead to miss-leading conclusions. The strategies must therefore always be understood as existing at one point in time.

Two examples were found in the analysis of women that moved between reintegration strategies. The first is the case of a woman moving from the vulnerable to the traditionalist reintegration category, and the second is the case of a woman moving from the enclavist to the reintegrated reintegration category. 
In the first case, when Kidist ${ }^{6}$ returned from the Middle East she was in a situation of vulnerability. She had been working over 18 hours per day in a household. She lost over ten kilos, began falling and fainted at work. Her employer took her to a hospital and she was diagnosed with tuberculosis. Kidist was fortunate that her employer paid for her medical expenses in the hospital for two months. After this time she was returned to Ethiopia. She wanted to continue her work, but her health was too poor, and against her wishes she was returned. Upon return, Kidist was embarrassed to go out due to her weight loss. Prior to migration, she had been studying and now did not want to see her friends because she was ashamed. Kidist was able to attend a training school for domestic worker returnees. At the training school she met another returnee that had been successful abroad and returned with enough savings to start her own business. They became good friends and opened a restaurant together. Now Kidist is more comfortable in Ethiopia, she has friends and networks and is confident to engage with society.

Kidist's story shows how she moved from being in a situation of vulnerability upon return to being in the traditionalist reintegration strategy. Through the training opportunity, Kidist was able to make new network connections that connected her to resources that allowed her to start the business. She now feels optimistic about the future and is no longer stressed about her situation, as she was upon her initial return. This situation highlights the important of access to networks and opportunities. Through participation in this course Kidist was able to transform her situation, however, without this opportunity her situation may have remained in one of vulnerability.

In the second case, Mary returned from the US to Ethiopia for the first time after fifteen years to deal with her family's property restitution. She had not been planning to return permanently, but during her visit she was offered a position in Ethiopia with an international organisation and decided to take the opportunity. Upon her initial return, she found the culture very frustrating and her network primarily consisted of other returnees and expats. Mary felt that although she spoke the language she could not communicate with locals. She was living within the enclavist reintegration strategy. One day she expressed her frustration with Ethiopian culture to a friend, who explained to her aspects about the culture that led her to re-think her interpretation. This exchange was the tipping point of a process wherein she was changing her perspective towards Ethiopian culture. She began to appreciate the culture and move with less frustration. She changed jobs to work for a local organisation and began to have daily interactions and regular friendships with locals. Through her change in employment and social networks Mary moved from the enclavist to the reintegration strategy.

\footnotetext{
${ }^{6}$ Names have been changed.
} 
Mary's case highlights that specific experiences, and access to certain types of information can be transformative in terms of the reintegration strategies. The strategies are not fixed and change over time with different resource acquisition and experiences. Formative events, networks and the resources provided by the networks can instigate the change of the returnee between reintegration strategies.

\section{The Reintegration Strategies}

The analysis elicits several observations regarding return and reintegration. First, as stated by Cassarino (2004), return migrants are a heterogeneous group that necessitates distinctions being made between different return migrants. The analysis has illustrated that different types of return migrants (based on the analyticalgroups) have diverse migration and return experiences that impacts their reintegration in different ways. Further to this, not only do different types of return migrants have different reintegration experiences, but return migrants within the same groups have different reintegration experiences. Reintegration strategies are influenced by the multiple dimensions and vary by return migrants and across analytical groups.

Secondly, culture is an important element in migration and return. The integration literature is rooted in the concept that migrants bring new cultural elements to the country of migration that distinguishes them from the local population. Much of the return literature and previous definitions of reintegration suggests that return migrants return to their own culture. The refugee literature acknowledges that returnees do not necessarily return "home", however, the focus is on resources, houses, structures, education systems, language and other changes that may have occurred (Hammond, 1999; Rogge, 1994). These are elements that make-up culture, but a direct discussion regarding changes in ways of being between returnees and the culture of the country of origin are less prominent in the literature. It is argued that if migrants 'integrate' abroad, the propensity to acquire new cultural values and behaviours is higher. Therefore, upon return, it must be questioned if they are returning to their own culture? Both the migration experiences abroad and the level of integration of the return migrant in the county of migration determine if the returnee is in fact returning to 'their culture' or not. This is reflected in the reintegration strategies as reintegrated and enclavist return migrants bring elements of the culture of the country of migration with them in return, whereas the traditionalists do not bring elements of the culture of the country of return. The lack of acquisition of new values and behaviours of the traditionalists means that they do not have the potential to vernacularize upon return from a cultural perspective. Reintegration is thus impacted by the migration and return experience and in specific the integration experience.

Upon return, return migrants can be reintegrated in different dimensions. Reintegration is a multidimensional concept and returnees may be reintegrated in one dimension, but not in all dimensions. For instance, a returnee with high 
preparedness may have a thriving business and be highly reintegrated economically. At the same time, however, they may choose to only network with other returnees, distancing themselves from the local population and culture, thus existing in an enclavist network and lacking cultural reintegration. In this example, the returnee is reintegrated in the economic dimension (access to rights, institutions, and the labour market) but not in the cultural dimension. Thus, optimal reintegration is one wherein the return migrant is reintegrated across all dimensions.

It must be noted, however, that cultural reintegration is not only the responsibility of the return migrant. As stated by Berry in the integration literature: "integration can only be "freely" chosen and successfully pursued by non-dominant groups when the dominant society is open and inclusive in its orientation towards cultural diversity" (1997: 10). The country and culture of return must therefore offer a level of acceptance for new cultural elements and behaviours brought by returnees. If these cultural and behavioural attributes are rejected by the country of return, return migrants only option is to assimilate to the culture of return, therefore rejecting the attributes acquired in migration, or to re-migrate. If return migrants reject the acquired identity attributes from the country of migration, which can include values, skills, and behaviours, then they do not have the potential to vernacularize upon return.

Not only does the returning society make a choice, the return migrant also makes a choice as to if they accept or reject the culture of the country of return. In as much as the culture of the country of return can reject the returnees, the returnees themselves can limit their ability to vernacularize by choosing to segregate themselves from the culture of the country of return, as is evidenced in the enclavist reintegration strategy. Therefore, in order for returnees to have the maximum potential to vernacularize they must be optimally reintegrated across all dimensions, choose to maintain identity attributes from the culture of migration, and choose to integrate with locals. Even if returnees are prepared and have mobilized resources for their return, upon return they make fundamental choices regarding their reintegration which impacts their ability to be agents of change.

In the same notion that return is a process, reintegration is a process unto itself. Reintegration takes time and resources. Different types of return migrants have different needs upon return and require different supports and resources for successful reintegration. For example, the reintegrated professionals need support in managing the local culture, whereas traditionalist domestics need support in training, and employment acquisition. Furthermore, with time reintegration strategies can change as returnees acquire new resources through networks or other means that allow them to change between the reintegration strategies.

In this study, the low skilled return migrants were not classified in the reintegration strategy, however, it should not be deduced that low skilled migrants 
cannot fit within the reintegrated strategy. Domestic work is a specific form of migration, and in the Middle East in particular it excludes migrants from the wider society. Constable found that Filipina domestic workers in Hong Kong, whom were allowed much greater freedoms than workers in the Middle East, "develop a plural vision that allows -perhaps requires- them to create a new place to fit in both in Hong Kong and the Philippines" (1999: 224). These women had developed new freedoms and independence in Hong Kong that they sought to bring with them back to the Philippines. Constable's study was conducted in Hong Kong, but she argues that upon return they will be in a different space having adopted new desires, options and visions from their migration (1999). Therefore, their cultural orientation would include elements of the country of migration and it is possible that upon return these women could adopt a reintegrated reintegration strategy. Low skilled workers that migrate to other countries and have the opportunity to interact with locals may have very different experiences than the domestic workers in this study. For instance, individuals that receive temporary protection visas for a few year period in a European country and then opt for assisted voluntary return may potentially be classified as reintegrated. They may be able to bring back cultural orientations and maintenance that place them within the reintegrated category.

\section{Summary}

This chapter has assessed the reintegration strategies of the return migrants and the relationship between the different reintegration strategies and the potential of the return migrants to act as vernacularizers. Further, the chapter assessed how returnees can move between the reintegration strategies illustrating that the reintegration strategies and the potential of return migrants to act as vernacularizers are fluid concepts that both change with time. On the whole, the reintegration strategies take a step further towards understanding the multidimensionality of reintegration, the challenges of reintegration for different return migrants and how reintegration experiences impact the potential of returnees to act as vernacularizers upon return. 


\section{Chapter 8: Conclusion}

Every day thousands of people return to their homelands and begin a process of adjustment. Our understandings of reintegration are evolving and this study has aimed to make a contribution to deepening our understanding of this complex process through the development of the reintegration strategies. This final chapter will provide a summary of the main findings of the study, explore the implications of the reintegration strategies, provide a final overview of return and reintegration in Ethiopia, assess the application of the model beyond the case study and offer final remarks.

\section{Main Findings: Reintegration Strategies}

The objective of this study is to increase understandings of reintegration and the process of reintegration for different return migrants. The primary research question guiding the study is: How do different return migrants reintegrate upon return? Through the study a second key question emerged of: How do the reintegration strategies impact the potential of return migrants to act as vernacularizers upon return?

In order to answer these questions, the first step in this study was to define reintegration. Through a comprehensive literature review of migration, forced migration, integration, transnationalism, social networks and social change, this study has put forth a new definition of reintegration. As stated in the introduction and demonstrated in this study, current definitions of reintegration do not account for the two-way process of adaptation of both the return migrant and the return society that is required for reintegration. Secondly, it is evident that many returnees do not return to their own culture. Returning to the quote on the first page of this thesis, the participant herself highlights that cultures and places are always changing. How you remember a place is different than how it is when you return. Returnees must find their place to fit in and this is part of the process of reintegration.

Taking into account these factors, reintegration has thus been defined in this study as: the process in which return migrants are supported in maintaining their cultural and social identities by the host society and the whole population acquires equal civil, social, political, human and cultural rights. This definition takes into account that returnees do have different cultural and social identities that they have acquired in their migration experiences. Upon return, these are often not absolved. The country of return, inclusive of the government, local population, and labour markets, must be willing to be open and accepting of returnees cultural and social identities in order for returnees to have an optimal reintegration. If the country of 
return rejects the returnees, then reintegration will be an illusion. This was the case cited by Steffanson (2004) in Bosnia wherein locals and the local government rejected returnees, thus resulting in return enclaves and a lack of reintegration for returnees.

This leads to the process of reintegration. Central to understanding the process of reintegration is to recognize that returnees are a highly heterogeneous group. The term return migration incorporates broad groups of people that are very different from each other, as was demonstrated in the case study with the comparisons between the professionals, students and domestics. It is essential to note that the structural environment of return and the individuals' reintegration strategy are different for different groups of migrants, and even within groups of migrants. This has direct implications for policy and practice in that one policy should not be expected to meet the needs of all returnees, and secondly, that we cannot expect similar outcomes from all returnees. For instance, we cannot assume that all return migrants will contribute to development when, as demonstrated in this study, specific conditions must be met in order for returnees to have the potential to act as vernacularizers.

There are central factors that shape the reintegration processes of return migrants. First, is the lifecycle of the returnee. This includes the experiences and class of the returnee prior to migration, their experiences abroad and opportunities for integration, and their process, and preparedness for return. The situation of migrants prior to their migration and their class differences often dictates their migration opportunities. For instance, students are able to migrate to Europe for a master's degree due to their positions. The students that receive these opportunities are the top of their field. Their opportunities are quite different than the domestics' whose only tangible opportunities for migration are for domestic work.

These different migration flows lead to fundamental differences in the country of migration. In the country of migration the opportunities for integration are central to the migrant being able to acquire new cultural and social identities, and to gain skills and resources for their return. The majority of the students found the exposure to the culture of the countries of Europe as transformative. The opportunities to see female empowerment and the way of life in Europe were motivational to this group. This greatly contrasts with the situation of domestic workers, wherein many of the participants were not able to leave the house of their employers and develop networks with other domestics, nevertheless locals. Their sheer isolation prevented any opportunities for gaining cultural and social capital in the country of migration. Opportunities for integration are thus essential for migrants to gain cultural and social capital that can be brought with them in their return.

In order for returnees to optimize their reintegration upon return they must be prepared for return and have engaged in a decided return. Cassarino's 
preparedness theory (2004) demonstrates that decided returnees are more likely to contribute to development. This study has the same finding in that return must be decided in order for returnees to have a high potential to contribute back home. Return preparedness means that resources and information have been acquired for return, such as a home, employment, or an established network. In essence, a prepared returnee has a strategy for their reintegration. Enforced or coerced returnees, on the other hand, have limited resources available for their return and low preparedness. Upon return they do not have established opportunities and struggle to re-establish themselves.

There are four elements that shape the reintegration strategies of returnees. First, there is the cultural orientation of the return migrant and where they fit upon the spectrum of valuing the culture of the country of migration to valuing the culture of the country of origin/return. This is a spectrum wherein returnees can be far to one end or the other end, or in the middle of the spectrum. For optimal reintegration and the potential to vernacularize, return migrants find a balance between the two cultures and are in the middle of the spectrum.

The importance of cultural orientation stresses that culture matters. As stated by Levitt and Lamba-Nieves (2013) there is a need to bring culture back into migration debates. Migration and return can result in increased cultural capital and reintegration includes decisions regarding cultural orientation and finding ways to embrace two cultures in return. The reintegrated professionals in the study exemplified the way to do this, and were able to 'move between two cultures with comfort and ease'. This is not always possible. Culture can also be a barrier to reintegration. Enclavists are often not able to overcome the cultural barriers between the country of migration and the local culture. This places them on the outside and operating only within return enclaves.

The second dimension is social networks. Networks provide access to resources and information essential in the process of reintegration. In the case analysis, professionals often make the most of their networks to gain valuable information for their reintegration. Access to and use of networks assisted professionals in establishing their own businesses, and learning about the culture of return from locals. Networks are not only a key element in the reintegration process; they play a vital role in moving between reintegration strategies, as will be discussed further below.

The third dimension of self-identification is essential in reintegration as it reflects a return migrants sense of identity and belonging. It is noteworthy, that even enclavists still feel a strong sense of belonging to Ethiopia. They do identify with a bi-directional self-identification that is slightly stronger towards the culture of migration, but they still have a strong identification with the country of return. There is arguably a tipping point along the spectrum of self-identification. Those that 
would be further towards the country of migration than the enclavists would presumably have re-migrated to the country of migration or would not return at all. Further investigation of those that returned and then re-migrated to the country of migration would be required to assess if this is the case.

The final dimension is access to rights, institutions, and the labour market. Economic reintegration is essential for successful reintegration. For the domestics, one of the greatest hurdles to reintegration was labour market reintegration. Lacking employment places people in a situation of susceptibility that must be overcome in order for them to have a successful reintegration. This dimension also includes citizenship rights and it is noteworthy that although many of the professionals do not have citizenship rights; they still have the greatest access to institutions in Ethiopia due to their social class.

Reintegration is multidimensional. Returnees can be integrated in only one dimension, in two dimensions, in three dimensions, or across all four dimensions. Too often labour market reintegration is association as an individual being 'reintegrated'. This study emphasizes a holistic view on reintegration and illustrates that the other dimensions are just as important as labour market reintegration. If a returnee cannot establish a sense of belonging in the country of return, then they will most likely re-migrate, as suggested above. Optimal reintegration occurs when returnees are reintegrated across the dimensions.

The interplay between the four dimensions results in the different reintegration strategies of return migrants. The resulting reintegration strategies show how different return migrants reintegrate. The four reintegration strategies of reintegration, enclavists, traditionalists, and vulnerable provide a typology for characterizing return migrants different strategies in return. It is evident that not only different categories of return migrants (in this case professionals, students and domestics) have different reintegration strategies, but that also returnees within categories have different reintegration strategies.

The reintegration strategy of a returnee is a fluid concept that changes over time as returnees can move between reintegration strategies. When speaking about reintegration strategies it is crucial to understand that factors shaping reintegration back home are not fixed in time and that some return migrants may redefine their own patterns of reintegration whereas others may not. This aspect constitutes a key finding of this research. The primary factors shaping the passage from one reintegration strategy to another are social networks and labour market opportunities. Through social networks returnees can change their cultural orientation and self-identification. For example, through network ties, returnees can increase their connections with locals, which may broaden their openness to the culture of the country of origin and increase their feelings of belonging in the 
country of origin. This may result in a change from the enclavist reintegration strategy to the reintegrated reintegration strategy.

As previously stated, in theory, a change could be made from any one of the reintegration strategies to any other; however, it is suspected that the most common changes would be either from the enclavist to the reintegrated or from the vulnerable to the traditionalist. Further research and exploration of the reintegration strategies would be required to better understand the process of more dramatic changes in reintegration strategies.

The final key element of this study was an examination of how the reintegration strategies impact the potential of return migrants to act as vernacularizers upon return. Vernacularizers are defined as individuals that "take the ideas and practices of one group and present them in terms that another group will accept" (Levitt and Merry, 2009: 446). The objective in this study was to understand how the reintegration strategies impact and empower the women to be able to share new ideas with the local population and their social environment and to frame issues in a way that will be accepted and embraced by the local population. In order to act as vernacularizers, returnees must be able to overcome cultural barriers to frame issues in a way that is relevant to locals, and second, returnees must be in positions of relative power in order to have the greatest impact. This leads to the five conditions required for return migrants to have the potential to act as vernacularizers: 1) Ability to integrate while abroad; 2) Voluntariness and preparedness for return; 3) Sustained networks upon return; 4) Willingness to work with locals and ability to frame discussions and topics; and 5) Occupying a position of power and demonstrating mutual respect for others. Only when returnees meet all five of these conditions, which further implies that they are optimally reintegrated across the dimensions, are they able to have a high potential to vernacularize. In this study, only 14 percent of the participants met this criterion and had a high potential to act as vernacularizers. Therefore, under the right conditions return migrants can have a high potential to be agents of change in their societies of return. It cannot be assumed, however, that all returnees have this potential. This study has demonstrated that there is a direct link between reintegration and the potential of returnees to have impact on their societies of return. Reintegration is a complex process and different reintegration strategies result in different potentials to vernacularize.

\section{Implications of the Reintegration Strategies}

In our increasingly globalized world, there is a central recognition that societies are becoming more diverse and plural. Debates regarding assimilation, multiculturalism and integration have been actively occurring across Europe, North America and Australia for decades. Yet, the reverse cultural influence and changes to local societies due to globalization, migration, and return is less understood. This 
relationship is often discussed in terms of progress, such as the transformative effects of the skills gain in India, the globalization of production, and increasing knowledge workers. The impact of returnees and migration on local communities more broadly has been explored through social remittances (Levitt, 2001) and transnationalism in recent decades. Increasing attention is being brought to these issues over the last decade, but key debates regarding plurality in society and cultural diversity of returnees at the national level in countries of return are infrequent occurrences.

It is evident from this study that culture is a central tenant in understanding return and reintegration. Amassari and Black (2001) put forth that the potential of returnees to contribute to development was based on their transfer of financial, social, and human capital to their countries of return. This study highlights the need to include cultural capital. Culture has wide implications for return and reintegration and can no longer be overlooked in the reintegration process.

This study has demonstrated the importance of recognizing the heterogeneity of return migrants and the different potentials and abilities of return migrants. It simply cannot be assumed that all return migrants will contribute to development. There must be a fundamental acceptance of the heterogeneity of returnees: recognition of the conditions that empower returnees to have the potential to vernacularize and share new ideas with their social environment, versus the acknowledgement of the needs and vulnerability of other returnees. Individuals in situations of vulnerability upon return need support. Policies and practitioners need to recognize the differences between different return migrants, where they are in their reintegration process, and what potential they have to be of benefit to the country of return or what assistance they need to become productive members of society.

\section{Female Return and Reintegration in Ethiopia}

This section will bring the assessment back to the case analysis of Ethiopia, as the structural environment of return plays a vital role in the reintegration of returnees. In Chapter 4 it was determined that for professionals and students, who have been assessed as the vernacularizers in this study, the overall structural environment towards returnees is neutral. In returning to Table 6 from Chapter 2, it is necessary to add a row to the table to depict the neutral structural environment of return. Table 14 shows that a neutral structural environment of return would result in the reintegrated having a medium-high potential to vernacularize and enclavists having a medium-low potential to vernacularize. 
Table 15: Vernacularization Potential of the Reintegration Strategies and Conditions of the Structural Environment of Return

\begin{tabular}{|c|c|c|c|c|}
\hline $\begin{array}{l}\text { Structural } \\
\text { Environment }\end{array}$ & Reintegrated & Enclaves & Traditionalists & Vulnerable \\
\hline Favourable & High & Medium & Low & None \\
\hline Neutral & Medium-High & Medium Low & Low & None \\
\hline Adverse & Medium & Low & Low & None \\
\hline
\end{tabular}

The local population was assessed in Chapter 4 as slightly adverse to return migrants. This was stated as locals do not consider diaspora returnees as 'really Ethiopian' and professionals have stated how they have needed to work to overcome these stigmatizations in order to create meaningful relationships with locals. Locals will tell you in Addis Ababa that changes from the returnees are evident all around you. Every corner has another restaurant from a returnee, named for where they were- Canada café, Amsterdam, or La Parisenne. The feelings from locals are that returnees think they are superior. Furthermore, locals berate returnees as being low skilled people who went and worked at the Dollar Store and have now returned with some money thinking they are better than everyone else.

This creates a difficult environment for women to overcome, build trust, and disseminate new values and ideas. The participants in this study agreed that it took them time and effort to build these bridges. They themselves had to have an open mind and be willing to keep trying to overcome the challenges they faced in order to be accepted by locals.

Several of the women interviewed also identified further challenges of being a woman in Ethiopia. Traditionally, the culture of Ethiopia has been patriarchal. The World Economic Forum Global Gender Gap Indices ranks Ethiopia as 118/ 135 in the world (2012). The indices assess gender relations on economic, political, education and health-based criteria. It must be noted that there is a significant difference between rural Ethiopia and urban areas, especially Addis Ababa. The capital is considered to be far more gender balanced. Several of the participants in this study stated that they did not feel they experienced gender discrimination; however, this contrasted approximately 50 per cent that did cite gender discrimination. Of the women that cited gender challenges, they recognized that changes were occurring in Ethiopia, but that there was still an existing gender gap. One participant stated this as follows:

"Well this culture is now changing, a lot more is done. We are working towards appreciating and respecting women and also realizing the importance of women in society. I personally believe they are more important than...But anyway. Coming here 
the cultural thing was- the man is the more important one. It's not every day, not everybody says it in your face- But it is there. Even on the streets you know? I was working for some institution then and I would be driving this four-wheel drive, and people would say, a woman is driving this car! And it's like I am the woman, the car is gender free- it's a car, it can still hit you. But little subtle things. The men earn the respect immediately you know, when we were on that side [country of migration] we're equal. If anything I got the respect actually, I was Mrs.. I was never...you know. When I had my children it was with lots of respect my right was there! Here I am not going to say my right was taken because it wasn't clearly taken but it was subtly, it's under the table it's there. So it kind of irritates you."

\section{- Participant 36}

Students also expressed challenges with gender roles. One student stated:

"Let me put it in this way, you have to be decent as a woman, as a young lady. It is a very big deal when you speak what you think, you know, you cannot speak what you think. Also time you have to be shy a little bit, decent. When I was there I was speaking my mind you know, I talk what I want and I talk what I feel. When I come here it was difficult for me."

\section{- Participant 53}

In addition to having the reintegration struggles of being a diaspora returnee, women have the additional challenge of finding their place within a male-dominated culture.

If men had been included in this study, I hypothesize that reintegration may have been slightly different for men in the Ethiopian context. This is because men are automatically accorded respect and prestige in return, whereas women are still fighting the gender gap. Several professional returnees mentioned anecdotally that reintegration is much easier for men as they have further status in Ethiopia upon return, whereas women have been accustomed to gender equality abroad and must readjust to gender hierarchies in Ethiopia upon return. I suspect that this additional challenge is felt throughout the entire reintegration process and influences the strategies that women adopt in their return. Perhaps professional Ethiopian male returnees may be more likely to opt for the traditionalist reintegration strategy as they may prefer the culture of Ethiopia to the culture of the country of migration. Further research would be required to test this in Ethiopia. 
It is for these reasons, that I was particularly interested to examine the experiences of female return migrants. Women returnees experience multiple layers of reintegration challenges that include being a returnee, being a woman, and for the most part, not fitting the mould of expectations in Ethiopia. The reintegrated and enclavist professionals and students in this study exemplified women that are challenging the status quo in Ethiopia. Reintegrated female returnees have the potential to be instigators of social change in Ethiopia due to their abilities to act as vernacularizers and frame new ideas in an acceptable manner for local culture.

\section{Beyond Ethiopia: The applicability of the Reintegration Strategies to Other Cases}

This study has brought forth a new typology for understanding reintegration and has tested this typology in the case analysis of Ethiopia. The results of the study lead to many questions for further research, refinement of the typology, and its application to other cases.

This case analysis was a qualitative assessment aimed at emphasizing the analytical relevance of reintegration strategies. The methodology allowed for depth of information and interpretation in an iterative cycle of analysis. It would be necessary to next quantify the reintegration strategies and test the typology amongst a large and diverse sample of returnees. This would allow for further understandings as to how different types of returnees reintegrate, if there are differences in gender, age, skills, and other variables. The limited and defined categories in this study have allowed for clear distinctions between returnees, but do not allow for broader interpretations of differences based on such characteristics.

Key return groups that were not included in this sample are repatriated refugees, assisted voluntary returnees, and decided low skilled returnees. I would argue that the typology is still relevant for both of these groups. In a study conducted in Burundi (Fransen and Kuschminder, 2012), it was found that repatriated refugees from Tanzania to Burundi that had been abroad for a long duration struggled upon return with language, and the culture of Burundi. As refugees in Tanzania these returnees gained cultural capital and changed their cultural and social identities. Upon return to Burundi they struggled with the local culture and were primarily return enclavists, wherein they only interacted with locals out of necessity and pleasantry and did not have meaningful social networks with locals. This study was conducted with a specific group of returnees in two communities. Of the 500,000 returnees to Burundi, there are most likely many other reintegration strategies. In essence, however, the typology should still be applicable to repatriating refugees and various other categories of returnees. This will have to be explored through further research and analysis, which should result in refinement of the strategies and a deepening understanding of reintegration. 


\section{Final Remarks}

There are several areas of further research to be explored from this study and I will highlight two specific areas of interest. The first is the need for longitudinal studies on reintegration. As stated, reintegration strategies can change over time. Longitudinal work would allow for more in-depth understandings of how peoples processes of reintegration evolve over time and the specific factors that drive the process of moving between reintegration strategies. This aspect of the framework requires further elaboration, which could be addressed through a study tracing returnees at several points in time over a five to ten year process of reintegration. This would also provide insight into the critical point at which returnees are in a position to redefine their reintegration strategies. It is important to understand the factors leading to this situation from a policy perspective as countries seek to attract their nationals to return.

A second area for further research is to understand the impact of return on social change. This is difficult to measure; however, expanding the focus of the study beyond only returnees and to members of their networks that are impacted by them may elicit new observations regarding the impact of returnees on the local population and social change. In a study on knowledge transfer of temporary returnees to Afghanistan, speaking to colleagues and students of the temporary returnees elicited several key points that were not raised by the returnees themselves (Kuschminder, 2013). This approach may lead to similar results with the reintegration strategies and is an area for further exploration.

The reintegration strategies require further testing, questioning, and refining. There are many caveats to be explored in understanding reintegration. In essence, this study has sought to demonstrate that reintegration can be just as complex as migration, and that it is not only the role of the returnee to ensure their reintegration, it is the role of the entire society of return. Countries of return are increasingly seeking to attract their migrants to return for knowledge, skills and capacity development. They must recognize and understand the role that they themselves and the local population play in reintegration. Promoting a culture of openness and welcomeness to their returnees will assist in the reintegration process and in general lead to tolerant societies open to cultural diversity and change. 


\section{References}

Allen, T. and Morsink, H. (1994). Introduction. When Refugees Go Home. Eds. Tim Allen \& Hubert Morsink. Geneva: United Nations Research Institute for Social Development.

Alquezar Sabadie, J., Avato, J., Bardak, U., Panzica, F., and Popova, N. (2010). "Migration and Skills: The Experiences of Migrant Workers from Albania, Egypt, Moldova, and Tunisia". Washington: The World Bank.

Ammassari, S. (2009). Migration and Development: Factoring Return into the Equation. Newcastle upon Tyne, Cambridge Scholars Publishing.

Anbesse, B., Hanlon, C., Alem, A., Packer, S., and Whitley, R. (2009). Migration and Mental Health: a Study of Low-Income Ethiopian Women Working in Middle Eastern Countries. International Journal of Social Psychiatry, 55(6), 557568.

Asis, M., Huang, S. And Yeoh, B. (2004). "When the Light of the Home is Abroad: Unskilled Female Migration and the Filipono Family". Singapore Journal of Tropical Geology 25(2), 198-215.

Atkinson, R. and Flint, J. (2001). “Accessing Hidden and Hard-to-Reach Populations: Snowball Research Strategies". Social Research Update. Sociology Department, Univeristy of Surrey.

Baxter, J. and Eyles, J. (1997) "Evaluating Qualitative Research in Social Geography: Establishing 'Rigour' in Interview Anaylsis." Transactions of the Institute of British Geographers 22(4): 505-525.

BBC, 2006. "Ethiopia asks diaspora to work at home". BBC. 14 November 2006. Available at: http://news.bbc.co.uk/2/hi/business/6136010.stm. Accessed on: 5 June 2012.

Berhane, M. (2012). "The exodus of women to the Middle East". The Reporter. 25 February 2012. Available at: http://www.thereporterethiopia.com/Livingand-The-Arts/the-exodus-of-women-to-the-middle-east.html

Accessed on: 5 June 2012. 
Berry, J.W. (1997). “Immigration, Acculturation, and Adaptation." Applied Psychology: An International Review 46(1): 1-68.

Black, R. and Koser, K. (1999). "The End of the Refugee Cycle?" The End of the Refugee Cycle? Eds. Richard Black \& Khalid Koser. United States: Berghahn Books.

Black, R. and Gent, S. "Sustainable Return in Post-Conflict Contexts." International Migration 44(3), 15-38.

Boyd, M. (1989). "Family and Personal Networks in International Migration: Recent Developments and New Agendas." International Migration Review 23(3): 638670.

Burt, R. (2002). “Bridge Decay”. Social Networks 24(4): 333-363.

Carling, J. (2004). "Emigration, Return and Development in Cape Verde: The Impact of Closing Borders." Population, Space and Place 10: 113-132.

Cassarino, J.P. (2000). Tunisian New Entrepreneurs and Their Past Experiences of Migration in Europe. England, Ashgate Publishing, Ltd.

Cassarino, J.P. (2004). Theorising Return Migration: the Conceptual Approach to Return Migrants Revisted. International Journal on Multicultural Societies, 6(2), 253-279.

Cassarino, J.P. (Eds) (2008). "Return Migrants to the Maghreb, Reintegration and Development Challenges." San Domenico di Fiesolo, Italy: European University. Institute (EUI), Robert Schuman Centre for Advanced Studies.

Cassarino, J.P. (Forthcoming, 2014). “A Case for Return Preparedness.” In Graziano Battistella (ed.), Theoretical Perspectives on Asian Migration. New York: Springer.

Castles, S. and Miller, M. (2009). The Age of Migration. London: Palgrave MacMillan.

Castles, S., Korac, M., Vasta, E., and Vertovec, S. (2003)"Integration: Mapping the Field." Report for the Home Office. 
Cattell, V. (2001). "Poor people, poor places, and poor health: the mediating role of social networks and social capital" Social Science and Medicine, 52, 1501-1516.

Central Statistics Agency (CSA). (2008). "Statistical Abstract." Available at: www.csa.gov.et. Accessed on: 5 June 2012.

Cerase, F. (1974). "Expectations and Reality: A Case Study of Return Migration from the United States to Southern Italy." International Migration Review 8(29): 245262.

Cerruti, M and Massey, D. (2001). "On the Auspices of Female Migration from Mexico to the United States." Demography 38(2), 187-200.

Christou, A. (2006). "Crossing boundaries- ethnicizing employment- gendering labor: gender, ethnicity and social networks in return migration." Social $\mathcal{E}$ Cultural Geography 7(1): 87-102.

Chammartin, G.M. (2004). "Women Migrant Workers Protection in Arab League States." In Gender and Migration in Arab States The Case of Domestic Workers Eds. Simel Esim and Monica Smith. International Labour Organisation, Beirut.

Collyer, M. (2012) "Deportation and the Micropolitics of Exclusion: The Rise of Removals from the UK to Sri Lanka". Geopolitics 17(2), 276-92.

Constable, N. (1999). "At Home but Not At Home: Filipina Narratives of Ambivalent Returns." Cultural Anthropology 14(2), 203-228.

Davies, A. (2004). "Restitution of Land and Property Rights". Forced Migration Review 21: $12-14$.

de Haas, H. (2007). "Migration and Development: A Theoretical Perspective." Center on Migration, Citizenship and Development Working Paper No. 29.

de Haas, H. (2010). “The Internal Dynamics of Migration Processes: A Theoretical Inquiry." Journal of Ethnic and Migration Studies 36(10): 1587-1617.

de Regt, M. (2008). "High in the Hierarchy, Rich in Diversity." Critical Asian Studies 40(4), 587-608. 
Donato, K. (1993). “Current Trends and Patterns of Female Migration: Evidence from Mexico". International Migration Review 27(4), 748-771.

Drotbohm, H. (2011) "On the Durability and the Decomposition of Citizenship: the Social Logics of Forced Return Migration in Cape Verde" Citizenship Studies 15(3-4), 381-96.

Epstein, G.S. (1998). "Herd and network effects in migration decision-making." Journal of Ethnic and Migration Studies 34(4): 567-583.

Ethiopian Investment Agency (EIA). (2011). "List of Licensed Diaspora Investment." Received April 2012. Addis Ababa.

Ethiopian Women Unleashed. (2013). “Frealem Shibabaw Yeneabat".

Available at:

http://www.ethiopianwomenunleashed.org/profile detail.php?PId $=117$

Embassy of Ethiopia Washington. (2009). "Duty Free Importation". Access available at:

http://www.ethiopianembassy.org/services/Duty\%20free.shtml Retrieved 15 June 2010.

Faist, T. (2008). "Transnationalization in International Migration: Implications for the study of Citizenship and Culture." Working Paper 99. Institute for Intercultural and International Studies, University of Bremen.

Gaetano, A.M., and Yeoh, B. (2010). "Introduction to the Special Issue on Women and Migration in Globalizing Asia: Gendered Experiences, Agency, and Activism." International Migration 48(6), 1-12

Glick Schiller, N., Calgar, A., and Karagiannis, E. (2003). “Similtaneous Incorporation of Migration". Paper delivered at the Max Planck Institute of Social Anthropology, Halle, Germany, July 17, 2003.

Gmech, G. (1980) “Return Migration.” Annual Review of Anthropology 9: 135-159. 
Gmelch, G. (2004). "West Indian Migrants and Their Rediscovery of Barbados". Coming Home? Refugees, Migrants and Those who Stayed Behind. Eds. Lynellyn Long and Ellen Oxfeld. Philadelphia: University of Pennsylvania Press.

Granovetter, M. (1973). "The Strength of Weak Ties." American Journal of Sociology 78: 1360-1380.

Gubert, F. and Nordman, C.J. (2011). "Return Migration and Small Enterprise Development in the Maghreb". Diaspora for Development in Africa. Eds. Sonia Plaza and Dilip Ratha. Washington: World Bank.

Habtamu, E. (2009). "From Diaspora to Mega Business: The Story of Boston Partners". Ezega News. 8 July 2009. Available at: http://www.ezega.com/News/PrintNews.aspx?newsID=1630

Accessed on: 5 June 2012.

Hagan, JM. (1998). "Social Networks, Gender, and Immigrant Incorporation: Resources and Constraints." American Sociological Review 63: 55-67.

Hammond, L. (1999). Examining the Discourse of Repatriation: Towards a More Proactive Theory of Return Migration. In: Black, R. \& Koser, K. The End of the Refugee Cycle? Refugee Repatriation and Reconstruction. Oxford: Berghahn Books.

Heckmann, F. (2001). "Effectiveness of National Integration Strategies Towards Second Generation Youth in a Comparative European Perspective." Final Report.

Horst, H. 2007 "You can't be two places at once: Rethinking Transnationalism Through Jamaican Return Migration" Identities 14(1-2): 63-83.

Human Rights Watch, 2008. "As If I am Not Human: Abuses against Domestic Workers in Saudi Arabia." Available at: http://www.hrw.org/sites/default/files/reports/saudiarabia0708 1.pdf Accessed on 1 August 2013.

Hunger, U. (2004). "Indian IT Entrepreneurs in the US and in India: An Illustration of the "Brain Gain Hypothesis"". Journal of Comparative Policy Analysis: Research and Practice 6(2): 99-109. 
IOM-SLM Addis Ababa. (2011). “Assisted Voluntary Return and Reintegration Annual Report 2010". Addis Ababa: IOM.

IOM, 2012. The Migrant. Volume 3, issue 1, March 2012, Addis Ababa

ILO, 2011. "Trafficking in Persons Overseas for Labour Purposes: The Case of Ethiopian Domestic Workers." Addis Ababa.

Jacobsen, K. and Landau, L. (2003). “The Dual Imperative in Refugee Research: Some Methodological and Ethical Considerations in Social Science Research on Forced Migration". Disasters 27(3): 185-206.

Kapur, V. (2013). "NRI Alert: India Bans Duty Free Import of TVs" Emirates 24/7. Available at: http://www.emirates247.com/news/emirates/nri-alert-indiabans-duty-free-import-of-tvs-2013-08-20-1.518174 Accessed on: 10 December 2013.

Kibreab, G. (2003). "Citizenship Rights and Repatriation of Refugees." International Migration Review 37 (1): 24-73.

King, R., Strachan, A.J. and Mortimer, J. (1983) Return Migration: a Review of the Literature. Discussion Papers in Geography, 19, Oxford Polytechnic, Oxford.

King, R. (1986). "Return Migration and Regional Economic Development: An Overview" Return Migration and Regional Economic Problems. Ed: Russell King. Kent: Croom Helm Ltd.

King, R. (2000). "Generalizations from the History of Return Migration" Return Migration: Journey of Hope or Despair. Geneva: IOM.

Knoke, D. and Kuklinski, J. (1982). Network Analysis. London: Sage Publications.

Koser, K. and Black, R. (1999). "The End of the Refugee Cycle?" in (eds). R. Black and K. Koser The End of the Refugee Cycle? Refugee Repatriation and

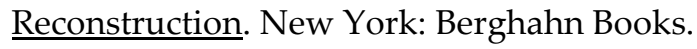

Kuschminder, K. (2013). “Knowledge Transfer and Capacity Building Through the Temporary Return of Qualified Nationals to Afghanistan" International Migration. Early View. 
Kuschminder, K., Andersson, L., and Siegel, M. (2012). "Profiling Ethiopian migration: A comparison of characteristics of Ethiopian migrants to Africa, the Middle East and the North" in: Cristina Udelsmann Rodrigues (Ed.), Crossing African borders: Migration and mobility, Center of African Studies (CEA), ISCTE-IUL, University Institute of Lisbon, Lisbon.

Kuschminder, K. and Siegel, M. (2013). "Diaspora Engagement and Policy in Ethiopia" Emigration Nations. Ed. Michael Collyer. Palgrave MacMillan.

Lazarsfeld, P.F. and Merton, R.K. (1954). 'Friendship as a social process: a substantive and methodological analysis'. In (eds) M. Berger Freedom and Control in Modern Society. New York: Van Nostrand.

Leaning, J. (2001). "Ethics of Research in Refugee Populations". Lancet 357: 14321433.

Ley, D. and Kobayashi, A. 2005. "Back to Hong Kong: return migration or transnational sojourn?" Global Networks 5(2): 111-127

Levitt, P. (2001). The Transnational Villagers. Berkley: University of California Press.

Levitt, P. and Glick Schiller, N. (2004). Conceptualizing Simultaneity: A Transnational Social Field Perspective on Society. International Migration Review, 38(145): 595-629

Levitt, P. and Merry, S. (2009). "Vernacularization on the ground: local uses of global women's rights in the Peru, China, India, and the United States." Global Networks 9(4): 441-461.

Levitt, P. and Lamba-Nieves, D. (2013). "Bringing Culture Back In." New Perspectives on International Migration and Development. Eds: Jeronimo Cortina and Enrique Ochoa-Reza. New York: Colombia University Press, 6792.

Lin, N. (1982). "Social Resources and Instrumental Action". Social Structure and Network Analysis. Eds. Peter Marsden and Nan Lin. California: Sage Publications.

Lin, N. (1999). "Building a Network Theory of Social Capital." Connections 22(1): 2851. 
Lin, N. (2001). Social Capital: A Theory of Social Structure and Action. New York: Cambridge University Press.

Lippman, B. and Malik, S. (2004). “The 4Rs: the way ahead?” Forced Migration Review 21: 9-11.

Long, L. (2004). "Viet Kieu on a Fast Track Back?" Coming Home? Refugees, Migrants and Those who Stayed Behind. Eds. Lynellyn Long and Ellen Oxfeld. Philadelphia: University of Pennsylvania Press.

Lori, N. (2012). "Temporary Workers or Permanent Migrants? The Kafala System and Contestations over Residency in the Arab Gulf States." Centre for Migrations and Citizenship, Paris.

MacDonald, J.S. and MacDonald, L.D. (1964). "Chain migration, ethnic neighbourhood formation, and social networks." Millbank Memorial Fund Quarterly, 42: 82-97.

Mackenzie, C., McDowell, C., and Pittaway, E. (2007). "Beyond 'Do No Harm': The Challenge of Constructing Ethical Relationships in Refugee Research." Journal of Refugee Studies 20(2): 299-319.

Madsen, K. and van Naerssen, T. (2003). "Migration, identity and belonging" Journal of Borderland Studies 18(1): 61-75.

Mahdavi, P. (2011). "'But we can always get more!" Deportability, the State and Gendered Migration in the United Arab Emirates". Asian and Pacific Migration Journal 20(3-4): 413-431.

Majidi, N. (2009). "Understanding the Return and Reintegration Process of Afghan Returnees from the UK". Altai Consulting.

Majidi, N. (2012). "The myth of return of return and reintegration in Afghanistan." Return Migration and Transnationalism: Alternatives or Complements. Workshop 4-5 September 2012. Peace Research Institute of Oslo (PRIO), Oslo, Norway.

Massey, D., Arango, J., Hugo, G., Kouaouci, A., Pellegrino, A., and Taylor, E. (1993). "Theories of International Migration: A Review and Appraisal." Population and Development Review, 19(3), 431-466. 
May, T. (2001). Social Research: Issues, methods and process. 3 ${ }^{\text {rd }}$ Edition. New York: Open University Press.

Mekuria, I. (2006). "Duty Free Amendment Offers Reprieve Until October." Addis Fortune. Access Available at: http://allafrica.com/stories/200608150483.html. Retrieved 8 August, 2010.

Ministry of Foreign Affairs (MFA), 2011. "Basic Information for Ethiopian in the Diaspora." Diaspora Engagement Affairs General Directorate. Available at: http://www.mfa.gov.et/Diaspora/Diaspora.htm

Accessed on: 27 May 2012.

Nannestad, P., and Svendsen, G.L.H., and Svendsen, G.T. (2008). "Bridge Over Troubled Water? Migration and Social Capital" Journal of Ethnic and Migration Studies 34(4): 607-631.

Nelson, N. (2006). “A Little Appreciation Can go a long way towards employee job satisfaction." Employment Relations Today 33(1): 19-26.

Noy, C. (2008). "Sampling Knowledge: The Hermeneutics of Snowball Sampling in Qualitative Research." International Journal of Social Research Methodology 11(4): 327-344.

Oeppen, C. (2009). A Stranger at Home: Integration, Transnationalism and the Afghan Elite. DPhil Thesis: University of Sussex.

Oeppen, C. (2012). "Transnationalism after return: Afghan returnees from the UK and Norway in Kabul." Return Migration and Transnationalism: Alternatives or Complements. Workshop 4-5 September 2012. Peace Research Institute of Oslo (PRIO), Oslo, Norway.

Office for Human Research Protections (OHRP). (1998). "Informed Consent Checklist." at: http://www.hhs.gov/ohrp/policy/consent/index.html Accessed on: 5 June 2012.

Oishi, N. (2002). "Gender and Migration: An Integrative Approach". Center for Comparative Migration Studies Working Paper No.49. San Diego, California. 
Organisation for Economic Cooperation and Development. (2010). "The Contribution of Diaspora Return to Post-Conflict and Fragile Countries" Available at: http://www.oecd.org/pages/0,3417,en $3940639639407473 \quad 1 \quad 1 \quad 111$ 1,00.html Accessed on: 28 November 2011

Oxfeld, E. and Long, L. (2004). "Introduction: An Ethnography of Return". Coming Home? Refugees, Migrants and Those who Stayed Behind. Eds. Lynellyn Long and Ellen Oxfeld. Philadelphia: University of Pennsylvania Press.

Pande, A. (2013). "'The Paper that you Have in Your Hand is My Freedom": Migrant Domestic Work and the Sponsorship (Kafala) System in Lebanon." International Migration Review 47(2): 414-441.

Parrenas, R. (2005). Children of Global Migration: Transnational Families and Gendered Woes. Stanford University Press; Stanford, California.

Piper, N. (2004). "Gender and Migration Policies in Southeast and East Asia: Legal Protection and Sociocultural Empowerment of Unskilled Migrant Women." Singapore Journal of Tropical Geology 25(2), 216-231.

Portes, A. (1998). "Social Capital: Its Origins and Applications in Modern Sociology." Annual Review of Sociology 24: 1-24.

Portes, A. (2010). "Migration and Social Change: Some Conceptual Reflections". Journal of Ethnic and Migration Studies 36(10): 1537-1563.

Portes, A., Guarnizo, L., Landolt, P. (1999). “The study of transnationalism: pitfalls and promise of an emergent research field." Ethnic and Racial Studies 22(2): 217-237.

Putnam, R.D. (2000) Bowling Alone: The Collapse and Revival of American Community. New York: Simon and Schuster.

Riiskjaer, MHB., and Nielsson, T. (2008). Circular repatriation: the unsuccessful return and reintegration of Iraqis with refugee status in Denmark. New Issues in Refugee Research Paper No. 165 UNHCR, Geneva. 
Rogge, J. (1994). "Repatriation of refugees." When Refugees Go Home. Eds. Tim Allen \& Hubert Morsink. Geneva: United Nations Research Institute for Social Development.

Rotary. (2013). “About us”. Available at: www.rotary.org Accessed on: 18 July 2013.

Ruben, R., van Houte, M, and Davids, T. "What Determines the Embeddedness of Forced-Return Migrants? Rethinking the Role of Pre- and Post-Return Assistance." International Migration Review 43(4): 908-937.

Schuster, L. and Majidi, N. (2013). "What happens post-deportation? The experience of deported Afghans". Migration Studies 1(2), 221-240.

Sennett, R. (2003). Respect in a World of Inequality. New York: W.W. Norton \& Company.

Silvey, R. (2004). "Transnational Migration and the Gender Politics of Scale: Indonesian Domestic Workers in Saudi Arabia." Singapore Journal of Tropical Geology 25(2), 141-155.

Sim, A., and Wee, V. (2009). "Undocumented Indonesian Workers in Macau." Critical Asian Studies, 41(1), 165-188.

Stefansson, A. (2004). "Sarajevo Suffering: Homecoming and the Hierarchy of Homeland Hardship." Homecomings: Unsettling Paths of Return. Eds: Fran Markowitz and Anders Stefansson. USA: Lexington Books.

Tasse, A. (2007). "Ethiopian Migration: Challenging Traditional Explanatory Theories". Revitalising Communities in globalising world. Ed. Lena Dominelli. Hampshire, England: Ashgate Publishing Ltd.

Temple, B. and Edwards, R. (2002). "Interpreters/translators and cross-language research: Reflexivity and border crossings". International Journal of Qualitative Methods 1(2).

Thomas-Hope, E. (1999). Return Migration to Jamaica and its Development Potential. International Migration, 37(1), 183-207. 
Tigabu, T. (2011). "Shattered Dreams". The Reporter. 6 August, 2011. Available at: http://www.thereporterethiopia.com/Society/shattered-dreams.html Accessed on: 5 June 2012.

Tsuda, T. (2009). Introduction. Diasporic Homecomings: Ethnic Return Migration in Comparative Perspective. Eds. Takeyuki Tsuda. Stanford: Stanford University Press.

UNHCR. (2004). “Handbook for Repatriation and Reintegration Activities”. Geneva: UNHCR.

UN Data, (2012). "Ethiopia”. Available at:

http://data.un.org/CountryProfile.aspx?crName=Ethiopia Accessed on: 5 June 2012.

UN DESA/OECD. (2013). "World Migration in Figures". Available at: http://www.un.org/esa/population/migration/documents/World Migration Figures UNDESA OECD.pdf Accessed on: 4 February 2014.

UNDP. (2012). Gender Inequality Index. Available at:

http://hdrstats.undp.org/en/indicators/68606.html Accessed on: 19 August 2013.

Verdirame, G. and Harrell-Bond, B. (2005). Rights in Exile: Janus Faced Humanitarianism. New York; Berghahn Books.

Vertovec, S. (1999). "Conceiving and researching transnationalism." Ethnic and Racial Studies 22(2): 447-462.

Vlieger, A. (2011). Domestic Workers in Saudi Arabia and the Emirates a socio-legal study on conflicts. Quid Pro Books, Louisiana.

Waldinger, R. (1993). “The ethnic enclave debate revisited." International Journal of Urban and Regional Research 17(3): 444-452. 
Walta Info. (2011). "Ethiopian Diaspora set up committee to Coordinate fund for Renaissance Dam." Walta Information Source. 19 December 2011. Available at: http://www.waltainfo.com/index.php?option=com content\&view=article\&id =1038:ethiopian-diaspora-set-up-committee-to-coordinate-fund-for-therenaissance-dam\&catid=52:national-news\&Itemid=291

Accessed on: 5 June 2012.

Walta Info. (2012). "Ethiopian Diaspora urged to exploit investment opportunities at home". Walta Information Source. 25 April 2012. Availablet at: http://www.waltainfo.com/index.php?option=com content\&view=article\&id =2954:ethiopian-diaspora-urged-to-exploit-investment-opportunities-athome\&catid=71:editors-pick\&Itemid=396

Accessed on: 5 June 2012.

Wax, E. (2004). “Ethiopia Rape Victim Pits Law Against Culture." Washington Post. Available at: http://www.washingtonpost.com/wp-dyn/articles/A208352004Jun6.html Accessed on 19 August 2013.

Weiss, R.S. (1995). Learning from Strangers: The Art and Method of Qualitative Interview Studies. Simon and Schuster Publishing.

Welcome NRI. (2013). "Import of Household Articles" Welome NRI. Available at: http://www.welcome-nri.com/info/project/takecargold.htm

Accessed on: 14 December 2013.

Wilson, DT. (1998). "Weak Ties, Strong Ties: Network Principles in Mexican Migration." Human Organisation 57(4): 394-403.

Wilson, DT. (2010). "The culture of Mexican Migration". Critique of Anthropology 30: 399-420.

Wilson, K. and Portes, A. (1980). "Immigrant enclaves: an analysis of the labo market experience of Cubans in Miami." American Journal of Sociology 88: 295-319.

Zlotnik, H. (1998). “International Migration 1965-96: An Overview." Population and Development Review. 24(3), 429-468. 


\section{Appendix 1: Return Migrants Interview Guide}

\section{Please tell me about your life prior to your migration?}

- Where did you live? With whom? Were you married? Children? Were you working? If yes, where you working? Did you like your job? How many hours per week did you work? What was your salary? What was your standard of living- were you struggling or were you comfortable? What were you daily tasks (ie: role within the household)? Were you involved in the community (participate in local events/ cultural events)? Who were the most significant people in your life/ who were your close friends? (Defined as close friends/ family, people that you could go to for assistance if needed.) Assign each of these people a number and write them on your piece of paper. Were you apart of any organisations or associations (examples: women's association, professional association, student association, edir, microfinance)? What did you like about your life? What did you dislike about your life? Did you feel a part of the community/ Did you have a sense of belonging?

\section{Why did you decide to migrate?}

- Who was involved in your decision (parents, friends, other family)? Did they support you in your decision? Why or why not?

- Were you influenced by anyone in your decision? Where did you receive information on migrating (person, friend, newspaper, $\mathrm{tv}$, radio)? Who from? What did they tell you about migrating?

- Where did you migrate to? What information did you have on this country before you migrated? Where did you get this information from?

- Did you want to migrate?

- Who assisted you in the migration process (gave money or other resources)? Did you go through the government? If yes, did you receive training? What kind? How long did the training last? What did you learn in the training? Was this information helpful?

- What kind of Visa did you have? How much did your migration cost? Where did you get this money?

- What were your expectations of migration? 


\section{How did you experience living in the country of migration?}

- Who assisted you in your initial arrival? Did you arrive at the airport (go through other countries)?

- Where did you get information on how to live in [country of migration]? Who provided you with support (money, information, other resources)?

- What was your occupation? (If domestic worker, what was the family like, how many people)? What tasks did you do? What was a typical day for you? How many hours did you work? What was your salary? Did you have time off? How did you spend your time off?

- Who did you interact with in the country of migration (locals, other Ethiopians, other foreigners, people from home country)? Where? How often? What did you discuss with them? Add these people to the network list and define the strength of the connections.

- How were you treated by the locals? How did this make you feel?

- Did you feel a part of the Ethiopian community in country $x$ ? Were you involved in any organisations/ associations in country of migration? Did you feel a sense of belonging in the country?

- Return to the previous listed social network. During your migration, which of these people did you maintain contact with? How often? In which way? What did you discuss with them?

- Did you send money home? To who? How much? How often? How was the money spent? Did you send money to anyone else (ie: friends on network list)?

- Did you ever visit Ethiopia temporarily while you were abroad? How long? When? What purpose?

- Did you take any classes/ learn any new skills (can include formal training ie: Masters/ Bachelor/ Diploma)? What kind of training/ class? For how long? What did you learn? Did you speak the language? Were you expectations met?

\section{Why did you decide to return to Ethiopia?}

- Who was involved in your decision to return (parents, spouse, friends)? Did they support in your return? Were you influenced by anyone?

- Did you want to return?

- Where did you receive information on returning to Ethiopia? Who from? Who assisted you in the return process (gave money or other 
resources)? Did you receive assistance from any organisations? What kind or assistance?

- Were you able to take any resources (money, things) with you in your return? (Amount of money, what kinds of things, gifts for whom)? Did you send any prior to your return?

- What were your expectations of return?

5. How do you experience living in Ethiopia since returning from [country of migration]?

- What happened when you returned? Who met you at the airport? Where do you live? If different from departure city, why did you return to this place? With whom? Are you married? Have children?

- Are you working? Where? Do you like it? How many hours? How did you get this job? Current Salary?

- Current standard of living- comfortable or struggling? How does this compare to prior to your migration?

- What is your role within your household? Do you feel more or less respected within your household? Do you have more independence? Please explain. And in Ethiopian society as a whole? More or less respected? Do you people treat you differently? In what ways? How does this make you feel?

- What have been the greatest challenges for you in your return? How have you dealt with those challenges? Who helped you to deal with them? In what ways?

- Have you done any training programmes since your return? Which organisation? Which programme? How did you hear about this programme?

- Do you participate in local events? Cultural events? What kinds? Do you vote/ plan to vote?

- Do you feel that your values or beliefs have changed at all from your migration/ views about the world/ perspectives on how things should be in society? Give examples. Do you discuss this with other people? Do you feel changed by your migration? In what ways? How does that affect your life now? What are the key differences in your life from now versus before your migration?

- How would you define yourself? Ie: Ethiopian, Ethiopian- country of migration?

- Return to Network list/ grid. Are you still in contact with these people (ask of the people from the original list and those added from the country of migration)? How often are you in contact with them? Define strength of relationship. How relationship has changed and why. 
- Do you maintain contact with people from the country of migration? Why or why not? How often and in what ways? Who would you go to if you needed assistance? What discuss primarily discuss with them? Do you encourage them to return?

- Since your return are there other people that have become significant to you? Whom? Other returnees- from where? How did you meet them?

\section{Have you ever been a member of an association?}

- Which organisation? How old is the organisation? What is the purpose of the organisation? How long have you been a member? What are the requirements of membership to this organisation? What does your participation give you? Have you ever received assistance from this association? If not, if you needed assistance would you be able to receive it from this organisation?

- If no, can you explain to me why not a member of an association?

\section{What are your plans for the future?}

- Do you plan to re-migrate? If yes, where? Why do you want to migrate/ why do you not want to migrate? Would you encourage others to migrate? (ie: If someone were to come to you and tell you that they want to migrate, what would you say to them?)

8. Is there anything else you would like to share with me? 


\section{Nederlandse samenvatting}

Het doel van deze studie is de verbetering van het begrip van de re-integratie en het re-integratieproces van terugkerende migranten. De belangrijkste vraag waarop deze studie een antwoord probeert te vinden, is: Hoe re-integreren verschillende groepen migranten zich bij hun terugkeer? In loop van de studie is er een tweede sleutelvraag opgedoken: Hoe hebben de re-integratiestrategieën invloed op het potentieel van terugkerende migranten om te handelen als "vernacularizers" bij hun terugkeer? Om deze vragen te beantwoorden, was de eerste stap in dit onderzoek re-integratie te definiëren. Via een uitgebreid literatuuronderzoek van migratie, gedwongen migratie, integratie, transnationalisme, sociale netwerken en sociale veranderingen, heeft deze studie een nieuwe definitie van re-integratie voorgesteld. Zoals aangetoond in deze studie, houden de huidige definities van re-integratie geen rekening met het wederzijds aanpassingsproces van zowel de terugkerende migrant als de samenleving waarnaar deze terugkeert, iets wat bij re-integratie onontbeerlijk is. Ten tweede is het duidelijk dat veel teruggekeerden niet terugkeren naar hun eigen cultuur. Rekening houdend met deze factoren is re-integratie dus in dit onderzoek gedefiniëerd als volgt: het proces waarin terugkerende migranten worden ondersteund in het behoud van hun culturele en sociale identiteit door de ontvangende samenleving en waarbij de hele bevolking gelijke civiele, sociale, politieke, menselijke en culturele rechten verwerft.

Deze studie stelt een nieuwe aanpak voor voor de re-integratie, reintegratiestrategieën genoemd. De re-integratiestrategieën definiëren het proces van hoe personen zich re-integreren via de vier dimensies van culturele oriëntatie, sociale netwerken, zelf-identificatie en toegang tot rechten, instellingen en de arbeidsmarkt. Het samenspel tussen deze vier dimensies resulteert in de verschillende reintegratiestrategieën van terugkerende migranten. De resulterende reintegratiestrategieën tonen aan, hoe verschillende terugkerende migranten zich reintegreren. De vier re-integratiestrategieën van gere-integreerden, enclavisten, traditionalisten, en kwetsbaren bieden een typologie voor het bepalen van verschillende strategieën voor terugkerende migranten.

Re-integratie is in dit opzicht multidimensioneel en omvat veel verschillende elementen. De re-integratiestrategieën worden fundamenteel beïnvloed door de levenscyclus van de terugkerende migranten en de keuzes die zij maken bij hun reintegratie. Ten tweede speelt de structurele omgeving van het land van terugkeer een vitale rol in de re-integratie. Terugkerende migranten kunnen zich niet reintegreren als ze niet door de lokale bevolking, de overheid en de arbeidsmarkt in het land van terugkeer aanvaard worden. Re-integratie is een vloeiend concept, en na het identificeren van het re-integratieproces door de re-integratiestrategieën 
onderzoekt de studie, hoe terugkerende migranten zich kunnen bewegen in deze reintegratiestrategieën.

Om de aanpak van de re-integratiestrategieën te verkennen, bestudeert deze studie het geval van vrouwelijke remigratie naar Ethiopië. Ethiopië beleefde een conflictperiode van 1974 tot 1991, maar kent sinds 2000 een grote economische groei. Zowel de migratie als de remigratie van en naar het land zijn geweldig toegenomen in de afgelopen tien jaar. Ethiopië is momenteel bezig aan de opbouw van een eigen onderwijsstelsel en een toenemend aantal Ethiopische studenten trekken naar het buitenland voor hun opleiding. Ondanks de groei in Ethiopië bestaan er hoge werkloosheidsniveaus, die vaak nog hoger liggen voor vrouwen dan voor mannen. Verschillende types van vrouwelijke migranten keren dus terug naar zeer verschillende omstandigheden en situaties in Ethiopië.

Deze studie onderzoekt de remigratie van drie analysegroepen:

- Professionelen- Vrouwen die voornamelijk in de jaren 1980 en 1990 gemigreerd zijn, en die na een lange tijd gewerkt te hebben in het land van migratie, waar ze vaardigheden verworven hebben, terugkeren naar Ethiopië met beroepservaring.

- Studenten- Recente migranten die voornamelijk migreren naar Europese landen voor het behalen van een bachelor- of masterdiploma.

- Huishoudelijke hulpen- Voornamelijk vrouwen uit lagere klassen die migreren naar het Midden-Oosten voor huishoudelijk werk.

Er werden 81 kwalitatieve interviews gehouden met vrouwelijke teruggekeerden uit deze drie analysegroepen, die de basis van de analyse vormen. Deze drie groepen hebben verschillende migratie-levenscycli, ervaringen en kansen opgedaan in het buitenland, en hebben verschillende redenen voor hun terugkeer. Bijgevolg hebben ze verschillende re-integratiestrategieën bij hun terugkomst. De analyse toont aan dat de professionelen en studenten de meeste kans maken op re-integratie, sommige professionelen zijn enclavisten en de huishoudhulpen zijn meestal traditionalisten of zijn kwetsbaar.

Het laatste sleutelelement van deze studie was een onderzoek naar hoe de re-integratiestrategieën invloed hebben op de mogelijkheden van terugkerende migranten om te handelen als "vernacularizers" bij hun terugkomst. "Vernacularizers" worden gedefiniëerd als personen die "de ideeën en praktijken van een groep overnemen en deze presenteren in termen die een andere groep zal accepteren" (Levitt en Merry, 2009: 446). Het doel van deze studie was, te begrijpen hoe de re-integratiestrategieën de vrouwen beïnvloeden en de kracht geven om in staat te zijn, nieuwe ideeën te delen met de lokale bevolking en hun sociale omgeving, en om bepaalde kwesties te kaderen op een manier dat deze door de lokale bevolking aanvaard zullen worden. 
De resultaten tonen aan dat, om op te treden als "vernacularizers", de terugkerende migranten in staat moeten zijn om culturele barrières te overwinnen vooraleer kwesties voor te stellen op een manier die relevant is voor de lokale bevolking, en ten tweede moeten gerepatrieerden zich in een relatieve machtspositie bevinden om zoveel mogelijk impact te hebben. Dit leidt tot de vijf voorwaarden voor terugkerende migranten om het potentieel te bezitten om als "vernacularizers" op te treden: 1) De bekwaamheid om zich te integreren in het buitenland; 2) Bereidheid tot een vrijwillige terugkeer; 3) Voortdurende netwerken bij de terugkeer; 4) Bereidheid om te werken met de lokale bevolking en het vermogen om discussies en onderwerpen in te kaderen; en 5) Een machtspositie innemen en respect tonen voor de anderen. Pas wanneer de gerepatrieerden aan deze vijf voorwaarden voldoen, wat verder impliceert dat zij optimaal gere-integreerd zijn, zijn ze in staat om een hoog potentieel te hebben om te "vernaculizeren". In deze studie voldeden slechts 14 procent van de deelnemers aan dit criterium en hadden ze dus een hoog potentieel om op te treden als "vernacularizers". Daarom kunnen terugkerende migranten onder de juiste omstandigheden een hoog potentieel hebben om te handelen als agenten voor de verandering in hun samenleving van terugkeer. Er kan echter niet worden aangenomen dat alle gerepatrieerden over dit potentieel beschikken. Deze studie heeft het bestaan aangetoond van een directe link tussen re-integratie en het potentieel van gerepatrieerden om invloed uit te oefenen op de samenlevingen waarnaar ze terugkeren. Re-integratie is een complex proces en verschillende re-integratiestrategieën resulteren in verschillende potentiëlen om te "vernacularizeren". 


\section{Valorization}

At present there are several assumptions regarding the positive impacts on development made by return migrants. These include investments, entrepreneurship, and knowledge transfer and innovations from bringing new ideas and technologies from abroad. Several origin country governments have worked to harness the potential of return migrants to impact development by creating policies to attract their diaspora to return. At the same time, governments in host countries have initiated programs to assist and support people in returning. Despite the increasing prevalence of policies to enhance return for development impacts, we lack understandings of the processes of return and reintegration that lead to positive development impacts.

The objective of this study is to increase understandings of reintegration and the process of reintegration for different return migrants. The ability to contribute to development upon return is highly dependent on the ability of the individual to reintegrate. Yet, our definitions and understandings of reintegration vary for different groups of return migrants. For this reason, this study puts forth a new definition of reintegration that can be applied across different groups of returnees: the process in which return migrants are supported in maintaining their cultural and social identities by the host society and the whole population acquires equal civil, social, political, human and cultural rights. This definition takes into account that returnees do have different cultural and social identities that they have acquired in their migration experiences. Upon return, these are often not absolved. The country of return, inclusive of the government, local population, and labour markets, must be willing to be open and accepting of returnees' cultural and social identities in order for returnees to have an optimal reintegration. If the country of return rejects the returnees, then reintegration will be an illusion.

Secondly, this study builds on our understandings of the process of reintegration. Central to understanding the process of reintegration is to recognize that returnees are a highly heterogeneous group. The term return migration incorporates broad groups of people that are very different from each other, as was demonstrated in the case study with the comparisons between three return migrant groups of: professionals, students and domestics. It is essential to note that the structural environment of return and the individuals' reintegration strategy are different for different groups of migrants, and even within groups of migrants. This has direct implications for policy and practice in that one policy should not be expected to meet the needs of all returnees, and secondly, that we cannot expect similar outcomes from all returnees. 
There are central factors that shape the reintegration processes of return migrants that must be understood for policies or programs targeting specific returnee groups. First, is the lifecycle of the returnee. This includes the experiences and class of the returnee prior to migration, their experiences abroad and opportunities for integration and their process, and preparedness for return. The situation of migrants prior to their migration and their class differences often dictates their migration opportunities. For instance, students are able to migrate to Europe for a master's degree due to their positions. The students that receive these opportunities are the top of their field. Their opportunities are quite different than the domestics' whose only tangible opportunities for migration are for domestic work.

These different migration flows lead to fundamental differences in the country of migration. In the country of migration the opportunities for integration are central to the migrant being able to acquire new cultural and social identities, and to gain skills and resources for their return. The majority of the students found the exposure to the culture of the countries of Europe as transformative. The opportunities to see female empowerment and the way of life in Europe were motivational to this group. This greatly contrasts with the situation of domestic workers, wherein many of the participants were not able to leave the house of their employers and develop networks with other domestics, nevertheless locals. Their sheer isolation prevented any opportunities for gaining cultural and social capital in the country of migration. Opportunities for integration are thus essential for migrants to gain cultural and social capital that can be brought with them in their return.

In order for returnees to optimize their reintegration upon return they must be prepared for return and have engaged in a decided return. Cassarino's preparedness theory (2004) demonstrates that decided returnees are more likely to contribute to development. This study has the same finding in that return must be decided in order for returnees to have a high potential to contribute back home. Return preparedness means that resources and information have been acquired for return, such as a home, employment, or an established network. In essence, a prepared returnee has a strategy for their reintegration. Enforced or coerced returnees, on the other hand, have limited resources available for their return and low preparedness. Upon return they do not have established opportunities and struggle to re-establish themselves.

Finally, we cannot assume that all return migrants will contribute to development - even with decided returnees- when, as demonstrated in this study, specific conditions must be met in order for returnees to have the potential to act as vernacularizers- "individuals that take the ideas and practices of one group and present them in terms that another group will accept" (Levitt and Merry, 2009: 446). 
Vernacularizers are individuals that are able to translate the knowledge and learnings acquired from abroad into terms that locals will accept, embrace and utilize. Not all return migrants have this ability and it is critical that return migrants are able to do this in order for them to be able to impact their social environment upon return.

The results demonstrate that in order to act as vernacularizers, returnees must be able to overcome cultural barriers to frame issues in a way that is relevant to locals, and second, returnees must be in positions of relative power in order to have the greatest impact. This leads to the five conditions required for return migrants to have the potential to act as vernacularizers: 1) Ability to integrate while abroad; 2) Voluntariness and preparedness for return; 3) Sustained networks upon return; 4) Willingness to work with locals and ability to frame discussions and topics; and 5) Occupying a position of power and demonstrating mutual respect for others. Only when returnees meet all five of these conditions, which further implies that they are optimally reintegrated across the dimensions, are they able to have a high potential to vernacularize. In this study, only 14 percent of the participants met this criterion and had a high potential to act as vernacularizers. Therefore, under the right conditions return migrants can have a high potential to be agents of change in their societies of return. It cannot be assumed, however, that all returnees have this potential. This study has demonstrated that there is a direct link between reintegration and the potential of returnees to have impact on their societies of return. Reintegration is a complex process and different reintegration strategies result in different potentials to vernacularize. 


\section{Biography}

Katie Kuschminder is a post-doctoral researcher at Maastricht University in Migration and Development. Throughout her PhD at Maastricht, Katie has worked on several migration projects for the Dutch Ministry of Foreign Affairs, German Development Cooperation, Australia Department of Immigration and Border Protection, United Nations High Commissioner for Refugees, and International Organization for Migration. Katie has taught in the Migration Specialization of the Masters in Public Policy and Human Development, and the Migration Management Diploma Programme. At Maastricht, Katie has also supervised Master thesis students, coordinated migration seminars and several events at the School of Governance.

Prior to joining Maastricht, Katie worked in Calgary, Canada as a Research Analyst at Alberta Health Services and a researcher at the Poverty Reduction Coalition of the United Way of Calgary. Katie holds a Master's degree in Migration Studies from the University of Sussex and Bachelor's Degree in International Development from the University of Guelph, Canada. She was born in Toronto, Canada. 


\section{MGSoG Dissertation Series}

\section{Metka Hercog}

Highly-Skilled Migration and New Destination Countries

MGSoG Dissertation Series, nr 41 (2014)

Margaret Agaba Rugadya

Can Remittances Influence the Tenure and Quality of Housing in Uganda?

MGSoG Dissertation Series, nr 40 (2014)

Ilire Agimi

New Governance Under Limited Statehood

The Case of Local Government Reform in Kosovo

MGSoG Dissertation Series, nr 39 (2014)

Kristine Farla

Empirical Studies on Institutions, Policies and Economic Development

MGSoG Dissertation Series, nr 38 (2013)

Marina Petrovic

Social Assistance and Activation in the Pursuit of Happiness:

Shedding New Light on Old Policy Solutions to Social Exclusion

MGSoG Dissertation Series, nr 37 (2013)

Laura Torvinen

Assessing Governance Assessments; The Case of Mozambique

Governance Assessments in the Context of Aid Effectiveness Discourse

MGSoG Dissertation Series, nr 36 (2013)

Biniam Egu Bedasso

Institutional Change in the Long Shadow of Elites

Essays on Institutions, Human Capital and Ethnicity in Developing Countries

MGSoG Dissertation Series, nr 35 (2013)

Sepideh Yousefzadeh Faal Deghati

Childhoods Embargoed

Constructing and Reconstructing Multidimensional Child Poverty in Iran 1984-2009

MGSoG Dissertation Series, nr 34 (2013) 
Robert Bauchmüller

Investing in Early Childhood Care and Education:

The Impact of Quality on Inequality

MGSoG Dissertation Series, nr 33 (2013)

Martin Rehm

Unified Yet Separated

Empirical Study on the Impact of Hierarchical Positions within Communities of Learning

MGSoG Dissertation Series, nr 32 (2013)

Dorcas Mbuvi

Utility Reforms and Performance of the Urban Water Sector in Africa

MGSoG Dissertation Series, nr 31 (2012)

Lina Salanauskaite

Distributional Impacts of Public Policies:

Essays in Ex-Ante and Ex-Post Evaluation

MGSoG Dissertation Series, nr 30 (2012)

Esther Schüring

To Condition or not - is that the Question?

An Analysis of the Effectiveness of Ex-Ante and Ex-Post Conditionality in Social Cash

Transfer Programs

MGSoG Dissertation Series, nr 29 (2012)

Joe Abah

Strong Organisations in Weak States

Atypical Public Sector Performance in Dysfunctional Environments

MGSoG Dissertation Series, nr 28 (2012)

Zina Samih Nimeh

Social Citizenship Rights: Inequality and Exclusion

MGSoG Dissertation Series, nr 27 (2012)

Lenka Eisenhamerová

Legitimacy of 'Humanitarian Military Intervention'

MGSoG Dissertation Series, nr 26 (2011) 
Sonila Tomini

Informal Payments for Health Care Services in Albania

MGSoG Dissertation Series, nr 25 (2011)

Jinjing Li

Dynamic Microsimulation in Public Policy Evaluation

MGSoG Dissertation Series, nr 24 (2011)

Aziz Atamanov

Rural Nonfarm Employment and International Migration as Alternatives to Agricultural

Employment:

The Case of Kyrgyztan

MGSoG Dissertation Series, nr 23 (2011)

Frieda Vandeninden

Poverty Alleviation: Aid and Social Pensions

MGSoG Dissertation Series, nr 22 (2011)

Juliana Nyasha Tirivayi

The Welfare Effects of Integrating AIDS Treatment with Food Transfers:

Evidence from Zambia

MGSoG Dissertation Series, nr 21 (2011)

Agnieska Ewa Sowa

Who's Left Behind? Social Dimensions of Health Transition and Utilization of Medical Care in Poland

MGSoG Dissertation Series, nr 20 (2011)

Emmanaouil Sfakianakis

The Role of Private Actors in the Provision of Public Goods with Applications to Infrastructure and Financial Stability

MGSoG Dissertation Series, nr 19 (2011)

Siu Hing Lo

White Collars Green Sleeves

An Interonganizational Compariso of Deteminants of Energie-Related Behaviors among

Office Workers

MGSoG Dissertation Series, nr 18 (2011) 


\section{Treena $\mathrm{Wu}$}

Constraints to Human Capital Investment in Developing Countries:

Using the Asian Financial Crisis in Indonesia as a Natural Experiment

MGSoG Dissertation Series, nr 17 (2011)

\section{Henry Espinoza Peña}

Impact Evaluation of a Job-Training Programme for Disadvantaged Youths:

The Case of Projoven

MGSoG Dissertation Series, nr 16 (2011)

Florian Tomini

Between Family and Friends

Understanding the Interdependency of Private Transfers

MGSoG Dissertation Series, nr 15 (2010)

Michał Polalowski

The Institutional Transformation of Social Policy in East Central Europe:

Poland and Hungary in comparative and historical perspective

MGSoG Dissertation Series, nr 14 (2010)

Maha Ahmed

Defining, Measuring and Adressing Vulnerability:

The Case of Post Conflict Environments

MGSoG Dissertation Series, nr 13 (2010)

\section{Pascal Beckers}

Local Space and Economic Success

The role of spatial segregation of migrants in the Netherlands

MGSoG Dissertation Series, nr 12 (2010)

Victor Cebotari

Complicting Demands in Ethnically Diverse Societies

Ethnopolitical Contention and Identity Values in Europe

MGSoG Dissertation Series, nr 11 (2010)

\section{Dennis Gyllensporre}

Competing and Complementary Perspectives on the EU as a Crisis Management Actor:

An Examination of the Common Security and Defence Policy through the Lenses of Idealism and Realism

MGSoG Dissertation Series, nr 10 (2010) 
Judit Vall Castello

Business Cycle and Policy Effects on Labour Market Transitions of Older and Disabled Workers in Spain

MGSoG Dissertation Series, nr. 9 (2010)

Keetie Roelen

False Positives or Hidden Dimentions: the definition and measurement of child poverty MGSoG Dissertation Series, nr. 8 (2010)

Denisa Maria Sologon

Earning Dynamics in Europe

MGSoG Dissertation Series, nr. 7 (2010)

Melissa Siegel

Money and Mobility: Migration and Remittances

MGSoG Dissertation Series, nr. 6 (2010)

Jessica S. Hagen-Zanker

Modest Expectations: Causes and effects of migration on migrant households in source countries

MGSoG Dissertation Series, nr. 5 (2010)

Mirtha R. Muniz Castillo

Human Development and Autonomy in Project Aid: Experiences from four

bilateral projects in Nigaragua and El Salvador

MGSoG Dissertation Series, nr. 4 (2009)

Christiane Arndt

Governance Indicators

MGSoG Dissertation Series, nr. 3 (2009)

Britta Augsburg

Microfinance - Greater Good or Lesser Evil?

MGSoG Dissertation Series, nr. 2 (2009)

Geranda Notten

Measuring and Managing Poverty Risks

MGSoG Dissertation Series, nr. 1 (2008) 